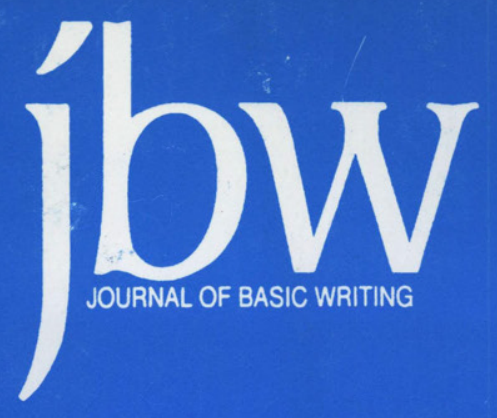

\title{
FALL 2002
}

VOLUME 21 NUMBER 2

Basic Writing and Policy Reform: Why We Keep Talking Past Each Other

Stanford T. Goto

Mixed Forms of Academic Discourse:

A Continuum of Language Possibility Judith Hebb

Learning to Change: The Development of a (Basic) Writer and Her Teacher

Shari Stenberg

Tinkering Toward WAC Untopia Samuel Cohen

Undergraduate Second Language Writers in the Writing Center Jessica Williams

Developmental Writing: Trust, Challenge, and Critical Thinking David Miller

High Schools as Crucibles of College Prep: What More Do We Need to Know? 



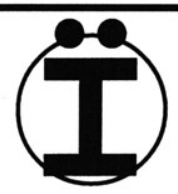

The paper used in this publication meets the minimum requirements of the American National Standard for Information Science -

Permanence of Paper for Printed Library Materials, ANSI Z39.48-1984.

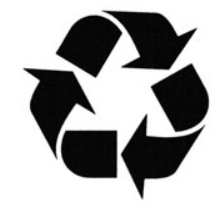

The text stock is also recycled.

\section{This publication is available in microform from UMI.}

Please send me information about the titles I've listed below:

Name

Title

Company/Institution

Address

City/State/Zip

Phone

\section{U.M.I}

A Bel I \& Howell Company

300 North Zeeb Road, Ann Arbor, MI 48106 USA 800-521-0600 toll-free

313-761-4700 collect from Alaska and Michigan 800-343-5299 toll-free from Canada 



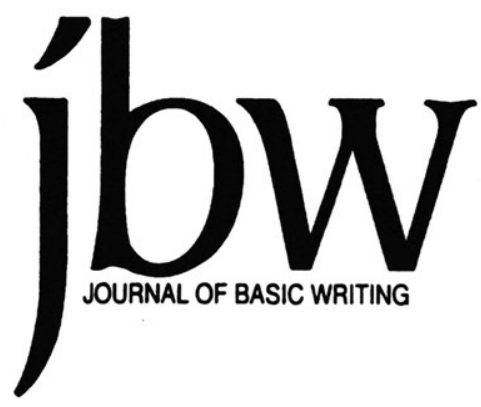

VOLUME 21 NUMBER 2

FALL 2002

The Journal of Basic Writing publishes articles of theory, research, and teaching practices related to basic writing. Articles are refereed by members of the Editorial Board (see overleaf) and the Editors.

\section{George Otte and Bonne August Editors}

\section{Rhona Cohen and Mikhail Gershovich Editorial Assistants}

\section{Mary E. Carney, Subscriptions}

The Journal of Basic Writing is published twice a year, in the spring and fall. We welcome unsolicited manuscripts and ask authors to consult the detailed "Call for Articles" in this issue. Subscriptions for individuals are $\$ 15.00$ for one year and $\$ 28.00$ for two years; subscriptions for institutions are $\$ 20.00$ for one year and $\$ 38.00$ for two years. Foreign postage is $\$ 10.00$ extra per year. ADDRESS:

Journal of Basic Writing

City University of New York

555 West 57 Street, Room 1601

New York, NY 10019 


\section{JOURNAL OF BASIC WRITING}

\section{EDITORIAL BOARD}

Peter Dow Adams

Essex Community College, Baltimore

Akua Duku Anokye

University of Toledo

Chris M. Anson

North Carolina State University

David Bartholomae

University of Pittsburgh

Sarah Benesch

College of Staten Island, CUNY

Bill Bernhardt

College of Staten Island, CUNY

Patricia Bizzell

College of the Holy Cross

Lynn Z. Bloom

University of Connecticut, Storrs

Nancy Carriuolo

University of New Haven

Richard Courage

Westchester Community College, SUNY

Donald Daiker

Miami University

Suellynn Duffey

Georgia Southern University

Sarah Warshauer Freedman

University of California, Berkeley

Karen L. Greenberg

Hunter College, CUNY

Brenda M. Greene

Medgar Evers College, CUNY

Muriel Harris

Purdue University

Irvin Hashimoto

Whitman College

Warren Herendeen

Mercy College

Myra Kogen

Brooklyn College, CUNY

\section{Patricia Ondek Laurence}

City College, CUNY

Elaine $\mathrm{O}$. Lees

Carlow Hill College

Andrea A. Lunsford

Stanford University

Jane Maher

Nassau Community College

Peter Miller

College of Staten Island, CUNY

Susan Miller

University of Utah

Nathaniel Norment, Jr.

Temple University

Jerrold Nudelman

Queensborough Community

College, CUNY

Jane Peterson

Richland College, Dallas County

Community College Distnct

Nell Ann Pickett

Hinds Community College

Charles I. Schuster

University of Wisconsin, Milwaukee

Tony Silva

Purdue University

Trudy Smoke

Hunter College, CUNY

Lynn Quitman Troyka

Oueensborough Community

College, CUNY, ret.

Karen S. Uehling

Boise State University

Billie J. Wahlstrom

University of Minnesota

Evelyn E. Webb

Mississippi State Board for

Community and Junior Colleges

Harvey S. Wiener

Marymount Manhattan College 


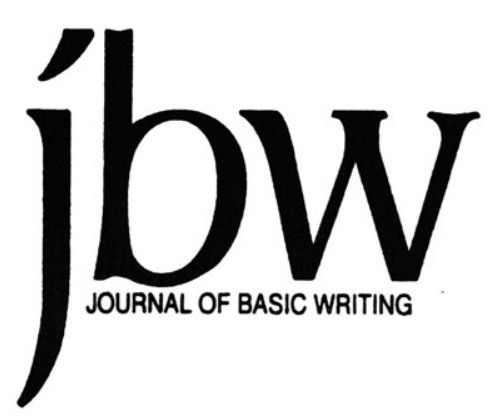

VOLUME 21

NUMBER 2

FALL 2002

Editors' Column

Basic Writing and Policy Reform:

Why We Keep Talking Past Each Other

Stanford Goto

Mixed Forms of Academic Discourse:

A Continuum of Language Possibility

Judith Hebb

Learning to Change:

The Development of a (Basic) Writer and Her Teacher

Shari Stenberg

Tinkering Toward WAC Utopia

Samuel Cohen

Undergraduate Second Language Writers in the Writing Center Jessica Williams

Developmental Writing:

Trust, Challenge, and Critical Thinking

David Miller

High Schools as Crucibles of College Prep:

What More Do We Need to Know?

George Otte

News and Announcements 


\section{CALL FOR ARTICLES}

We welcome manuscripts of $10-20$ pages on topics related to basic writing, broadly interpreted.

Manuscripts will be refereed anonymously. We require five copies of a manuscript and an abstract of about 100 words. To assure impartial review, give author information and a short biographical note for publication on the cover page only. Papers which are accepted will eventually have to supply camera-ready copy for all ancillary material (tables, charts, etc.). One copy of each manuscript not accepted for publication will be returned to the author, if we receive sufficient stamps (no meter strips) clipped to a self-addressed envelope. Submissions should follow current MLA guidelines.

All manuscripts must focus clearly on basic writing and must add substantively to the existing literature. We seek manuscripts that are original, stimulating, well-grounded in theory, and clearly related to practice. Work that reiterates what is known or work previously published will not be considered.

We invite authors to write about such matters as classroom practices in relation to basic writing theory; cognitive and rhetorical theories and their relation to basic writing, social, psychological, and cultural implications of literacy; discourse theory, grammar, spelling, and error analysis; linguistics; computers and new technologies in basic writing; English as a second language; assessment and evaluation; writing center practices; teaching logs and the development of new methodologies; and cross-disciplinary studies combining basic writing with psychology, anthropology, journalism, and art. We publish observational studies as well as theoretical discussions on relationships between basic writing and reading, or the study of literature, or speech, or listening. The term "basic writer" is used with wide diversity today, sometimes referring to a student from a highly oral tradition with little experience in writing academic discourse, and sometimes referring to a student whose academic writing is fluent but otherwise deficient. To help readers therefore, authors should describe clearly the student population which they are discussing.

We particularly encourage a variety of manuscripts: speculative discussions which venture fresh interpretations; essays which draw heavily on student writing as supportive evidence for new observations; research reports, written in nontechnical language, which offer observations previously unknown or unsubstantiated; and collaborative writings which provocatively debate more than one side of a central controversy. 


\section{EDITORS' COLUMN}

In the last issue, this column took note-once again - of the perennial redefinition of $J B W$ s enterprise: What we talk about when we talk about basic writing. A second persistent and no less vexing matter is the audience, or audiences, to whom and with whom practitioners of basic writing talk. The cast of stakeholders in basic writing is large and frequently contentious, calling upon practitioners not only to demonstrate the worth of their work but also to insure that they - we "do no harm." The student who challenges us to explain what she will gain from a basic writing course, especially if it offers no credit or blocks the way to a chosen major; the policy maker who questions why such courses are offered in our colleges at all; the colleague who defines basic writing as inevitably discriminatory or marginalizing - each audience has different concerns and different criteria.

Several pieces in this issue address questions of how and to whom we explain, justify, defend, and offer our work. Policy makers, in particular, often present unsympathetic audiences because, suggests Stanford Goto, policy-oriented discourse and pedagogically-oriented discourse are so difficult to translate into one another's terms or constructs. "Basic Writing and Policy Reform: Why We Keep Talking Past Each Other" points out the tendency of policy-related discourse to frame issues in a vertical, hierarchical construct that is hard to justify with the non-linear, sometimes horizontally-oriented constructs favored in the discourse of pedagogy. Goto recommends strategies that might help advocates to bridge this "methodological gap."

The language(s) spoken in academia and the problematic and contested term "academic discourse" concern Judith Hebb in "Mixed Forms of Academic Discourse: A Continuum of Language Possibility." Taking off from some of Patricia Bizzell's thinking, Hebb conceives of a continuum of discourse in which students might locate themselves, thus enabling them to enter and contribute to academic conversation without stigma and, having found a place there, perhaps to enrich it.

It is not only academic language that might be seen as potentially more fluid or malleable. Our representation of ourselves as teachers, both to students and to ourselves, need not be fixed or static. Rather, Shari Stenberg argues that it might beæand perhaps can best be conceived of as a dynamic process of negotiation. In "Learning to Change: The Development of a (Basic) Writer and Her Teacher," Stenberg describes a dialogic process through which, by learning to allow a student to establish her own identity and goals as a writer, the teacher was able to construct an identity for herself that better supported that student. Stenberg's case study prompts further questions about teachers' interventions in students' writing process.

DOI: $\underline{10.37514 / J B W-J .2002 .21 .2 .01 ~} 1$ 
Two authors advocate what would be in effect dialogues between related fields. Samuel Cohen imagines a potentially useful dialogue between basic writing and writing across the curriculum in "Tinkering Toward WAC Utopia." WAC as a field could learn - as he contends that basic writing has - that its goals, including the apparently purely formal and instrumental ones, will best be achieved if the broader goal of helping students develop as thinkers informs the overall enterprise.

Jessica Williams, in "Undergraduate Second Language Writers in the Learning Center," reviews a substantial range of second language acquisition research to determine what it offers tutors and teachers of basic writing. English Language Learners and members of what has become known as Generation1.5 (the group of students who may have immigrated as young children or who may even have been born here but whose home language is not English) often find their way to basic writing classrooms or even more often to writing centers. Williams argues that the application of interactional and Vygotskyan approaches in these settings could result in more appropriate and more effective instruction.

David Miller, in "Developmental Writing: Trust, Challenge, and Critical Thinking" begins with Mike Rose's term "mental arabesques." Complex and subtle critical thinking is not, in his view, something entirely alien and unfamiliar to developmental students, but rather can be seen as "extensions and abstractions of cognitive and metacognitive functions" that are routine and familiar. If, however, teachers are to help students in their-to borrow words from Kutz, Groden, and Zamel - "discovery of competence," they must establish structures in which risk seems possible and even inviting and which provide extended application and practice.

Two issues back, George Otte commended his outgoing co-editor, Trudy Smoke. Now it is the turn of a still novice co-editor to acknowledge George's contribution and leadership. Two outstanding characteristics mark George's tenure at $J B W$, as indeed they mark so many of his accomplishments: he is a consummate collaborator and he looks forward rather than backward. Singularly not doctrinaire, George has never envisioned $J B W$ as the reflection of his own views-except in its openness to the full spectrum of positions and ideas and in its respect for the student writers who are its chief concern. He has sought out the multiple voices speaking for and about basic writing and stimulated thoughtful dialogue among them. His impressive talents have been devoted to encouraging authors, to offering advice (but never mandating it) to help them shape their texts into clear and forceful expressions of their thinking, and to insuring that the journal met his own deadlines - the summer and winter solstices.

Ever alert to new opportunities, especially those offered by tech- 
nology, and to new winds blowing from theoretical, pedagogical, or political directions, George makes wise use of what has been learned in the past to anticipate and address the needs of the future. In his valedictory, "High Schools as Crucibles of College Prep: What More Do We Need to Know?" George calls out for both research and action in the areas where high school and college intersect. Writing out of a career devoted to creating bridges between different segments of the academic enterprise, George argues not only that high school teachers and their college-level counterparts need to work together in extended and collaborative ways, but also that we need serious inquiry into the very nature of our task, as change quickly overtakes secondary and higher education. Typically, George's own involvement is active as well as reflective.

The contributions to this issue offer many possibilities for dialogue and conversation - and some for action, as well.

- Bonne August and George Otte 


\section{Stanford T. Goto}

\section{BASIC WRITING AND POLICY REFORM: WHY WE KEEP TALKING PAST EACH OTHER}

ABSTRACT: Attacks on basic writing and liberal admissions in the late 1990s highlight a perennial gap between faculty and policy advocates. Each group approaches the "remediation debate" in very different ways. This article explores some of these differences by analyzing spatiall directional metaphors used by individuals in each professional domain to describe notions of access and standards. Advocates in the policy-oriented discourse tend to use vertical metaphors, emphasizing linear mobility and hierarchically organized standards, favoring certain types of quantitative methodologies. Educators engaged in the pedagogical discourse tend to use horizontal metaphors, emphasizing the non-linear negotiation of contextually situated standards, privileging qualitative judgments. But there are ways proponents of basic writing might bridge the methodological gap and introduce horizontal perspectives to the vertical discourse of institutional policy.

The dust hasn't settled yet. Universities from New York to California are still assessing the consequences of admissions reform carried out over the last five years. Through the late 1990s, the conservative crusade to "save" academic standards swept through basic writing programs across the country, profoundly altering the shape of liberal-admissions education. With rare exceptions, reforms were passed with little consideration of faculty input. There were, as Romer notes in the case of CUNY, various political and organizational factors at the institutional level that made it difficult for faculty to participate in the policy-making process. More generally, there is a conceptual gap between those who teach composition courses and those who determine institutional policy. ${ }^{1}$ Composition instructors and policy advocates tend to approach the education of underprepared students with different concerns and different ideologies, compounding the challenge of communicating across professional domains. This, I realize, is hardly a new revelation to $J B W$ readers. Basic writing instructors saw, first hand, how fiscal concerns led CUNY officials to scale back open admissions in the mid-1970s (see Lavin and Hyllegard). Then, for the next two decades, the worlds of policy making and classroom teaching settled back into their respective orbits. The system-level discourse had rela-

Stanford Goto is an assistant professor of Curriculum \& Instruction at the University of Wisconsin, Madison. His research has focused on composition programs and basic writing students in community colleges. He formerly taught composition at Vista Community College in Berkeley, California. 
tively little consequence for faculty. Now, reform has come crashing back into basic writing, and the effects are reverberating throughout the profession. Wiener argues compellingly that the reconfiguration of basic skills instruction makes it necessary for faculty to respond directly to audiences outside of composition studies. If we remain aloof from policy-oriented discussions, we leave basic writing open to future ideological attacks from outside critics. This is a concern whether we choose to contest or comply with recent policy changes.

It is worthwhile comparing how composition educators and policy observers have approached the so-called remediation debate. In doing so, we might determine how the professional discourses differ and where they may be spanned. Central to the controversy is the question of how basic writing promotes institutional access and maintains academic standards. Some, whom I will call supporters (e.g., Day and McCabe, Greenberg) argue that basic writing instruction performs both functions reasonably well (or could do so with minor refinements within the existing apparatus). Others, whom I will call critics (e.g., Traub, Ravitch), claim that basic writing cannot fulfill one or both mandates so the system should be radically altered or scrapped altogether. Typically, the remediation debate is characterized as an ideological tug-of-war between these factions.

I find it useful to make finer distinctions. There are supporters and critics among composition faculty, just as there are supporters and critics among policy advocates. We might characterize the remediation debate as two concurrent professional discourses, each of which embrace distinct assumptions about access and standards. How can classroom-based advocates of basic writing span these conceptual differences to respond to critics at the policy level? The politics of such an undertaking are complicated, indeed. Perhaps I can approach the political question indirectly by addressing some of the rhetorical challenges.

\section{Dimensions Of Contrast: Two Examples}

To get a sense of the ideological rift between these groups, we might consider two contrasting statements. The first is from former Assistant Secretary of Education Bruno Manno, whom I consider a policy-oriented critic. The other is from composition educator Tom Fox, whose book Defending Access offers a composition educator's response to critics. Obviously, these individuals take opposite stances on the issue liberal admissions. In addition, they articulate their arguments using different metaphorical images, which reflect conceptual differences in the discourses of policy and pedagogy. Manno argues: 
Today, access to postsecondary institutions is afforded those who are prepared to do college-level work as well as those who are not. We undermine the promise of American life and do neither group a service when we use race or class or some other substitute rather than academic criteria to determine college advancement. Further, by continuing the 'race for the bottom'... we create a sea of remediation on campuses that... devalues the worth and significance of a college degree... .

This statement shows a consistent pattern of spatial/directional imagery. Consider the reference to "a sea of remediation." Any number of adjectives (e.g., vast, tranquil, life-sustaining) might come to mind when we think about a sea. However, Manno calls attention to a specific quality when he evokes this metaphor. He associates remediation with a "race to the bottom" which "devalues the worth" of a college degree. The pertinent characteristic, here, is depth. The sea of remediation is deep, and the treacherous waters threaten to drag academic standards to the bottom (where faculty and students presumably will die a horrible death). The conceptual movement is vertical; things are moving downward. The theme is repeated in the phrase "undermine the promise." Again, the threat comes from below. The answer, according to Manno, is to raise academic standards, which presumably will strengthen the meritocratic system of sorting and screening by ability. We might say that Manno sees the relationship of access and standards primarily in vertical terms.

Now, let's consider Fox's perspective. The topic of institutional admissions is policy-oriented, but the author's approach to admissionsrelated issues is not typical of policy discussions. In his comments we see a different set of spatial/directional metaphors:

My argument is that there is not a crisis of standards, but a continuing crisis of access. This crisis of access is caused by wide-ranging economic, social and political issues - only some of which can be solved by changes in higher education. I want to argue specifically and strongly against the narrow view that the crisis of access is caused mainly by undepreparation or a lack of literacy skills on the part of students of color. (10)

This declaration contrasts sharply with Manno's statement urging educators to focus exclusively on the issue of academic preparation. In Fox's view, issues of race and class are not irrelevant distractions as Manno asserts. Rather, such socio-historical factors must be considered in any analysis of student progress. Note the spatial connotations of the terms "wide-ranging" and "narrow view." Width and narrowness are descriptions of horizontal distance. Fox uses a broad lens 
to critique narrowly conceived notions of discoursal competence. To put it another way, the author argues against a vertical emphasis on standards by offering a horizontal interpretation of access.

These examples illustrate a distinction between what might be called vertical and horizontal perspectives on open-door education. This is an important dimension of contrast between the policy-oriented discourse (which tends to frame issues in predominantly vertical terms) and the pedagogical discourse (which tends to contexutalize vertical relationships in horizontal terms). I borrow these terms from Basil Bernstein, who explains:

A vertical discourse takes the form of a coherent, explicit, systematically principled structure, hierarchically organized, or it takes the form of a series of specialized languages with specialized modes of interrogation and specialized criteria for the production of texts. (171)

A horizontal discourse consists of local, segmentally organized, context-specific and dependent strategies for maximizing encounters with persons and habitat. (171)

Bernstein uses these concepts to describe how patterns of language are situated in relation to each other. Applied to discussions of basic writing, this taxonomy calls attention to structural differences between the discourses of pedagogy and policy. Moreover, going beyond Bernstein's definitions, the vertical/horizontal distinction highlights differences in how policy advocates and composition instructors characterize the subject matter of their respective discourses.

There is also a methodological dimension of contrast between the two professional discourses. This is evident in the ways that Manno and Fox develop their arguments. Manno cites various statistics (e.g., percentage of institutions offering credit for remedial courses; percentage of institutions allowing students to take regular and remedial courses concurrently) to argue that instruction below the regular college level necessarily degrades academic standards. This rhetorical pattern is common in the policy-level discourse concerning basic skills instruction. Policy advocates (both critics and supporters) typically declare an ideological stance, which they bolster with statistical data that support their position. In this respect, the policy-oriented discourse (particularly the means of evidentiary support) is largely quantitative. The pedagogical discourse, in contrast, is mostly qualitative. We see this in Fox's response to those who claim that standards are declining. Fox cites some statistics (e.g., increasing SAT scores among African Americans), but for the most part he avoids fighting numbers with numbers. Instead, he questions how abstract notions of standards serve 
to restrict access. In responding to critiques of basic writing, classroom-based supporters generally have not refuted statistically-based arguments directly, but rather, have challenged fundamental assumptions underlying the open-door debate.

I consider Fox's piece an important step in responding to policyoriented critics of basic writing. Fox lays out a set of conceptual tools for composition educators to wield in defense of accessible education, but he does not land the knockout punch. This is not necessarily a shortcoming of his argument, but rather a function of whom he addresses and how he frames his discussion. It appears that Fox directs his discussion primarily to an audience of composition educators and secondarily (i.e., indirectly) to policy critics. He explains, "Unless we rigorously examine the assumptions about standards that we hold, our political commitment to economic and social access for students is compromised" (3). The "we" in this statement refers to those who are already sympathetic to Fox's political stance. In a sense, he is preaching to the converted, rallying supporters of accessible education. In doing so, he employs professional language and theoretical constructs that are familiar to composition instructors, particularly those who embrace critical multiculturalism. If we composition educators were to present Fox's argument or any other discipline-based argument to policy advocates, we would need to find ways of penetrating the vertical, quantitative discourse.

\section{Vertical Discourse, Quantitative Emphasis}

Central to the policy-oriented discourse is a vertical, linear conception of institutional mobility. Administrators and policymakers often talk about students "climbing the educational ladder" or "moving up the pipeline." We can imagine people climbing a ladder or crawling into an inclining pipe: Everyone starts at one end and moves upward. There are no side entrances or alternative routes. The supporting structure compels everyone to move in a straight line. The ladder/pipeline metaphors suggest that gaining access to college involves coming into the academy and pulling oneself upward from one rung-like level to the next along a designated route. A related assumption is that the standards regulating movement along the ladder/pipeline are, likewise, arranged in a linear hierarchy. Everyone presumably must pass through progressively more restrictive checkpoints in order to move through the programmatic sequence.

This linear/vertical model lends itself to an all-too-common notion that access and standards are inversely related. As conservative critics see it, the enforcement of high standards requires educators to deny advancement to individuals who do not meet requirements. Con- 
versely, the pursuit of equitable access supposedly requires educators to dumb down the curriculum. Traub draws both conclusions in City on a Hill, which has become a favorite citation among opponents of liberal admissions. Underlying his zero-sum argument is an assumption that there is only one legitimate way to define standards. He further assumes that academic proficiency must be judged on a linear scale (i.e., from high to low) indicating the extent to which a student meets universal standards. While Traub claims to endorse the principle diversity, his unidimensional understanding of aptitude prevents him from recognizing the diverse abilities of the students he encounters. Ultimately, he concludes that individuals are deficient if they do not advance through the institutional hierarchy in the prescribed ways.

More than a few postsecondary administrators and policy advocates disagree with the "either/or" logic of the access-versus-standards argument. Defenders of open admissions claim that, given sufficient resources, public institutions can fulfill the promise of open-door education. This argument hinges on premise that colleges and universities can simultaneously promote social equity and academic rigor, a claim summed up in the title of Roueche and Baker's work Access and Excellence. College presidents Day and McCabe declare:

In a democratic society, higher education is one means of gradually reducing the inequality of the human condition... In this context, the investment in remediation provides a direct return: the costs are low and the success rate is impressive. Students develop the skills and confidence to become selfsufficient; and, business and industry gain a better-prepared workforce. (10)

Obviously, the authors' stance on remedial education is opposite that of Manno. Day and McCabe argue that remediation is not only a democratic imperative, but also a viable instructional approach. Beyond this, the distinctions between the arguments become rather blurred. Day and McCabe implicitly assume that students should move up through the academy to build the "skills and confidence" necessary to meet the requirements of the academy and the private sector. Like Manno, Day and McCabe draw on vertical metaphors in their conceptions of institutional advancement. And like him they use a particular form of vertical logic in evaluating the viability of remedial education. They conduct cost/benefit analyses weighing one variable (e.g., monetary expenditures, institutional prestige) against another (e.g., number of graduates). The degree to which remediation is deemed helpful or harmful depends on whether the "cost" is higher or lower than the "benefit." 
This analytical approach has led policy advocates on both sides of the remediation debate to focus on a narrow range of predominantly quantitative questions: How many students who take remedial courses move up through the system to complete coursework at regular college levels? Do these students actually meet standards in academic courses? Or do instructors have to lower the bar to allow underprepared students to pass? Presumably, the debate over access and standards would be put to rest if research could prove that high percentages of initially underprepared students eventually go on to complete academic programs, meeting regular academic standards. A number of studies and research reviews (e.g., Adelman, Koski and Levin, Boylan et al.) have attempted to identify national patterns of student progress through and beyond remedial programs. Supporters and critics of remediation have thoroughly mined these works in search of evidence for their arguments.

Drawing on Bernstein's notion of vertical discourse, we might say that those engaged in the vertical debate have developed a "specialized language" for talking about open-door education. Particularly, in discussing basic writing, observers use "specialized criteria for (evaluating) the production of texts." In considering the viability of basic instruction, policy advocates use "specialized modes of interrogation" to weigh the costs and benefits of educating underprepared students. We might gather from Bernstein's terminology that the specialized nature of this discourse has had a homogenizing effect, limiting the ways that policy advocates view the challenges of open-door instruction. To put it more bluntly, discussions of open-door policy generally suffer from vertical tunnel vision - fixing one's gaze either downward or upward.

One consequence of this tunnel vision is that policy advocates across the political spectrum have not acknowledged some key limitations of their reforms. Conservatives have cast their attention downward to implement reforms below the university. The overwhelming conservative response to the "remediation crisis" has been to impose tighter admissions standards to keep underprepared students from infiltrating the university. Additional measures include offering remedial classes in satellite locations; paying private contractors to handle remediation; and pressuring high schools to "do a better job" preparing graduates for postsecondary education. The strategy in all of these "solutions" is to shift the pedagogical responsibility downward to sites that are sequentially lower and/or less prestigious than the university. These policies offer no new innovations as far as pedagogy is concerned. The lack of innovation reflects a narrow view of learning as the accumulation of skills taught in school. Advocates of downwardlooking reforms fail to consider how extra-academic factors, such as employment or family responsibilities, influence how adult learners progress in college. 
Progressive reforms differ markedly from conservative approaches but, ultimately, they too are limited by vertical tunnel vision. In the 1970s and early 80s, supporters of open-door education readily acknowledged that college students frequently had to contend with challenges in their lives, making it difficult for them to move through a conventional sequence of coursework. Sympathetic policy observers (e.g., Cross) advocated alternative instructional formats (e.g., learning modules, open-entry/open-exit courses, learning centers, peer tutoring) to accommodate individuals who were not well-served by traditional classes. Central to these first-generation reforms was the notion of "individualized instruction," which had particular connotations. This did not necessarily mean that instructors customized the writing curriculum to suit the particular needs of each student. Rather, individualization usually involved offering several ways for students to meet a given set of literacy-related goals. In this respect, first-generation reforms were vertical and upward looking; remedial programs offered multiple, parallel pathways leading to the same destination first-year composition. More recently, the emphasis on accommodating diverse student needs has slipped from the spotlight. Instead, policy reformers are focusing more intently on moving students expeditiously into the academic mainstream - a goal summed up in Levin's notion of accelerated learning (see Levin and Hopfenberg). There is a certain irony in these developments. Progressive policy advocates have generally supported instructional configurations that accommodate diverse learning styles and needs. At the same time, they tend to accept the traditional premise that all students should learn the same form of essayist literacy, regardless of their interests or academic goals. Policy advocates generally have not taken into account how literacy practices vary from one discipline to another (see Street), let alone from academic disciplines to extra-academic areas (e.g., vocational programs). This is a subtle but pervasive form of upward-looking tunnel vision.

\section{Horizontal Discourse, Qualitative Emphasis}

Since the inception of open admissions, composition faculty have moved simultaneously with and against the grain of the vertical discourse of institutional mobility. While we recognize the need to help students move upward to higher levels of the academy, we have tended to theorize this pedagogical challenge in horizontal terms, challenging vertical notions of academic ability. Consider how the terms "outsider" and "insider" are used to categorize students. The "insider" label connotes privileged status or knowledge. An outsider, then, is someone who occupies a less prestigious position. In one respect, the power relationship between outsiders and insiders is defined verti- 
cally. Mina Shaughnessy tried to de-emphasize this vertical relationship - particularly the notion that the transition from outsider to academic insider is a step upward to an inherently privileged position. She pointed out that the academy is one of many social domains with particular conventions of language use. Anyone who moves from a familiar language-using setting to an unfamiliar setting necessarily goes from an advantaged position to a disadvantaged one. (So a composition instructor might have as difficult a time adapting to the literacy practices of livestock auctioneers, for example, as a returning adult student might have in adapting to the literacy practices of English majors.) Shaughnessy used this notion of sociolinguistic relativism to destigmatize the outsider status of basic writers. In what Lu called an act of "linguistic innocence," Shaughnessy embraced a more neutral (i.e., non-hierarchical) definition of outsider as simply one who is on the outside. We can imagine an individual standing outside of a building and then stepping through a door to enter the interior. The conceptual movement, as Shaughnessy saw it, was horizontal. For better or for worse, this notion of horizontal progress has stayed with composition educators to this day.

Employing various horizontal lenses, composition educators tend to interpret the access-versus-standards controversy quite differently than policy advocates do. A statement by Lu illustrates this point nicely:

I want to articulate one 'import' of multiculturalism here by exploring the question of how to conceive and practice teaching methods which invite a multicultural approach to style, particularly those styles of student writing which appear to be ridden with 'errors.' And I situate this question in the context of English studies, a discipline which, on the one hand, has often proclaimed its concern to profess multiculturalism but, on the other hand, has done little to combat the ghettoization of two if its own cultures, namely composition teaching and student writing. (442)

It is useful to compare Lu's statement and Manno's, however unlikely this pairing might be. Their language and their political stances are so different that it is difficult to tell that both authors address similar issues. Where Manno discusses how educators must control access to the institutional hierarchy, Lu considers how writing instructors facilitate access to various sociolinguistic traditions within the institution. Both authors recognize that academic domains have different levels of prestige and that elite domains (e.g., literature courses) maintain exclusive entry standards. This is where the similarities end. Manno sees differences in standards as strictly hierarchical; in his view, academic criteria in basic writing are simply lower than those in regu- 
lar college English. Lu, in contrast, points to categorical differences. In mapping the intellectual topography of English studies, Lu suggests that there are different disciplinary domains with different standards. To put it in Bernstein's terms, the horizontal discourse in English education is localized and segmentally organized. Lu touches on concerns held by many basic writing educators who, for the most part, do not see a binary choice between access and standards. Particularly for those of us who embrace multicultural notions of style, the question is not simply how do we promote access while enforcing standards, but rather, how do we acknowledge the diversity of text-using traditions within the academy and among our students while simultaneously promoting access to a system that presumes the existence of universal standards.

Like Fox, Lu uses a broad socio-political lens to contextualize and critique excessively restrictive definitions of academic competence. This is a common rhetorical strategy among advocates of basic writing - to counter the vertical tunnel vision of policy reform with what might be called horizontal panorama vision. Obviously, my terminology is biased. An observer who has a panoramic view presumably sees more than one who has tunnel vision. But panoramic views have blind spots, as well. Imagine a panoramic photograph: You get a wonderfully broad view left to right, but you don't see much above the horizon. This is a limitation of horizontal retorts to basic writing's critics: In defending the field, composition educators have said little relatively little about how students fare beyond the horizon of basic writing.

One work that moves in a constructive direction is Democracy's Open Door by Marlene Griffith and Ann Connor. A noteworthy feature of this book is that the authors (both veteran composition faculty) primarily address legislators and trustees, particularly at the twoyear college level. Their intentions are unambiguously articulated in the first few pages:

We urge policymakers at all levels to recognize the uniqueness of the Open Door community colleges and to work to maintain their comprehensiveness, their low cost, and their ability to accommodate students who are learning on their own terms and in their own time. (xiv)

Like Fox, the authors argue that non-White/non-middle class students are generally ill-served by policies that restrict access in the name of upholding standards. They point out that any number of outside factors - work, family responsibilities, transportation, childcare - might prevent students from following a pattern of linear, continuous enrollment which is the traditional benchmark of successful progress. Here, again, we see composition educators employing a panoramic (hori- 
zontal) perspective to complicate narrowly defined notions of access. In addition, the authors go a step further, using a broad lens to interpret longitudinal patterns of enrollment. Drawing on case studies of students and interviews with college leaders, Griffith and Connor suggest that college students may progress in circuitous or intermittent ways but, given sufficient time and curricular flexibility, individuals often move up to higher levels of education and employment. While this argument is not a new revelation to composition educators, it is significant in the way it is framed. Mindful of their audience, the authors strategically address policy-oriented concerns. For instance, they discuss issues of stop-out and reverse transfer - perennial topics among college leaders. We might assume that, being conversant in the discourse of institutional policy, the authors would gain a broad audience beyond composition studies.

Unfortunately, this may be only partially true. Democracy's Open Door has been widely acknowledged among two-year college faculty and administrators (as evidenced by an enthusiastic session at most recent Conference on College Composition and Communication convention devoted to this work). I suspect, however, that readership is lower among the intended audience of policymakers, who rarely cite this work. The relative lack of response in policy circles contrasts with the hoopla surrounding Traub's City on a Hill, which also presents the open-door controversy (albeit from a very different perspective) to broad audiences. Perhaps this is not a fair comparison. Traub's work was published at the right place at the right time - just as opponents of open admissions were planning their assaults. Tensions in community colleges are less volatile and less visible outside of two-year college circles. Still, the publication of Democracy's Open Door was timely. I would argue that the research is no less rigorous than Traub's, and the examples are no less compelling. Why, then, didn't policymakers particularly those concerned with community college issues - come flocking?

To understand this phenomenon, we must consider, not only the timing of publication in relation to political developments in academe, but also how readers perceive the evidence provided. Griffith and Connor use virtually the same qualitative methodology as Traub - embedding individual case studies within a broader institutional analysis, including a review of institutional history and interviews with key leaders. Ethnographers (e.g., Miles and Huberman) recognize a variety of ways that descriptive methodologies such as these gain perceived validity - through triangulation (i.e., deriving similar findings from different data sources), multiple/extended observations (i.e., documenting a phenomenon many times or over a long period of time), large sample size - to name a few possibilities. Griffith and Connor or Traub may have used some or all of these techniques in 
gathering data but, in their published texts (probably for reasons of readability), they chose to include only brief vignettes of a few individuals or programs. Even without extensive methodological documentation, the descriptions in Democracy's Open Door seem reasonable to me (and, I suspect, to many other composition educators) because we have spent enough time around college writers to judge the representativeness of Griffith and Connor examples. However, policyoriented critics of basic writing - people who are not sympathetic to Griffith and Connor's argument and who generally have not spent much time in writing classrooms - are likely to view their descriptions as free-floating anecdotes, not as hard evidence. Ironically, the same critics (Manno, for one) often embrace City on a Hill, even though it offers no more factual evidence than Democracy's Open Door. The difference is that Traub's work neatly affirms critics' preconceived assumptions about what is "wrong" with liberal admissions and basic writing. Traub's accounts of burned-out instructors and befuddled students serve as convenient sound bites that are easily inserted into ideological attacks on basic writing. It would seem that the burden of proof is substantially greater for proponents of basic writing to influence skeptics.

\section{Across the Divide}

How, then, do we span the two-fold divide between pedagogy/ policy and supporters/critics? It would be naïve to suggest that clear argumentation would sway ideologues who categorically oppose the principle of open-door education. However, I believe it is possible to foster dialogue with critics of basic writing who are sympathetic to liberal admissions and who are open to considering evidence. This possibility is evident in remarks by policy analyst Henry Levin, principle organizer of the Conference on Replacing Remediation in Higher Education:

Although there are examples of reportedly successful remedial courses, the evidence on the efficacy of remedial courses in terms of student achievement, persistence, and graduation rates is mixed. This lack of evidence concerning the efficacy of remedial coursework suggests that such coursework has not, in some instances, achieved its goal of preparing students for later college coursework.... (1)

In one respect, it would be a fairly straight-forward matter to assemble the statistical evidence that Levin mentions. Studies of persistence and outcomes already exist. But simply pointing to favorable numbers 
would be a tacit endorsement of vertical/linear notions of access and standards that composition educators have so vigorously contested. The challenge for basic writing advocates is to assess the significance of quantitative research (what it reveals or doesn't reveal) and to scrutinize the theoretical assumptions underlying this methodology.

I am reminded of Ira Shor's challenge to composition educators to produce "hard evidence that BW courses shelter more than they shunt" (96). Shor's statement stands out in my mind because he speaks from a hybrid position. He is a critic of remediation and an advocate of equitable access; he is a composition educator who takes interest in policy matters. Considering some of his concerns might help us to take a transitional step toward addressing policy-oriented critics. This step is not direct. Shor's radical stance is a far cry from the conservative and centrist politics embraced by most reformers. However, he and moderate critics, such as Levin, have at least some theoretical ties. Like other radical educators (e.g., Apple, Freire), Shor directs his attention to material conditions and political practices that enforce or disrupt structures of power. Central to his critique of basic writing is the work of organizational theorists, such as Burton Clark, who argue that the structure of open-door education "cools out" the aspirations of non-elite students. This analysis meshes well with a neo-Marxist view of social reproduction, and it provides the theoretical basis for mainstream critiques of basic writing (see, Shaw). This is a common thread linking Shor's argument with the vertical discourse of remedial policy reform. Participants in this discourse focus on how institutional practice facilitates or hinders upward movement through higher education and, more generally, through boundaries of social class.

I can't easily dismiss Shor's call for professional self-scrutiny. I think it is appropriate that Shor challenges us to look more closely at the relationship between pedagogical practice and socio-economic mobility. It is worthwhile reminding ourselves of the need to document how instruction affects students after they leave our classes. This point (regarding the study of socio-economic advancement) has been obscured in the last decade, in part, due to poststructural and sociocultural theories, which have shaped how we think about student mobility. These theories have led observers to steer away from static models of social structure and cultural reproduction, to focus instead on how individuals negotiate various social terrains. But this theoretical orientation has also contributed to the blind spots of horizontal panorama vision. Trimbur warns that it is possible to take the deconstructive enterprise too far. In de-emphasizing the solidity of social structures, we run the risk of underestimating how material conditions influence students' lives. Trimbur urges literacy educators to re-introduce a "dose of vulgar Marxism" into the professional discourse" - to reconsider physical and political factors that contribute to 
social inequity. This is Shor's point, which has become even more relevant in light of postsecondary reforms of the late 1990s. Material conditions, like the tightening of admissions criteria, have ominous implications for the life prospects of non-elite students.

Still, I'm not entirely comfortable with the way Shor and other critics frame their evidentiary expectations. My concern has to do with the ways postsecondary observers use structural critiques like Clark's to design and interpret research. Structuralist models generally assume that students normally progress in a continuous and linear manner through an academic program until they graduate. This is considered the benchmark of successful matriculation. Many policy analysists further assume that deviation from this pattern (particularly dropping out or switching to a less prestigious program) is evidence that the educational system has done something to discourage students from their original plans. So if a study were to find high dropout rates among current/former basic writers, structural critics would most likely conclude that basic writing caused them to drop out- a classic post hoc fallacy. Shor's argument is not this simplistic, but it can easily be misappropriated by opponents of remediation who have linear/vertical assumptions about student progress.

There is an immediate need, then, for additional inquiry into issues raised by Griffith and Connor and Fox, who question linear/vertical notions of access. One step is to evaluate the findings of exisiting longitudinal studies. Lavin and Hyllegard, for instance, provide compelling statistical evidence supporting the efficacy of open-door education at CUNY. Their analysis of student outcomes supports Griffith and Connor's contention that unconventionally prepared students have reasonably high rates of success in college if allowed extra time for program completion. We also must conduct more of our own longitudinal research. I'm thinking particularly of Marilyn Sternglass's landmark study of how a cohort of CUNY students developed writing and thinking skills. Nancy Sommers also has a multi-year study of literacy development among students at Harvard. While her findings are not necessarily generalizable to basic writers, her methodology might serve as another model for longitudinal studies of non-elite students. Such fine-grained, qualitative studies at the program level would be a powerful complement to large-scale, multivariate analyses examining how curricular and extra-institutional factors influence the long-term trajectories of underprepared students. Clifford Adelman and other researchers at the National Center for Educational Statistics have conducted work along these lines. In principle, a combination of research methodologies could indicate how effectively basic writing moves students into the academic mainstream. Research might also suggest the extent to which institutional practices are responsible for unconventional enrollment patterns. Whatever methodologies we employ, we 
should ask some fundamental questions about the design and purposes of the research: What populations should we study? What contexts should we consider? How long should we follow students? How should we approach the notion of standards? What are reasonable benchmarks of academic success? What constitutes sufficient evidence of success?

I realize that, for writing faculty who have lost programs and students, this call for inquiry-based dialogue is woefully little and late. Many educators have tried to use evidence and rational argumentation to fend off institutional reforms that restrict access to higher education. Meanwhile, universities continue to raise hurdles. As discouraging as the situation is, I believe the tumultuous changes in our field make it as important as ever for us to document how basic writing instruction serves the needs of students.

\section{Note}

1. I use the terms "policymakers", "policy advocates", and "policy observers" to describe those who determine or analyze policies across a given a university or postsecondary system. These groups include trustees, state legislators, presidents, and faculty who study higher education. For purposes of this article, the "policy" rubric does not include individuals (e.g., department chairs, deans, faculty) who administer policies at the departmental or programmatic level.

\section{Works Cited}

Adelman, Clifford. Answers in the Tool Box: Academic Intensity, Attendance Patterns, and Bachelor's Degree Attainment. Washington, D.C.: National Center for Educational Statistics, 1999.

Apple, Michael W. Official Knowledge: Democratic Education in a Conservative Age. 2nd ed. New York: Routledge, 2000.

Bernstein, Basil. Pedagogy, Symbolic Control and Identity: Theory, Research, Critique. London: Taylor \& Francis, 1996.

Boylan, Hunter R., Leonard B. Bliss, and Barbara S. Bonham. "Program Components and Their Relationship to Student Performance." Journal of Developmental Education 20.3 (1997): 2-8.

Clark, Burton R. The Open Door College: A Case Study. New York: McGraw-Hill, 1960.

Cross, K. Patricia. New Students and New Needs in Higher Education. Berkeley: U of California P, 1972.

Day, Philip R. Jr. and Robert H. McCabe. Remedial Education: A Social and Economic Imperative. Executive Issue Paper, American Association of Community Colleges, October, 1997. 
Fox, Tom. Defending Access: A Critique of Standards in Higher Education. Portsmouth, NH: Boynton/Cook, 1999.

Freire, Paulo. Pedagogy of the Oppressed. (Myra Bergman Ramos Trans.) New York: Continuum, 1993.

Greenberg, Karen. “A Response to Ira Shor's 'Our Apartheid: Writing Instruction and Inequality.'" Journal of Basic Writing 16.2 (1997): 90-94.

Griffith, Marlene, and Ann Connor. Democracy's Open Door: The Community College in America's Future. Portsmouth, NH: Boynton/Cook, 1994.

Koski, William and Henry M. Levin. Preliminary Report and Literature Review Regarding the Extent, Content, and Effects of Remediation in Postsecondary Education. Draft ms. National Center for Postsecondary Improvement, Stanford U, 1997.

Lavin, David E., and David Hyllegard. Changing the Odds: Open Admissions and the Life Chances of the Disadvantaged. New Haven, CT: Yale $\mathrm{U} P, 1996$.

Levin, Henry M. Background. Conference on Replacing Remediation in Higher Education, Stanford U., January, 1998.

Levin, Henry M. and Wendy S. Hopfenberg. "Don't Remediate: Accelerate!" Principal 70.3 (1991): 11-13.

Lu, Min-Zhan. "Redefining the Legacy of Mina Shaughnessy: A Critique of the Politics of Linguistic Innocence." JBW10.1 (1991): 2640.

-. "Professing Multiculturalism: The Politics of Style in the Contact Zone." College Composition and Communication 45.4 (1994): 442-458.

Manno, Bruno V. "Remedial Education: Replacing the Double Standard with Real Standards." Change 27.3 (1995): 47-50.

Miles, Matthew B. and A. Michael Huberman. Qualitative Data Analysis: A Sourcebook of New Methods. Newbury Park: Sage, 1984.

Ravitch, Diane. "Do it Right the First Time (College Should Not Need to Offer Remedial Classes)." Forbes 159.3 (1997): 80-84.

Romer, Nancy. "The CUNY Struggle: Class and Race in Public Higher Education." New Politics 7.2 (1999): 1-10.

Roueche, John E., and George A. Baker. Access and Excellence: The OpenDoor College. New York: Teachers College Press, 1987.

Shaughnessy, Mina. Errors and Expectations: A Guide for the Teacher of Basic Writing. New York: Oxford UP, 1977.

Shaw, Kathleen M. "Remedial Education as Ideological Battleground: Emerging Remedial Education Policies in the Community College." Educational Evaluation and Policy Analysis 19.3 (1997): 284-296.

Shor, Ira. "Our Apartheid: Writing Instruction and Inequality." JBW 16.1 (1997): 91-104.

Sommers, Nancy. "Harvard Study of Undergraduate Writing: The Freshman Year." Conference on College Composition and Communication Convention. Atlanta, GA, 1999. 
Sternglass, Marilyn S. Time to Know Them: A Longitudinal Study of Writing and Learning at the College Level. Mahwah, NJ: LEA, 1997.

Street, Brian V. "What Is Meant by Local Literacies?" Language and Education 8.1-2 (1994): 9-17.

Traub, James. City on a Hill: Testing the American Dream at City College. Reading, MA: Addison-Wesley, 1994.

Trimbur, John. "Review: The Politics of Radical Pedagogy: A Plea for 'a Dose of Vulgar Marxism'." College English 56.2 (1994): 194-206.

Wiener, Harvey S. "The Attack on Basic Writing - And After." JBW 17.1 (1998): 96-103. 


\section{Judith Hebb}

\section{MIXED FORMS OF ACADEMIC DISCOURSE: A CONTINUUM OF LANGUAGE POSSIBILITY}

ABSTRACT: "Academic Discourse," "Hybrid Discourse" - these are contested terms. Recently, scholars in composition studies have begun to question and problematize the issues of writing in academic discourse communities. While scholars are now publishing in alternative discourses, including "mixed" or "hybrid" forms, college students are only beginning to find acceptable spaces for their alternative writing styles in academia. This is especially true for inexperienced writers and those for whom English is a second language. If hybrid discourse were viewed along a continuum of linguistic and cultural possibility instead of according to its proximity to the dichotomies of academic/norm and nonacademic/"other," the term "hybrid discourse" and the writing it describes could become both useful and valued in the academy.

Broadly defined, a "hybrid discourse" is a mix of home and school languages. A term as slippery as "academic discourse," hybrid discourse was loosely defined in a 1999 article by Patricia Bizzell as nonacademic discourses blending with traditional academic discourses ("Hybrid" 11). In a later article, Bizzell asserted that

to prepare students now for success in school, it may no longer be necessary to inculcate traditional academic discourse. Rather, what is needed is more help for students in experimenting with discourse forms that mix the academic and nonacademic, or what I have called "hybrid" forms of academic discourse. ("Basic Writing" 5-6)

Bizzell refined this position by questioning the term "hybrid" because it is "at once too essentializing and too suggestive of independent " parent' strands" ("Basic Writing" 4). She also advocated a stronger classroom pedagogy - that writing instructors should find ways to encourage "mixed" forms in their teaching ("Basic Writing" 4). While I agree with Bizzell's pedagogical admonition, I would like to propose that the term "hybrid discourse" need not be as negative as Bizzell claims. If we were able to change our perspective and think of hybrids as dis-

Judith Hebb is Assistant Professor of English and Spanish at Atlanta Christian College, where she is Chair of the Department of Humanities and General Studies, directs the writing program, and teaches first-year composition, upper division English courses, and Spanish. She has published in English Journal and has a forthcoming article in Academic Exchange Quarterly.

(c) Joumal of Basic Writing, Vol. 21, No. 2, 2002 
course forms along a continuum rather than as mixed forms between a dichotomy of academic and nonacademic discourses, perhaps neither the term "hybrid discourse" nor the acceptance of alternative discourse use in college classrooms would be as problematic. This notion is of primary importance to college students in the margins for whom English is a second language and for under-prepared basic writers, whose discourse is measured for correctness against "traditional" academic discourse, whatever that may be. When viewed on a continuum that extends from the completely traditional mainstream to the entirely idiosyncratic and unintelligible, the discourses of under-prepared writers could be viewed as attempts at meaningful discourse rather than as failures, and their true value would emerge.

Besides Bizzell, scholars such as Mina Shaughnessy, Peter Elbow, David Bartholomae, Joseph Harris, Min-Zhan Lu, bell hooks, Mike Rose, and Elspeth J. Stuckey have problematized the term "academic discourse." In fact, I would argue that no such entity exists; the term defies definition. Bizzell's list of the characteristics of traditional academic discourse, an extension of the work of Helen Fox, although perhaps the most comprehensive compilation, is not exhaustive ("Hybrid" 10-11). To rehearse a taxonomy of traditional academic characteristics would seem to imply a fixed unchanging entity, which is a myth (Bizzell, "Basic Writing" 6). Furthermore, since discourses are inherently "ideological," composing a list of traditional academic discourse traits would serve to reinforce its privileged sociopolitical position within the academy. Therefore, I choose not to produce such a list. The heteroglossic nature and shifting characteristics of academic discourse, whether in the scholarship produced within composition studies or in the writing of first-year college students, render the term nearly useless. When alternative discourse forms are juxtaposed against traditional notions of academic discourse, they are viewed as unacceptable violations representative of the marginal voice of the "other." The traditional reaction of college instructors has been to force students to transform writer-centered discourse into reader-centered discourse. However, mixed or hybrid forms of discourse might be deemed acceptable for doing intellectual work in institutions of higher learning when viewed along a continuum of language use. I propose to advance this argument by showcasing the acceptable use of and value of "hybrid" discourses by scholars in various disciplines - composition/ rhetoric, discourse theory, linguistics, and cultural and postcolonial studies - and by illustrating the possibility of acceptable student writing in college. The ideology represented by such a stance would serve to resist the notions of privilege and power assumed by traditional academic discourses.

This showcase of hybrid discourse scholars is not intended to be comprehensive; rather, I have selected representative examples from 
various disciplines and included writers and scholars fore-grounded by Bizzell in her ongoing alternative discourse work in academia. Bakhtin is perhaps the first scholar, in discourse theory, to have used the word "hybrid." He locates discourse on a continuum of language use that highlights the value of a variety of complex, purposeful utterances. Bakhtin posits the term "hybrid construction" to describe a double-accented, double-styled structure that has "enormous significance in novel style" (not poetic style) (Bakhtin 304-05). This utterance belongs to a single speaker but "actually contains mixed within it two utterances, two speech manners, two styles, two 'languages,' two semantic and axiological belief systems" (Bakhtin 304). According to Bakhtin, who denies the existence of individual voice, an utterance is multivocal, a polyphony socially constructed from many voices, which are in an internal dialogic (Halasek 30-31). Furthermore, there are no "formal" boundaries between these voices and languages (Bakhtin 305). "Hybridization" is, therefore, the mixing of two or more different linguistic consciousnesses - an encounter - within a single concrete utterance, separated from one another by an epoch, by social differentiation, or by some other factor (Bakhtin 358, 429). It is precisely "between 'languages,'" "on the borderline between oneself and the other," that the individual consciousness lies (Bakhtin 293).

It is my contention that the inseparable mixing of oneself and the other(s) operates hazily along a continuum of consciousness and empowerment, the positioning of the subject ever moving back and forth as one reveals and takes control over more and less of the true self. This "ideological becoming" - a continuum - is a "process of selectively assimilating the words of others," a "struggle within us for hegemony among various available verbal and ideological points of view, approaches, directions, and values" (Bakhtin 341, 346). While these discourses continue to "interact or inform one another," the subject is liberated by the ability to freely choose the discourse(s) employed rather than be unconditionally bound to another discourse (Halasek 109). Under-prepared writers, whose discourse may be viewed as idiosyncratic and unintelligible, could then be valued as writers not only learning to write but as human beings writing to learn, consciously making choices and mixing discourse forms.

According to Bartholomae, a developmental writer lacks choices, options, and control ("The Study of Error" 255). How will a basic writer learn to make choices if never presented with any? As a first-year writing teacher, one of my goals is to help students be critical thinkers, i.e., make choices and ask the right questions (Maimon 116-17). At my institution, where under-prepared writers are mainstreamed with prepared writers, every student and his/her discourse is valued, although some need more guidance in making critical "writerly" choices. We 
require a one-credit writing workshop to supplement English 101 for inexperienced writers. In any case, the ability to make effective choices simultaneously empowers beginning writers, resists the political and linguistic hegemony of academia, and encourages the emergent self of the writer. To prepare my students to succeed in other disciplines rather than do them a disservice, I further stress the importance of asking the right questions in each discipline, where they are likely to find that all things are not valued equally and they must make appropriate choices.

Throughout his seminal essay "Discourse in the Novel," Bakhtin characterizes discourses as public and private, external and internal, centripetal and centrifugal (heteroglossia), direct and indirect, literary and everyday, personal and impersonal, authorial and "other," and authoritative and persuasive. The interaction (interanimation) between these diametrically opposed systems creates a dialogic tension-a resistant "internally persuasive" language - that results in multi-layered creative relationships with new contexts and new perspectives ("newer ways to mean") (Bakhtin 314, 345-47). The resulting "languages of heteroglossia," "a unique artistic system of languages," or "images of languages," become mirrors that reflect aspects which are "broader, more multi-leveled, containing more and varied horizons than would be available to a single language or a single mirror" (Bakhtin 414-16). Intentional hybrid styles have as their goal "the illumination of one language by means of another, the carving-out of a living image of another language" (Bakhtin 361). This purposeful mixing of languages results in an enriched language with the potential to produce meaningful discourse both creative and intellectual that would otherwise not be possible in the expression of only one language.

Frequently, meaning springs from tension, both in life and in reading and writing. The apprehension basic writers feel because of their failure to meet the expectations of any, much less all, of their various academic discourse communities should be viewed as an opportunity for discovery. Carol Severino compares the clash between basic writers and academia to "hybrid snack 'nachos' [...] tortilla chips coated with melted, processed American cheese" (5). The chips and the cheese (artificial and not particularly nutritional, like academic discourse) may not seem compatible at first glance, but in fact, when mixed together, their individual flavors are enhanced. I contend that the intentional mixing of discourse forms is similarly unconventional yet appetizing. Severino's notion of commonality and intersection lends itself to the idea of a discourse continuum rather than to a relationship of discourses in opposition. Furthermore, inexperienced writers would not be evaluated by their proximity to and approximation of a particular discourse. Taking on a new dialect, such as SAE, is likely to result in more production errors, especially in early drafts, than texts written in home vernacular. For basic writers, particularly, the initial "freedom from 
failure" may be the catalyst for achieving confidence and control over subsequent texts, with both the writer and the writing being transformed in various ways in the process.

The acceptance of hybrid discourses for accomplishing serious academic work will revolutionize the academy and create new and interesting intellectual possibilities. However, in order to decrease tension and facilitate the negotiation of students across distinct academic discourse communities, all college teachers should clearly voice their expectations and model the writing conventions valued in their particular disciplines. Since writing teachers are usually the first to meet beginning college students, they need to purposely communicate that reading and writing allow writers to learn more about themselves, their feelings, their ideas, their language use, and their writing process, things they might never discover any other way except through the cognitive and metacognitive reflections of the inner mirror of language use. As they are confronted with (and helped to make) writerly choices and gain control over texts, developmental writers, especially, will achieve confidence and experience success in the college classroom. They will see that they are able to accomplish intellectual work that is valued.

My first-year writing classroom includes speakers of SAE, English as a second language, AAVE, regional Georgia dialects, and bilingual speakers. I try to communicate to my students that all of these languages, dialects, and varieties are valued and that we as a writing community are enriched by the linguistic and cultural mixture. One way I do this is to have individual students share their writing within our local discourse community and in published collections on our college website. We also read multi-cultural texts written in multiple discourse styles and genres, including film, some in home vernacular (from Making Literature Matter, edited by John Schilb and John Clifford, and supplemental texts). If such hybrid texts are acceptable as models, why must student drafts be transformed? As Bizzell has pointed out, no one speaks SAE ("The Future").

In my writing classroom, we continually point out language differences, we explore the possibilities of language use, and we talk about the importance of language choices. Furthermore, clashes of culture and language are foregrounded as students read texts against each other and against their own experiences. Assigning mixed discourse forms a place on a discourse continuum rather than a value derived from their distance to/from acceptable/unacceptable positions frees teachers from having to valorize discourses and allows us to appreciate the uniqueness of each as they illuminate our multilingual classroom conversations. I also stress to my beginning writers that the individuals who belong to each particular discourse community and the languages they use make it unique, not only without but also within the discipline of English, including my own different sections of English 101 
and English 102. To succeed in college and at work, students must learn to identify the characteristics and expectations of each discourse community they wish to (or are forced to) join. One of my goals in first-year writing is to have my students "try on" various reading and writing strategies in order to fill their reading and writing toolboxes with tools that might be helpful to them in the many, sometimes contradictory, discourse communities they will be asked to negotiate both at school and in the workplace.

It might be helpful to revisit Volosinov's bridge metaphor for the utterance as a two-sided act "thrown between myself and another" (qtd. in Halasek 44). Hybrid discourse is best imagined as a bridge (a connection, a continuum) between travelers (conversants) free to travel unrestricted and unlimited in either direction. Both prepared and under-prepared college writers should have the freedom to travel this bridge of discourse in either direction. Further, the value of travel in both the literal and metaphorical senses should not be underestimated, as wide experiences broaden not only our cultural but our linguistic horizons as well. From the complex interaction and mixing of discourses, possibilities arise for new ways of thinking, new ways of doing ("creativity"), and enrichment not otherwise possible in a mythical monolithic language. Certainly, experimenting with various mixtures of styles and dialects will better prepare our students to make effective choices in the multiple rhetorical situations in the overlapping discourse communities they will encounter in academia and on the job.

Many scholars have argued for broadening the concept of acceptable academic discourse(s), investigating new forms, and accepting alternatives discourses within the academy (Bizzell, Chase, BridwellBowles, Sledd, Pixton, Eskey, Delpit, Bishop, Helen Fox, Tom Fox, Schroeder). Bizzell has demonstrated how in recent years academic scholars (Rose, Helen Fox, Gilyard, and Villanueva) have revolutionized their "successful, published academic" discourses by employing many or all of the traits she has identified as characteristics of "hybrid discourse," such as writing in variant forms of English and using nontraditional shared cultural references and assumptions, personal experience, "offhand refutation," "appropriative history," humor, and indirection ("Hybrid" 16-17). These hybrid discourse forms are mixtures of personal narratives, poetry, prose, and commentary, as well as languages and dialects. The acceptance of alternative discourses and mixed forms has changed the way the academy views and writes "academic discourse." Bizzell considers well-done, deliberate hybrid discourse to be an enriched discourse that has the capacity for accomplishing reflective, dense, rigorous, serious intellectual work that could not be done in traditional discourse ("Hybrid" 11,13). As Bartholomae has pointed out, university students must "invent" themselves by ap- 
propriating the language of academic discourse communities to earn the right to speak and enter the conversation ("Inventing the University"). As college "outsiders" try on their Bakhtinian masks (identities and languages), they are tested against the changing discourse of academic "insiders." Since these shifting discourses mix along a continuum of academic discourse, both experts and novices should have the freedom to move simultaneously along the academic discourse continuum instead of being separated as they adapt and mix home and school languages to the intellectual work of the academy.

Of course, just because I say so doesn't make it so. Folks in disciplines outside of English (and some inside of English) do not and will not value mixed discourse forms for intellectual work. We can propose to analyze published texts in other disciplines and make other scholars and teachers aware of their own use of hybrid discourses in their published scholarship (as, for example, at CCCC 2001 convention in Denver, Bizzell, in an address entitled "The Future of College Composition," analyzed an article written in hybrid discourse by Joel Williamson in the Journal of American History). We can share how our students are using mixed discourse forms to do intellectual work (and we are accepting them) in our classes. Perhaps this can develop from a formal discussion or from a casual conversation with a colleague commenting on the grammar, spelling, and punctuation inadequacies of their students and our responsibility as English teachers to "fix" them. We can provide models of teacher response based on the pleasure of responding to the content of student writing for colleagues who choose to value form over content. We can talk about our students as individuals and as interesting people who, through hybrid discourses, allow us glimpses into their true selves. We need to start and/or continue meaningful dialogues among our colleagues.

Discourse theorists and linguists hold similar theories about the goals of discourse and speaker/writer roles and oral versus written language (Summerfield, Britton, Horowitz and Samuels, Tannen, Lakoff); however, Brandt, Horowitz and Samuels, Tannen, and Lakoff have worked to dispel the dichotomy between oral and written ("literate") languages. Tannen, for example, refers to the "oral-literate continuum." From a linguistic perspective, an "interlanguage" resembles a hybrid discourse. Whether the "middle ground" between students' language and academic discourse is viewed as transitional or not (Kutz 393), this dynamic, overlapping, and ever-shifting interlanguage lies along a continuum between home and school languages. Harris describes how teachers might build on the "overlap' ["polyglot"] between the students' 'common' discourses and the 'academic' ones of their teachers" to encourage a "polyphony" ("an awareness of and pleasure in the various competing discourses that make up their own") $(17,20)$. When viewed along a continuum in which characteristics of 
oral and written - home and school - languages are mixed, a place will be opened up for hybrid discourses that serve both writer and reader. Judging hybrid discourse by the dual measuring sticks of "traditional" and "nontraditional" academic discourse - theoretically, culturally, or linguistically - will always render it "other" - "substandard," "abnormal," "deviant," "a violation," or "unacceptable." Hybrid discourse will forever be devalued as impoverished (Kells uses the term "linguistic shame" due to "dialect misconceptions"), even as academic discourse has and will continue to change (Kells 137).

On the contrary, the rich, varied, and unique textures of discourse are to be found somewhere in-between, in the mixing of the traditional and the innovative, the personal and the impersonal; discourses that fall at both ends of the discourse continuum then become impoverished, for they reflect neither the complexity and multivocality of group nor the individual voice(s) of self. When assessed from a continuum perspective, alternative discourses are valued and not dismissed as aberrations. Hybrid discourse is the language of possibility not restriction. This is good news for basic writers, who bring valuable linguistic resources and personal experiences with them to college, which must be acknowledged rather than discounted. Inviting under-prepared writers to cross the bridge of hybrid discourse, thereby entering the conversation of the university, will serve to empower them; the alternative is to silence them by continuing to measure their discourse by its distance from a pre-determined (yet undefined and unstable) point (academic discourse).

Bizzell coined the term "hybrid discourse" by borrowing the word "hybrid" from postcolonial theory because it upsets the dichotomy between academic discourse and students' home discourses and implies that discursive and cultural boundaries are blurred ("Basic Writing" 7). However, cultural and postcolonial scholars have negative associations with "hybridity," a term linked for them to the context of colonial subject. For example, Deepika Bahri and Mary Vasudeva call the hybrid "the exiled, the dislocated, the multi-located" in a "condition of betweenness" sliding between identities $(9,13)$. Bahri and Vasudeva assert that postcolonial theorists rely on the "inadequately nuanced binary colonizer/colonized" despite their efforts to resist dichotomous constructions that force postcolonialists to write back to Eurocentrism $(138-39,152)$. They challenge postcolonialists to produce "a discourse free from colonial reminiscing," as the colonizer/colonized (us and them) dichotomy because "it casts the 'postcolonial' as passive victim and encourages a culture of blame and self-pity" (Bahri and Vasudeva 145). Furthermore, since postcolonial terms such as "hybridity" tend to refer to metropolitan locations, thereby obscuring those in the Third World, the term becomes essentialist, homogenizing whole groups and reinforcing stereotypical attitudes and failure to 
genuinely investigate other cultures and voices (Bahri and Vasudeva $142,154)$. But Bahri and Vasudeva do not suggest that these terms be abandoned; rather, they admonish us to confront their inherent contradictions and open them up to new readings (152). They charge that "the persistent reading of culturally 'Other' texts for their 'difference' and distance from the dominant culture could foster rather than erase divisions," and they challenge us to "activate the continuum rather than the polarities between binaries" (Bahri and Vasudeva 154, 158). This call is parallel to my continuum argument for hybrid discourse, which seeks to abandon the oppositional binaries of academic and nonacademic discourses. Rather than reject the term "hybrid discourse," we ought to problematize then embrace it as the discourse of possibility not limitation.

When Homi Bhabha refers to the growing number of cultural hybrid communities, he speaks of oppression, assimilation, and resistance, the "defined" and the "not defined." Hybridity is an in-between reality, a halfway point of non-definition (neither one or other) (Bhabha 6-14). In this "hybrid gap," where the colonial subject takes place and its subaltern position is ascribed, there is no relief, only anxiety and anguish associated with "vacillating boundaries" drawn with "subversive political lines" (Bhabha 58-59). This discriminatory "ambivalent space," signifying the displacement of value, is inhabited by "other," the hybrid split of the self (Bhabha 112-14). Bhabha contends that the bearers of a hybrid identity are caught in discontinuous time; however, he challenges us to explore the "Third Space," the in-between space that carries the burden of the meaning of culture, a space of translation free from "the politics of polarity" where the others of our selves may emerge (38-39). Bhabha thinks of this space as a passage, borrowing from Benjamin's idea that "the important thing about translation is to focus on the continuum of transformation" (Olson 14-15). This passage implies movement on three levels: spatially, as in opening up a space; as in a rite of passage (transition); and as an inscription (holding the moment of transition) (Olson 14). For Bhabha, hybridization is "the process of negotiation," a "move away from the notion of the subject of recognition toward the subject of enunciation" in which one is both subject and object at once (living in "double-time") (Olson 18-19, $23,31)$. By opening up a physical space for hybrid discourse in college classrooms, beginning writers, especially, will be helped to negotiate through their passages from outsider to insider and make their unique marks on the ensuing conversations along the journey.

However, this "cross-boundary process" is fraught with tension (Olson 20, 25). Although Bhabha labels hybridity as a "zone of nowhere-ness," as Bizzell has pointed out, this zone is a very real place, a "contact zone" defined by Mary Louise Pratt as a "social space where cultures meet, clash, and grapple with each other, often in contexts of highly asymmetrical relations of power, such as colonialism, slavery, 
or their aftermaths as they lived out in many parts of the world today" (Pratt qtd in Bizzell, "Basic Writing" 10). This space is not free of conflict, as "border-crossing can be dangerous and potentially fatal" (Bahri 39). As a discourse with the potential to discover, negotiate, and revise hybrid identity, I believe the language of the hybrid Third Spacea shifting continuum of cultural and linguistic (and ethnic) mixing, meaning, value, and possibility - is hybrid discourse.

Scholars in cultural and postcolonial studies (Anzuldúa, Spivak, Mohanty, Bhabha) have called "hybrid" people-people (in the words of Jacqueline Jones Royster)

who either have the capacity by right of history and development, or who might have created the capacity by right of history and development, to move with dexterity across cultural boundaries, to make themselves comfortable, and to make sense amid the chaos of difference. (37)

While this hybridization process allows for survival, Royster contends that it also breeds the emergence of genius. The fusion of cultural and linguistic (and ethnic) boundaries, like hybrid discourse, "allows for the development of a peculiar expertise that extends one's range of abilities well beyond ordinary limits, and it supports the opportunity for the development of new and remarkable creative expression" (Royster 37). Just as the agronomist chooses the best traits to yield a unique and better breed, hybrid discourse mixes the best of academic and nonacademic characteristics. Further, if our interpersonal and cross-cultural goals are to exchange perspectives, negotiate meaning, and create understanding, hybrid discourse is the perfect language for our conversation of cooperation and collaboration. Hybrid discourse may be the vehicle to achieve these same goals in college classrooms.

Gloria Anzaldúa creates an evocative hybrid voice in her writing. In Borderlands/La Frontera, she refers to herself as a "hybrid progeny," a mixture of races. However, "rather than resulting in an inferior being, [...][this racial mixture] provides a mutable, more malleable species with a rich gene pool" (Anzaldúa 77). Although there may be $\mathrm{a}^{\prime \prime}$ choque (cultural collision) between cultures, the new mestiza can emerge with la conciencia (a new consciousness) [Freire's conscientização?], a breaking down of the "subject-object duality" that keeps her a prisoner (Anzaldúa 80). Anzaldúa illustrates how by true faces we will be known:

I am visible - see this Indian face-yet I am invisible. I both blind them with my beak nose and am their blind spot. But I exist, we exist. They'd like to think I have melted in the pot. But I haven't, we haven't. (Anzaldúa 108) 
Anzaldúa views her self, her culture, and her language along a continuum of mixed changing images ("hybridized metaphors") rather than as fixed points of heritage. From the resulting tension created by this rich, continual mixing and ambiguity of the private and the public, new but true identities are released.

In the Preface to Borderlands, Anzaldúa explains how the codeswitching between Spanish and English languages (and dialects) she writes in results in the cross-pollination and revitalization of the languages. This new way of speaking illuminates her feelings and ideas in a way not possible in only one language. A reflection of her hybrid self, she describes her writing ("a creative act") as a "mosaic," "montage," "weaving," "hybridization," "beaded work," "assemblage," "crazy dance" (Anzaldúa 66, 73). Clearly, Anzaldúa's distinctive fusion of language, self, and meaning could only have been achieved through her unique hybrid discourse. In fact, she claims that living in a Borderland state "is what makes poets write and artists create" (Anzaldúa 95). Anzaldúa is the "new Mestiza," a successful inhabitant of the Third Space, "the borderland space that is home to her multiple identities and voices" (Lunsford 44).

Anzaldúa explains how, through the cracks between two worlds, borderland residents have access to other worlds" (Anzaldúa 237). It is in this space that she finds her "non-binary identity," an identity always in process (Bakhtin's "ideological becoming"), a fusion of self and other (the peripheral 'I's within a person, the personal 'I's, and the collective 'we' of her ethnic community) (Lunsford 44,47). Anzaldúa feels the ambivalence, perplexity, strife, insecurity, indecisiveness, and restlessness of the border struggle:

\author{
Because I, a mestiza, \\ continually walk out of one culture \\ and into another, \\ because I am in all cultures at the same time, \\ alma entre dos mundos, tres, cuatro, \\ me zumba la cabeza con lo contradictorio. \\ Estoy norteada por todas las voces que me hablan simultáneamente.
}

(Anzaldúa 99-100)

(A soul between two worlds, three, four, my head is buzzing with the contradictions. I am steered to the north by all the voices that talk to me simultaneously) [my translation]

In a continuation of Borderlands, Anzaldúa refers to the "Nepantla," a "Nahuatl word for the space between two bodies of water, the space between two worlds" (Anzaldúa 237). She describes this limited space as "a space where you are not this or that but where 
you are changing. You haven't got into the new identity yet and haven't left the old identity behind either-you are in a kind of transition," which is "very awkward, uncomfortable and frustrating ... because you are in the midst of transformation" (Anzaldúa 237). Anzaldúa uses the Spanish pronoun for "we" (women), "nosotras," to disrupt binary oppositions and to illustrate that for her, there is no such thing as "other." "Us" (" nos") and "them" ("otras") are interchangeable, for " $[t]$ he other is in you, the other is in me" (Lunsford 52). From within this Third Space, Anzaldúa's language - a reflection of her blurred identities - has emerged. For her, language and identity are inseparable; she says, "I am my language" (Lunsford 45). Nepantla is not only a place where identities get created but wheren "reality gets constructed" and "knowledge gets produced," a concept that is "articulated as a process of writing" (Anzaldúa 237). This hybrid language of possibility results in "new and remarkable creative expression," to use Royster's words, a rich mixture of genres" - a "Mestiza Rhetoric" (Lunsford 45). Should we deny our students the same remarkable possibilities of being, creating, and doing through their writing?

In my earlier work, I have demonstrated how a beginning college student successfully used hybrid discourse (as defined by Bizzell) to negotiate various academic discourse communities English, Speech, Broadcasting, Radio-TV across the curriculum and how he was unsuccessful in those communities that did not accept his unique, creative discourse, such as History (Hebb). I analyzed the writing of Jeremy, a student of mine in English 101 at Texas A\&M University-Commerce, across several disciplines over a period of two years (and have his permission to cite his work).

Jeremy's Essay \#6 for English 101, “Voice-The Ambrosia of Language," is a response to the question "How is language a form of resistance and/or power? The writing assignment required at least five total citations from the essays "From Outside, In" by Barbara Mellix and "From Silence to Words: Writing as Struggle" by Min-Zhan Lu and the film Oleanna. Excerpts from the beginning and end of this essay, written in hybrid discourse, effectively illustrate the importance of language for empowering (or silencing) personal voice (and the identity of the writer):

Everyone must have their say in this and that these days. Got to argue the belief of oneself...right. So how can someone get the attention of another to be heard?

Beep...What is a voice Alex? That is correct. a voice is power and can be used in the speaking or the writing sense. It's the key to take an opponent and rip out their beating heart and shove it in their face verbally. 
The battle of the voices is an ugly one. I had an experience in one of these with a high school junior English teacher who we will name "Mrs. I only like a select few." [...]

\section{$[\ldots]$}

So now I leave you with this fact that the voice is very powerful, creative, and can be silenced by the outside foes. So be on your toes wizards and warriors. Keep fighting for the forces of good and protect your vocal cords and scrolls for the War of Language is never over... (Drake Essay \#6; bracketed ellipses indicate omissions, while others occurred in the student's original)

In this essay, Jeremy clearly demonstrates how his hybrid mix of home and school languages enriches his discourse and advances his argument. His nontraditional cultural references, comparing language use to an intellectual contest (like the game show "Jeopardy") and to physical combat and a joust (offhand refutation), as well as his colloquial language and humor, add new, insightful, colorful perspectives on the hegemony of academia. Furthermore, reading his personal experience against the experiences of Mellix, Lu, and Carol in Oleanna illuminates his forceful, resistant voice and reinforces his argument for the power of language in a way that would not have been possible in entirely traditional academic discourse. We ought to validate the sometimes marginal spaces inhabited by hybrid discourse writers such as Jeremy and invite them to enter into and illuminate the intellectual conversations in institutions of higher learning rather than dismiss them as irrelevant. Along the continuum, there are spaces for experts and novices alike to mutually enrich one another's discourse.

The term "hybrid discourse" has a rich, complex, and multi-layered history and context. Whether viewed through the lenses of compositionists, rhetoricians, discourse theorists, linguists, or postcolonialists, hybrid discourse is the discourse of possibility not limitation. Language and identity are inseparable. In some sense, we are all linguistic and cultural hybrids, continually revised and constructed by many voices, both collective and individual. We should acknowledge and revel in the polyphony that shapes us. As long as we are careful to equate all discourses along the discourse continuum with heteroglossia, the term "hybrid discourse" will be valid. By abandoning a dualist perspective and perceiving mixed discourse(s) along a continuum of conversation, we could value hybrid languages and the people who speak them. These are goals shared by those who study and teach both language and culture. This theoretical and pedagogi- 
cal move would help to bridge gaps between languages, people, ideologies, and experiences both within and without the academy. Think of the possibilities!

\section{Works Cited}

Anzaldúa, Gloria. Borderlands/La Frontera: The New Mestiza. San Francisco: Aunt Lute Books, 1987.

Bakhtin, Mikhail. "Discourse in the Novel." The Dialogic Imagination. Trans. Caryl Emerson and Michael Holquist. Austin: U of Texas P, 1981. 259-422.

Bahri, Deepika. "Terms of Engagement: Postcolonialism, Transnationalism, and Composition Studies." JAC 18 (1998): 2944.

Bahri, Deepika, and Mary Vasudeva, eds. Between the Lines: South Asians and Postcoloniality. Philadelphia: Temple UP, 1996.

Bartholomae, David. "Inventing the University." When a Writer Can't Write. Ed. Mike Rose. New York: Guilford, 1985. 134-65.

-. "The Study of Error." CCC 31 (1980): 253-69.

-. "Writing with Teachers: A Conversation with Peter Elbow." CCC 46 (1995): 62-71.

hooks, bell. Talking Back: Thinking Feminist, Thinking Black. Boston: South End Press, 1989.

Bhabha, Homi K. The Location of Culture. London: Routledge, 1994.

Bishop, Wendy. "Preaching What We Practice as Professionals in Writing." Genre and Writing. Ed. Wendy Bishop and Hans Ostrom. Portsmouth, NH: Boynton/Cook, 1997. 3-16.

Bizzell, Patricia. "Basic Writing and the Issue of Correctness, or, What to Do with 'Mixed' Forms of Academic Discourse." JBW19 (2000): 4-12.

-. "Hybrid Academic Discourses: What, Why, How." Composition Studies 27 (1999): 7-21.

-. "The Future of College Composition: Impacts of Alternative Discourses on Standard English." Address. Conference on College Composition and Communication Convention. Adam's Mark Hotel, Denver, 16 Mar. 2001. (Reference is specifically to author's notes on this address.)

Bridwell-Bowles, Lillian. "Discourse and Diversity: Experimental Writing Within the Academy." CCC 43 (1992): 349-68.

- . "Freedom, Form, Function: Varieties of Academic Discourse." CCC 46 (1995): 46-61.

-. "The Impact of Crossdisciplinary Studies on Academic Rhetorics." Rhetoric in the Vortex of Cultural Studies: Conference Proceedings of the Fifth Biennial Conference. Ed. Arthur Walzer. St. Paul, MN: Rhetoric Society of America, 1993. 201-07. 
Britton, James, et al. The Development of Writing Abilities (11-18). Hong Kong: MacMillan, 1975.

Chase, Geoffrey. "Accomodation, Resistance and the Politics of Student Writing." CCC 39 (1988): 13-22.

Delpit, Lisa D. "The Politics of Teaching Literate Discourse." Freedom's Plow: Teaching in the Multicultural Classroom. 1993. Rpt. in Negotiating Academic Literacies: Teaching and Learning Across Languages and Cultures. Ed. Vivian Zamel and Ruth Spack. Mahwah, NJ: Lawrence Erlbaum, 1998. 207-18.

Drake, Jeremy. English 101 Essay \#6 "Voice-The Ambrosia of Language." Texas A\&M University-Commerce. Fall 1998.

Elbow, Peter. "Reflections on Academic Discourse: How It Relates to Freshmen and Colleagues." College English 53 (1991): 135-155.

Eskey, David E. “Standard/Nonstandard English: Toward a Balanced View." EJ65 (1976): 29-31.

Fox, Helen. Listening to the World: Cultural Issues in Academic Writing. Urbana, IL: NCTE, 1994.

Fox, Tom. Defending Access: A Critique of Standards in Higher Education. Portsmouth, NH: Boynton/Cook, 1999.

Freire, Paulo. Pedagogy of the Oppressed. Trans. Myra Ramos. New York: Seabury, 1970.

Gilyard, Keith. Voices of the Self: A Study of Language Competence. Detroit: Wayne State UP, 1991.

Halasek, Kay. A Pedagogy of Possibility: Bakhtinian Perspectives on Composition Studies. Carbondale, IL: Southern Illinois UP, 1999.

Harris, Joseph. "The Idea of Community in the Study of Writing." CCC 40 (1989): 11-22.

Hebb, Judith. Hybrid Discourse and Academic Writing. Diss. Texas A\&M University-Commerce. 2000. Commerce, TX: UMI. 2000. 072699.

Horowitz, Rosalind, and S. Jay Samuels. Comprehending Oral and Written Language. San Diego: Academic Press, 1987.

Kells, Michelle Hall. "Leveling the Linguistic Playing Field in FirstYear Composition." Attending to the Margins: Writing, Researching, and Teaching on the Front Lines. Ed. Michelle Hall Kells and Valerie Balestar. Portsmouth, NH: Boynton/Cook, 1999. 131-49.

Kutz, Eleanor. "Between Students' Language and Academic Discourse: Interlanguage as Middle Ground." CE 48 (1986): 385-96.

Lakoff, Robin Tolmach. "Some of My Favorite Writers are Literate: The Mingling of Oral and Literate Strategies in Written Communication." Spoken and Written Language: Exploring Orality and Literacy. Ed. Deborah Tannen. Norwood, NJ: Ablex, 1982. 239-60.

Lu, Min-Zhan. "From Silence to Words: Writing as Struggle." CE 49 (1987): 437-48. Rpt. in Living Languages: Contexts for Reading and Writing. Ed. Nancy Buffington, Marvin Diogenes, and Clyde Moneyhun. Upper Saddle River, NJ: Prentice Hall, 1997. 157-69. 
Lunsford, Andrea. "Toward a Mestiza Rhetoric: Gloria Anzaldúa on Composition and Postcoloniality." Race, Rhetoric, and the Postcolonial. Ed. Gary A. Olson and Lynn Worsham. Albany: State U of NY P, 1999. 43-78.

Maimon, Elaine. "Maps and Genres." Composition and Literature: Bridging the Gap. Ed. Winifred Horner. Chicago: University of Chicago $P, 1983.110-25$.

Mellix, Barbara. "From Outside, In." Living Languages: Contexts for Reading and Writing. Ed. Nancy Buffington, Marvin Diogenes, and Clyde Moneyhun. Upper Saddle River, NJ: Prentice Hall, 1997. 80-89.

Oleanna. Dir. David Mamet. Perf. William H. Macy, Debra Eisenstadt. Samuel Goldwyn Mayer, 1994.

Olson, Gary A., and Lynn Worsham, eds. Race, Rhetoric, and The Postcolonial. Albany: State of U of NY P, 1999.

Pixton, William H. "A Contemporary Dilemma: The Question of Standard English." CCC 25 (1974): 243-53.

Pratt, Mary Louise. "Arts of the Contact Zone." Profession 91 (1991): 33-40.

Rose, Mike. Lives on the Boundary. New York: Penguin Books, 1989.

Royster, Jacqueline Jones. "When the First Voice You Hear is Not Your Own." CCC 47 (1996): 29-40.

Schilb, John, and John Clifford. eds. Making Literature Matter: An Anthology for Readers and Writers. Boston: Bedford/St. Martin's, 2000.

Schroeder, Christopher. Reinventing the University: Literacies and Legitimacy in the Postmodern Academy. Logan: Utah State UP, 2001.

Schroeder, Christopher, Helen Fox, and Patricia Bizzell, eds. Alt Dis: Alternative Discourses and the Academy. Portsmouth, NH: Boynton/ Cook, 2002.

Severino, Carol. "Where the Cultures of Basic Writers and Academia Intersect: Cultivating the Common Ground." JBW11 (1992): 4-15.

Shaughnessy, Mina. Errors and Expectations: A Guide for the Teachers of Basic Writing. New York: Oxford UP, 1977.

Sledd, Andrew E. "Pigs, Squeals and Cow Manure; or Power, Language and Multicultural Democracy." JAC14 (1994): 547-58.

Stuckey, J. Elspeth. The Violence of Literacy. Portsmouth, NH: Boynton/ Cook, 1991.

Summerfield, Geoffrey, and Judith Fishman Summerfield. "States of Mind, Acts of Mind, Forms of Discourse: Toward a Provisional Pragmatic Framework." The Territory of Language. Ed. Donald A. McQuade. Carbondale, IL: Southern Illinois UP, 1986. 238-50.

Tannen, Deborah, ed. Spoken and Written Language: Exploring Orality and Literacy. Norwood, NJ: Ablex, 1982.

-. "The Myth of Orality and Literacy." Linguistics and Literacy. Ed. William Frawley. New York: Plenum Press, 1982. 37-50.

Villanueva, Victor Jr. Bootstraps: From an American Academic of Color. Urbana, IL: NCTE, 1993. 


\section{Shari Stenberg}

\section{LEARNING TO CHANGE: THE DEVELOPMENT OF A (BASIC) WRITER AND HER TEACHER}

ABSTRACT: The piece examines issues of student and teacher development and identity, considering how our metaphors for basic writers often constrain possibilities for teacher learning. So long as we position ourselves as problem-solvers (with the basic writers standing in for the problem), we foreclose potential for changing ourselves in relation to students. By examining my interactions with an African-American, working-class, basic writer, I argue for the importance of attending to the identities students construct for themselves (Gray-Rosendale) and of enacting a two-way dynamic between teacher and student, whereby students and teachers together negotiate their identities, needs, and developmental goals.

Basic writing scholarship has devoted substantial attention to examining how we construct our students' identities and needs, and how these constructions impinge upon our pedagogies. As Joseph Harris has argued, three metaphors for teaching basic writers have dominated the scholarship: growth, initiation, and conflict ${ }^{1}$. Each metaphor, which critiques and extends the one preceding it, claims an increasingly complex understanding of students, their social locations, and their needs as learners. What this "evolution" has not sufficiently altered, however, is the teacher's identity and role in relation to student writers. Even in those "critical" or "conflict"-based pedagogies, which are driven by claims of de-centered classrooms and student empowerment, the teacher often occupies the same position she did in seemingly less "progressive" pedagogical approaches: expert, authority, hero.

As Laura Gray-Rosendale contends in her 1999 article "Investigating Our Discursive History: JBW and the Construction of the 'Basic Writer's' Identity," no matter which metaphor is employed, "scholars [tend to] produce constructions of student identities which their preferred theoretical models are likely to solve" (127). She likens this tendency to the computer software hackers who create computer viruses so that they may later market antidotes (127). Consequently, a top-down relationship is created, whereby the expert/researcher's role

Shari J. Stenberg is Assistant Professor of English and Director of Composition at Creighton University. She teaches courses in writing, composition theory, and pedagogy. She is currently at work on a book-length project examining issues of professing, disciplinarity, and teacher development. 
is to diagnose and solve the problem, the teacher's job is to enact the solution, and the student's role is to simply be (or stand in for) the problem. This one-way dynamic from researcher down to student often blinds us to the ways students, themselves, construct their identities and needs in specific learning contexts, as well as to the ways we need to change in relation to our students.

Of course, there have been efforts to alter this dynamic, and in fact, Gray-Rosendale contends that a new "contextual" metaphor is underway, which views the basic writer's identity as describable only "in terms of specific situations, specific activities, specific institutions, or specific moments," and thus emphasizes "students' own self-constructions of their identities" ("Investigating" 125, 129). (See for instance Fox 1999; Gray-Rosendale 1996; Harrington and Adler-Kassner 1998; Severino 1995; Mlynarczyk 1995; Young 1996; Herrington and Curtis 2000). Rather than viewing this new "trend" as necessarily progressive, however, Gray-Rosendale reminds us that even as we work to "construct disruptive perspectives that operate to challenge the predominance of these metaphors," we need also to attend to the ways assumptions about "growth," "initiation," and "conflict" continue to seep into our pedagogies and our representations of students (129). In addition, I would contend that we would be served by more carefully examining how these assumptions result in limiting teacher identities, often in ways that foreclose possibilities not only for writing development, but also for teacher development.

In this article, I ask not "Who is the basic writer?" but "How do particular basic writers construct their own identities?" and "How do we, as teachers, construct our own identities in relation to students?" In doing so, I-a white, middle-class teacher-will study my interactions with Linda - an African-American, working-class, basic writerand her efforts to construct an identity in a writing studies curriculum, in which she was one of the only "basic writers."

This inquiry, then, is intended to both argue for and enact a twoway dynamic, whereby Linda and I are both subjects undergoing "revision" as we learn together. It is only by studying these specific interactions with students - who commonly refuse the categories we have pre-assigned them - that we are able to see how dominant ideology infiltrates even the most "critical" approaches to the classroom. Indeed, my work with Linda enabled me to wrestle with unexamined assumptions in a way that my training as a writing teacher and my reading in basic writing research could not.

In the end, then, this piece is less about what I offered Linda, and more about the pressure Linda exerted on my construction of a basic writer, a category informed by my reading of her cultural identity. But I want to be clear: this is not a story of moving from darkness into light. The interactions Linda and I had, while unique in their strong 
impact, happen in small ways every semester; this is an education that should be ongoing, since our metaphoric investments, always informed by dominant ideology, can never finally be unlearned.

\section{Writing in the Sequence: English 202}

When I met Linda in our department's introductory Writing Sequence course, Rhetoric and Poetics (English 202), she had recently transferred to the university from a community college, where she had studied journalism but hadn't, she felt, gained adequate experience or expertise as a writer. Consequently, she enrolled in our Writing Sequence, a five-semester series of courses emphasizing the study and practice of rhetoric and poetics.

Linda explained that she enrolled in the Sequence because she wanted an opportunity to move beyond journalistic forms into more creative ones, and to work on her greatest challenge as a writer: grammar. "When I sit down to write," she told me, "the first thing I think about is grammar, and I know that takes away from the writing." Because of the latter concern, it is likely that at another university, Linda may not have found her way into a program like the Writing Sequence.

Unlike many first year writing programs, where placement is determined by a written diagnostic exam, enrollment in the Writing Sequence was first-come, first served. This meant writers of all "levels" were thus welcomed in the program. And while the study and practice of "poetics" is typically reserved for advanced students, or even graduate students - as it is often a mode of writing presumed to follow one's "mastery" of academic discourse - our entry level course focused on rhetorical and poetic writing, and raised issues of authorship, form and genre, and subjectivity.

The driving assumption behind the curriculum was that students are best enabled as writers when they are allowed, as Wendy Bishop puts it, to "explore creativity, authorship, textuality, and so on, together, all at once" (129). Linda clearly agreed, having self-selected into the program. I, too, believed that the Writing Sequence seemed as appropriate a site for her study as it did for any of our other writers. But it was true: most students in the program - the ones we imagined to occupy its center - were not "basic writers." They tended to have a good grasp of mechanics, and to see themselves as adept writers, either in creative or "academic" forms, often in both. Of course, herein lies part of the problem: I was defining "basic writer" based on a naturalized, uncritical understanding of the term. Even in this institutional context where "basic writer" didn't have a referent, the construction still exiisted in our, or at least my, mind. 
So as much as I felt she would be served by the program, I also worried that Linda would feel like an "outsider," that the surface-errors in her texts would signal to her or to the other students that she did not belong. And in some ways, I suppose $I$ wondered if she belonged. That is, I experienced a conflict between my desire to position her as a writer, and my reading of her-her body, her texts - as positioned outside of that subject position. I saw it as my job, then, to serve as initiator-not primarily by helping her assimilate to "standard" English usage - but by enabling her to assume the identity of a writer and to participate confidently in our workshop.

This issue of the writer's identity was the first we addressed in 202, using an assignment drawn from Linda Brodkey's "scene of writing." Students were asked to think about their conception of a writer, and to consider whether (and how) they fit into that understanding. I hoped this assignment would work in two different ways. I knew that many students entered the Sequence with romanticized notions of writing and writers, whereby writing is understood as an individual statement that should not be touched or revised, and as externally inspired rather than a process one has to work at. On the one hand, then, I wanted to disrupt this conception, so as to challenge those students who came in to class imagining themselves in this way, or hoping to adopt this subject position.

On the other hand, I saw the assignment as a means to empower students to think of themselves as writers, not as mere "student" writers in relation to "Authors." I wanted to work against a tradition of writing classrooms in which students are constructed as, or as Susan Miller puts it, required to be, "presexual, preeconomic, prepolitcal" subjects (87). In such models, the writing class is established to prepare students to later participate in disciplinary conversations, to learn the skills necessary to write about content. Alternatively, I wanted to my students to see writing as a disciplined activity, and themselves as writers who had something to say, argue or express right now. I expected that many would enter my classroom having learned something quite different, and that it was my job to empower them to think differently about themselves.

When I asked students to share the writer and the scene each described, I heard much of what I expected: an old, white man writing alone on an old typewriter, often with a bottle of hard liquor by his side. Linda described a writer, however, who looked much like herself:

She is a professional person but derive real pleasure and satisfaction from writing. She writes about events and subjects others wouldn't write about or subjects deemed taboo in our society. 
After a long day at the office writing was a way of winding down as the day came to a close, it was a way of recapping pleasant moments or escaping some of the unpleasantness she encounters from day to day. When she get a cup of hot tea, pen and pad she becomes transformed into this new person. As silence surrounds her she breaks from time to time in deep thought waiting for the right words or next line the muscles beneath her smooth skin seemed undisturbed. However her face provided you with story lines of love, hope, laughter and tears, failure and success.

In our discussion of these scenes, Linda shared that this, indeed, was a picture of her-that writing became the "real" job she did after completing a long day of work and school. Her response surprised me, as I expected that her "marginal" status in the class-as both a "basic" writer and an African-American woman-would also place her on the margins of this construction. That is, I assumed she would have internalized this model that excluded her, when in fact, she came to class already having challenged this dominant construction, already positioning herself as a writer, ready to pursue a project she had already begun.

Linda's "project" became clearer to me when I read her response to my next assignment, which was designed to build upon the first. Here students were invited to respond to Zoë Wicomb's piece "An Author's Agenda," which argues that all writers do political work and write from a social location. In their responses, I asked students to respond to Wicomb's notion of "political" writing and to articulate their own "subject positions" as writers. Many students had difficulty with this piece, associating "political" with Republicans and Democrats, and not an interested, particular social location. Linda, however, demonstrated a more complicated understanding of the term and of her position as a writer:

At times I see myself as a political writer because I try to write from a position away from the norm of ideology, not only as a black woman but as a person. I write from the political position of a working African American and student. These "subject positions" inform my writing because I bring to the table a number of issues that are political from the start and being black is the number one issue, just being black is political, as a student how I've being perceived by the professors and students in view of my opinions of the world around may be viewed differently from the students and instructors and not being black may make it difficult at time impossible to understand who and what I am as a person. 
As Gray-Rosendale notes, one of the central problems with the assumptions about basic writers' identities that pervade our scholarship is that they prevent us from acknowledging the fact that"the students we call"'Basic Writers' seldom, if ever, think of themselves as such" ("Revising" 26). Even those "conflict" approaches that seek to highlight the social and political aspects of basic writers' positions, and to empower them to move beyond those constraints, make the assumption that students are not already engaged in critical thought, are not already aware of the complicated positions from which they write. I assumed Linda would need me to make her aware of the cultural conditions that contributed to her disenfranchisement as a writer. Even as I proposed to work out of "critical" position, focusing on the political dimensions of my students' identities, my assumptions were clearly laden with remnants of the "growth" metaphor, whereby students are understood as cognitively immature; students remain "prepolitical," waiting to be enlightened by the critical knowledge of the teacher. In either case, the result is the same: the teacher is positioned as knowing more about the student than she does herself, as well as having access to knowledge (whether skill-based or "critical") that will improve her writing and her life.

Linda's response not only challenged the pre-political status I assigned her, but implicitly asked me to re-think my assumptions about whom I was teaching and how I understood their needs. I had assumed my students would fall into two categories: those who felt unentitled as writers, and those who felt wrongly entitled. Not only did Linda not fit neatly into one of those categories, she disrupted them entirely. She understood the subject position of writer to be central to her identity, and even more, she understood it as socially informed and informing, necessarily dependent on cultural values and assumptions. She did not locate herself on the outside of our curriculum at all; her work as a writer and thinker, in fact, seemed to be a perfect fit for the program.

Linda was correct to contend that the text of her body impinges upon how she is read by her professors and students-that her "opinions of the world" always exist alongside others' readings of her raced body. Of course, the body of her written texts-marked as they are with linguistic tendencies of Black English - also contributes to a particular reading of her identity and needs. Though I had designed the assignment to enable students' to name their specific subject positions, and to think about the implications of such, I now needed to consider how I was making sense of my students' social, embodied locations, and how I was responding pedagogically to those assumptions. 


\title{
“The Look": Making Writing Visible/Making Selves Visible
}

\begin{abstract}
As an African American woman struggling to become a writer I know what it is to be oppressed politically on a smaller scale, often times when I express my opinion on an issue it becomes a problem not because of the context of my opinion but the mere fact that I have one. I sometimes feel that society see us as they once saw children that they should be seen and not heard. Black women are like an invisible race, our voice is not heard enough, and when we began to speak out on issues it is often misunderstood most often in a negative way. This can paralyze as writers, thinkers and verbal participants. $\left(3^{\text {rd }}\right.$ response paper)
\end{abstract}

As I continued to read and consider Linda's early response papers, which were circulated only between the two of us, I came to see her not as a "victim" or marginalized presence in our course, but as a source of subjugated knowledge, from whom her classmates and I could learn. I saw it as my objective, then, to encourage and make a space for her resistant writing, to foster what I understood to be her project. Rather than a rescuer, I would act more as a facilitator of her knowledge.

In the above response, Linda raises an interesting tension: on the one hand, she notes that making her voice heard, in whatever capacity, brings with it a certain degree of risk, risk that she will be misunderstood or will remain unheard because of the position from which she speaks. On the other hand, she knows that not speaking is equally risky, as it potentially reifies the cultural invisibility of black women. My hope, my expectation, was that Linda would use our first formal assignment to further pursue this issue of visibility and invisibility, black women's voice and silence. In the assignment, students were asked to articulate one of the lenses through which they see the world:

Zoë Wicomb argues that each of us writes from a political position, meaning that both how and what we write is necessarily informed by our location(s) in the "social." So in your process of writing, you'll reflect on a moment in your life that will in some way show your readers how and why you have come to see the world in certain way. In this piece, you'll work to move beyond just "telling" this moment to also "show" or represent this through the form of this piece-so that the form and content are working in a meaningful way.

I saw this, in many ways, as an ideal assignment for Linda, allowing 
her to continue the examination of her interlocking subjectivities, particularly how her race, class, and gender informed her writing self. Even more, it seemed to set up clear roles for us as student and teacher. Linda would continue the inquiry she'd begun in her early response papers, and I would help her to critically scrutinize her text and the social conditions that shaped it. I could imagine the kind of response I would offer even before reading her piece.

But Linda's piece, "The Look," did not look as I predicted it would. In response to the assignment, she composed an office romance narrative, written in third-person perspective, which seemed to move away from the overtly political realm entirely. The "Linda" she had composed in her earlier pieces had been replaced by "Ann," a character who was seemingly constructed according to dominant understandings of "good" or "nice" women. Ann is raceless, concerned with what others think of her, ashamed of herself when she gossips or thinks "wrong" thoughts, and is hesitant in conversation with the male protagonist:

Ann was the kind of person who didn't get caught up in office gossip and treated everyone with kindness and respect.

One day Peter needed some information on a customer and Ann had a difficult time getting the information from a policy writer. "I need to find a rich man to sweep me off my feet and get me out of this office." Disgusted at her co-worker, these words just sorta uncontrollably flew out of her mouth and she thought "Oh my god, what did I just say?"

Because I had expected a particular "version" of Linda in this "autobiographical" piece, and was instead presented with Ann, I was uncertain about how to respond. I wanted to get her back "on track," to help her resume the line of inquiry she'd begun, which involved exploring the way her race, class, and gender informed her writing. My response dealt largely with questions about character construction:

$I^{\prime} m$ wondering why you chose to tell the story in $3^{\text {rd }}$ person. What effect do you want it to have? How would it change the story if Ann told it in first person? For me, Ann gets a little lost in the piece. I want to know more about her. Why doesn't she engage in office gossip? Why is she hesitant about starting a new relationship? I want to know more of Ann's thoughts, and more of the stories of her life so that I get a better understanding of who she is and why she responds the way she does. Right now, I'm reading her as a very sweet character, quiet, understanding, thoughtful-but I'm left still curious. I guess I want her to be even fuller in the story- 
more complicated. I want to see the contradictions in her, maybe what she's like when she's with friends-not on her best behavior at work.

As I consider my response, with the benefit of hindsight, I am aware of its multiple implications. First, despite my many warnings to students that autobiography is not a synonym for "truth," that we must not conflate the narrator or main character with the writer, I wanted to do exactly that: to see a character who reflected the Linda I had come to know, the Linda who would write overtly political texts. In doing so, I may have been containing her just as I perceived her to be containing Ann, asking for a voice I assumed to be more authentic because she is black, because I wanted to believe her earlier writings as "true." I wonder, despite my claims about the "fictionalizing" of autobiography, how much I expected students to disclose of themselves in these pieces - of selves that fit in with my readings of them, that is. As Lester Faigley writes, " The freedom students are given in some classes to choose and adapt autobiographical assignments hides the fact that these same students will be judged by the teachers' unstated assumptions about subjectivity and that every act of writing they perform occurs within complex relations of power" (128).

Indeed, Linda was writing within complex relations of power. Not only was she the only (traditionally defined) "basic writer" in the room, but she was one of only three African-American women. And she was being asked to make her writing public to her classmates for the first time. I am reminded of Linda's claim: "my opinions of the world around may be viewed differently from the students and instructors and not being black may make it difficult at time impossible to understand who and what I am as a person." If, instead of assuming that Linda's piece was "lacking" something, I read her textual choices as choices made amidst complicated contexts, I can see that it may have been more important for Linda to construct her main character according to dominant conceptions of "any woman" rather than to risk making further visible to her mostly white class the social location she named in earlier pieces.

What she did make visible to her writing partner, though, was a need for help with grammar. I discovered this when reading her writing partner's letter in response to "The Look": "Well, I'm not sure what else to say that I haven't already said, except for I decided not to edit your paper for grammar. It just feels funny to me! If you really, really insist I do so...well, okay. Next time." It likely felt "funny" to him because I had emphasized to the class that they should fully engage each other's texts, not simply edit or "correct" them. I didn't want any writer - particularly Linda - to feel condescended to, to have her piece engaged only at the surface level. I wanted her piece to be approached 
no differently than her classmates' pieces. In retrospect, however, I see that my commitment to an approach I deemed more "progressive," and to the role of "progressive" teacher-focusing on her subjectivity as a writer rather than on formal or grammatical issues - may have hurt Linda. As Lisa Delpit argues, those elements of education often considered to be most "progressive" do not always work for those students who need "skills" and thus function to reproduce unequal relations of power both within and outside the classroom (384).

Gray-Rosendale further contends that as much as the focus on political dimensions of basic writers' identities has resulted in a pedagogical advance - a movement tied to the "conflict" metaphor - there are also risks. These emphases, as Gray-Rosendale notes, "may also relegate other contexts and metaphors for Basic Writers' situations to a kind of second-class status, less important, and implicitly less worth attention, than the 'big' sociopolitical ones." My intention was to treat Linda as a writer, but in doing so, I overlooked the needs she articulated. Steering students away from editing each other's papers or pointing out grammatical issues not only set up a dichotomy between "real" writerly issues and "surface" ones, but may have led Linda to believe that her needs weren't worth addressing - that they were too basic. She didn't see a contradiction between being a writer and needing grammatical help - only I did.

The more I worked with Linda, and the more she complicated my assumptions and implicitly challenged my pedagogy, the clearer it became that I was trying to name and respond to her identity apart from her, when in fact, my pedagogy needed to be made with her, alongside my engagement with her texts and her articulated needs and interests.

\section{English 303: Re-presenting and Re-positioning Ourselves as Learner and Teacher}

Typically, we don't get a second chance to interact with our students. We learn from them, and then move on to a new group, whose needs may be entirely different. I was fortunate, however, to have the opportunity to work with Linda a second semester, this time in English 303: Argumentative and Persuasive Writing. In this course I wanted to do a better job of placing her needs and interests and my course goals in dialogue, and of understanding our roles as teacher and learner (with each of us occupying both roles) as dynamic and inprocess. I sought, then, to create a space for more dialogue during the class, so that I could be better aware of her needs and interests - as well as those of the other students - as they arose.

I was particularly interested in how my students would have their 
development measured, and what practices they felt would best enable this growth. I knew, for instance, that I needed to provide Linda with more opportunities to work on formal and technical aspects of her text-something I'd previously considered outside the realm of my "critical" pedagogy. But in conversation, she also reminded me that creating room for such conversations did not mean abandoning the goals of my pedagogy. In fact, she said that the "writing process is not just putting things on paper" but is a "spider web of things you try to learn to do:"

The writing process is like a learning process of responding to other people, learning how to take response from other people, learning how to change. [...]If you just say it's the writing and that's all you do, you're not exposed to the workshops and to other people's ideas and writing and you limit yourself.

For Linda developing had become a social process requiring interaction with other writers, as well as a commitment to change. The developmental goals she named for herself were to "make people think" and "make the points clear that I'm trying to get across." Those points, she explained, had to do with "seeing changes in society" and allowing marginalized voices to be heard.

In the same way, the teaching process should not be only about "putting our own pedagogical goals on students" but, like writing, should involve a "web" of things we learn to do in relation to our students. Linda's claim that we must "learn to change" seems as, if not more, important for teachers than it does students - who, after all, are always expected to change. Of course, it is easier for teachers to occupy the stable role of problem-solver; pre-determined roles (no matter how "critical") allow comfort and stasis. In what follows, I trace several more moments where I had to learn how to change, to give up my comfortable role as "critical" teacher, and instead to negotiate a role that would help challenge and further Linda's project.

Our course was centered around a semester-long assignment that asked students to choose an issue that they found problematically represented in culture and felt compelled to use their writing to revise or re-present. Though many students struggled to articulate a project, Linda quickly came up with hers. She wanted to address her own fears about driving through the Arbor Hill neighborhood, a mostly black and poverty-stricken area that is highly trafficked, since one of its roads connects the interstate and downtown Albany. She had recently been shaken after witnessing some disturbing activity on that main road and instead of heeding the warnings of most of her friends and co-workers to simply avoid the area, Linda decided to go into the neighborhood and talk to the residents. In this way, she hoped to use 
the assignment not only to re-present the neighborhood, but also to revise her self in relation to it, to alter her self through her writing. As she writes, "The writing was not just about experimenting with the use of language, but defining who I am as a person[...]." My work with her would thus require me to attend to both her textual construction and self-construction.

To aid the students' projects, we studied issues of language and discourse, subjectivity, and representation. Their first "formal" assignment required them to write a 5-7 page paper considering how discourse impacted their chosen topics: how their issue has been described and named by others, and how they hoped to intervene in that construction. In preparing for her language piece, Linda and I discussed the media representations of the Arbor Hill area, and she decided while those "texts" would certainly inform her piece, she wanted to work less to critique those media depictions and more to create new narratives by showing positive work in the community. Her aim was to allow her readers to hear a different version of the story, told from often forgotten voices. After providing a short discussion of the media representations of Arbor Hill, Linda moved on to demonstrate how these media representations informed her own experience of driving through the neighborhood, specifically describing a time when she did experience some of what the media describes:

I recall one evening driving home from work onto Henry Johnson Blvd., shortly after passing the first traffic light off the exit I noticed a young man trying to free himself from a man who was holding his coat. I thought it was just a playful moment but as I got closer I realized it was something more. Trying to avoid hitting either of them I swerved my car and moved over to the turning lane. After the young man freed himself from the man's grip, he hurried himself away. The man continued into the streets and over to my car. To avoid hitting what appeared to be a drunken man I completely stopped my car. The dirty curly blond hair man crossed in front of my car looking directly at me as he made his way to my door. I completely froze. The only thing I could think of is that he was going to kill me.

Another car was coming up the street diverting his attention, he slowly walked over and grabbed the car door handle. The middle aged white driver did not stop but drove faster while the man held on and was dragged at least two blocks. His body tossed about the pavement like a rag doll.

I sat frantically in my car waiting for the car stop hoping and praying the man would still be alive. Finally the car came to a red traffic light and stopped. The man slowly let go of the 
handle got up and soberly staggered away.

After a couple of sleepless nights and trying to make sense of the whole thing by talking about it with friends I began to realize it is not a black or white issue but a people issue. It could be any neighborhood, there is no neighborhood exempt from crimes. However there is more exposure given to the poorer neighborhoods.

In responding to Linda, I noted the many possibilities already evident in the piece. Still, I wanted to encourage her to think further about the media's effects, and suggested that she might expand her first section by providing some more specific examples. In my comments on this draft, I also focused extensively on challenging her conclusion that "it is not a black or white issue but a people issue." In fact, the question of whether this is "not a black or white issue" or how race should be foregrounded in the piece informed my dialogue with Linda throughout her work on this project. Because Linda focused in several places on the stereotypical image of the black male criminal and highlighted the importance of African American community in Arbor Hill (which is, in fact, a predominantly black neighborhood), I first read Linda's insistence upon leaving this line about it being a "people issue" as resistance to considering the systemic issues at play. Seeing it this way, of course, helped simplify our roles - if she were naïve to these racial dynamics, then I could prompt her to read the neighborhood more "critically"; I could use my "critical knowledge" to help her fill the "lack" in her piece.

When Linda and I met in a conference, though, I began to understand Linda's reasons for choosing to maintain her argument - and to see that my role might need to be different than I'd expected. Linda told me that while addressing racial issues is important to her work, she wanted to be careful not to simplify racial categories in a way that pitted races against each other. Linda was worried, she told me, that people in our (mostly white) class would not want to engage her piece because they might read her project as blaming white people. This made her even more careful to tell the story in a way that would allow her to be heard by a wide range of readers. Despite my work with Linda the previous semester, this is something I had not thought sufficiently about during the class - the difficulty of taking on an overtly political topic dealing with an issue (race) that could be read onto the writer. Like the "autobiographical" piece in 202, Linda was aware of how choosing this topic might be read as an issue about her. And indeed, she was right: during one of our workshops, her classmates continually made comments implying Linda lived in Arbor Hill, even as she located herself as a visitor to the neighborhood. Her raced body, in many ways, spoke louder than her writing.

Interestingly, Linda shared with me that she, too, fell victim to 
the same kind of assumptions her peers were making. She was surprised that the troubling incident she witnessed was between two white, not black, men in Arbor Hill. Doing so helped her recognize the assumptions she-an African American woman-was making about black men and black neighborhoods. "I didn't expect to see a white face," she told me. "I thought everyone who lived there was black." Linda said this moment was so important to her because it disrupted her assumption that bad neighborhoods are necessarily conflated with black neighborhoods; it allowed her to see that she was essentializing blackness and to re-think her association of darkness with criminal behavior.

By occupying the role of listener and learner, I began to understand that Linda was already engaged in the complex and "critical" work of theorizing her own internalized racism. And she was right: this was a "people issue." None of us live outside of dominant ideologies, including racist ones. In fact, I came to understand that my ongoing readings of Linda, and her writing, were informed by this ideology - as much as I sought to work against it.

As we talked, I discovered that Linda wanted to use this incident and her resulting new reading of the neighborhood as a rhetorical strategy to point out to her readers that these problems of race and poverty (and the desire to ignore them, as we see in the man who looked straight ahead and kept driving) affect white and black people. Because Linda wanted her audience to include members of both races, she was careful, then, not to construct this as simply as story that pitted one race against the other or that makes racial categories seem coherent and homogenous. Though Linda chose not to explicitly articulate this idea of internalized racism, with the encouragement of her workshop group, she added details to make the white man more visible in the scene and to show how her assumptions about the neighborhood were triggered by the event:

The curly blond haired man crossed in front of my car. We made eye contact as he made his way to my door. The street lights were so bright that I could see his blue eyes and ruddy skin. I was shocked to see a white male in that neighborhood and wondered why he was there. I completely froze. The only thing I could think of was that he was gonna kill me. News reports of gun fire and a dead body quickly flashed through my mind. I saw myself as another victim of violence.

I came to see that discussing the choices Linda made in the textwhile she was in the process of making them-allowed me to better enable her to make visible those arguments she wanted to foreground, and to help her position herself in the ways she thought most effective. Occupying the role of learner, though, meant that I had to resist im- 
posing a pre-determined reading on her text; instead, I worked to understand her reasons for making the choices she did, which we could then discuss and complicate.

When we moved to the subjectivity assignment, which asked students to consider the people who factored into their pieces as culturally informed subjects, Linda decided to focus on three community members: the director of the Arbor Hill Community Center; a beauty salon manager; and a local minister. Her aim was to show these people as "role models," a subjectivity very important to this neighborhood, and an identity that would allow her to continue to focus on "the positive." In the draft following interviews with these folks, Linda did the important work in this piece of guiding her readers away from Henry Johnson Boulevard - the one street most traveled upon by non-residents - and into other areas of the neighborhood, areas rarely represented in the media. This draft also showed more carefully constructed detail and added significant factual information about the neighborhood. Like many of my students, Linda struggled with wanting to include the details and descriptions she uses in her fiction writing but feeling that non-fiction writing should be "factual." Here she began to search for a balance, seemingly discovering that some of the strategies she used in fiction writing could enhance her non-fiction prose:

As I drove down the one-way streets in search of a parking space, I began to observe parts of the Arbor neighborhood away from Henry Johnson Blvd. [...]I decided to drive further and came across the Arbor Hill Community Center. The tan structure was surrounded by clean manicured grounds. Surprised at the door not being locked, I walked in to a place so clean it mirrored my image as I made my way to the office. [...] The wall displayed a huge painting of the bouquet of flowers on the coffee table and two African American paintings. One picture was of a boy giving another a piggy-back ride titled " $\mathrm{He}$ is my brother," and the other was what seemed to be a father embracing his young sad son, it was titled, "Part of Growing up." The entrance was full of photos of trips, literature and sketches of black leaders like Malcom X and Dr. Martin Luther King.

In her later drafts, Linda struggled to create a hybrid piece-a piece, I might add, that looked very different from the one I expected, or the one I might have encouraged her to write. But her choice made good sense, as she relied on observation, interview - both skills she'd learned as a journalist - as well as personal narrative, argument and fiction strategies such as description and detail. Once I could see where Linda wanted to go in terms of form -I could help her complicate and nego- 
tiate such categories as" "non-fiction" and "fiction" or "creative" and "factual." It eventually helped Linda to think of herself as telling a story - so that she could use the strengths she'd already developed as a fiction writer to construct characters and scenes. I learned, at the same time, that I was best able to aid Linda's development when I approached her as a kind of "hybrid" writer - a story teller, a journalist, a political writer - who chose to play different roles at different times, and whom I could not finally pin down to one identity, including that of basic writer.

\section{Messing up Our Metaphors}

In the end, Linda accomplished many of the developmental goals she established for herself. She provided a re-presentation of Arbor Hill for her readers, constructing an image of the neighborhood and its residents that we might not have otherwise witnessed. She challenged her own assumptions about Arbor Hill. As she said, "I'm not afraid to drive through there anymore." And she produced a piece that abided by the rules of "authorized" language, which she felt necessary in order to publish it in our Writing Sequence anthology.

In achieving this range of developmental goals, Linda constructed a complex identity for herself as a writer, with complicated and changing needs and interests. No one metaphor-no single "solution" - finally "fit" her. And in fact, the most significant developmental moments for Linda and me were a result of "messing up" of predetermined ideas and roles. As David Bartholomae argues, we are often so focused on mastery and acquisition that we do not place adequate value on the important learning that accompanies "undoing," disrupting, or confusing (14).

So I want to value the disrupting Linda did - the messing up of categories that would be more easily left coherent and unified. While it would have been easier to stay out of the Arbor Hill neighborhood as her friends suggested, Linda went into it, hoping to "confuse" things for herself. While it would have been easier to tell a story of victims the story we are used to when we think of poverty stricken areasLinda sought out a different version of the story, and found it. And Linda found the important balance of making readers aware of the problems in the neighborhood while also calling attention to the practices already taking place in the neighborhood to alter them.

In her piece, where she creates such productive "messes," she offers a useful metaphor for teaching. That is, we might approach our interactions with students not as a way to confirm our beliefs about what they need, but to "confuse" things - to discover whether there is a different version of the story, and to attend to what is already hap- 
pening, what we can build on, rather than what is lacking.

Indeed, my process of working with Linda resulted in the "messing up" of my pedagogy and my role in relation to her, as I was asked to make it a little less neat,"not quite so finished" (Bartholomae 14). Despite my self-proclaimed "student-centered" and "critical" approach to teaching, I found that I was abiding by metaphors and dominant ideologies I assumed I had long surpassed. And this, of course, is a danger of assuming that we are following a progressive history, that a "conflict" metaphor will necessarily be better than a "growth" metaphor. It is also dangerous to assume that we can finally unlearn racist or classist ways of reading students. To assume such a clean, neat path is to forget the ways in which remnants of old models remain, to overlook the way we might still position students as immature, pre-political, or lacking. And the way that teachers are still positioned as masters, problem-solvers, heroes. Giving up the idea that we can discover an all-encompassing metaphor, though, is messy. It means also surrendering the idea that we can figure students out and subsequently figure out what, exactly, they need, because as soon as I felt I had Linda figured out, she reminded me that she was much more complex than any metaphor, and pedagogical answer, I could come up with.

If there is an answer, then, it is that both teachers and students will be better served if we leave room in our pedagogies for students to compose their own metaphors, and room for ourselves to change in relation to them. It's neater and cleaner, certainly, to abide by a oneway dynamic where only the students are being asked to change. Twoway dynamics, where our students exert pressure on our assumptions, our values, our practices, require constant, messy negotiations. But it is only in this ongoing, mutual mess-making that genuine development-on the part of the teacher, the student, and the pedagogy-occurs. It is only through this process that both teachers and students can, as Linda puts it, learn to change.

\section{Note}

1. The author has obtained the student's permission to write this account and quote from the student's writing.

2. According to Harris $(1995,1997)$ the "growth" metaphor encourages teachers to see students as immature language users, stalled in an early stage of language development. Teachers are to respect the skills with which students enter their classrooms, and to enable them to develop nascent writing skills. The "initiation" metaphor assumes students are positioned outside of a sanctioned academic "discourse community"; basic writers are thus understood as in need of access to rules, 
values, and practices that will allow them to enter privileged language system, but will also require them to leave behind their "home" language. The "conflict" model critiques the two previous models, viewing the basic writer as the "nexus of clashing cultural forces and relations of power within the classroom" (Gray-Rosendale "Revising," 26). This model aims to both respect students' background and to teach academically sanctioned language practices, often foregrounding a critique of the social forces that contribute to basic writers' disenfranchisement in the first place.

\section{Author's Acknowledgements}

I would like to thank Steve North for his important teaching on issues of writing development. Thanks also to Amy Lee for her challenging and supportive input as I revised the piece, and to Chris Gallagher, for pushing me to re-think and re-see the piece in its final stages, always in the context of critical colleagueship.

\section{Works Cited}

Bartholomae, David. "What is Composition and (if you know what it is) Why Do We Teach It?" Composition in the Twenty-First Century. Eds. Bloom, Daiker, White. Carbondale: Southern Illinois University Press, 1996. 11-28.

Bishop, Wendy. "Crossing the Lines: On Creative Composition and Composing Creative Writing." Writing on the Edge 4.2 (1993): 117133.

Delpit, Lisa. "Skills and Other Dilemmas of a Progressive Black Educator." Harvard Educational Review 56.4 (1986): 379-385.

Faigley, Lester. Fragments of Rationality: Postmodernity and the Subject of Composition. Pittsburgh: University of Pittsburgh Press, 1992.

Fox, Thomas. Defending Access: A Critique of Standards in Higher Education. Portsmouth: Boynton Cook/Heinemann, 1999.

Gray-Rosendale, Laura. "Revising the Political in Basic Writing Scholarship." Journal of Basic Writing 15.2 (1996): 24-49.

-. "Investigating Our Discursive History: $J B W$ and the Construction of the 'Basic Writer's' Identity." JBW18.2 (1999): 108-135.

Harrington, Susan and Linda Adler-Kassner. "'The Dilemma that Still Counts': Basic Writing at a Political Crossroads." JBW17.2 (Fall 1998): 3-24.

Harris, Joseph. "Negotiating the Contact Zone." JBW14.1 (1995): 2743.

-. A Teaching Subject: Composition Since 1966. Upper Saddle River: 
Prentice Hall, 1997.

Herrington, Anne and Marcia Curtis. Persons in Process: Four Stories of Writing and Personal Development in College. Urbana: NCTE, 1999.

Miller, Susan. Textual Carnivals: The Politics of Composition. Carbondale: Southern Illinois University Press, 1991.

Mlynarczyk, Rebecca Williams. "Finding Grandma's Words: A Case Study in theArt of Revising." JBW15.1 (1995): 3-22.

Severino, Carol. "An Urban University and Its Academic Support System Program: Teaching Basic Writing in the Context of an 'Urban Mission.'" JBW15.1 (1995): 39-56.

Wicomb, Zoë. "An Author's Agenda." Critical Fictions. Ed. Philomena Mariani. Seattle: Bay Press, 1991. 13-16.

Young, Morris. "Narratives of Identity: Theorizing the Writing and the Nation." JBW15.2 (Fall 1996): 20-50. 


\section{Samuel Cohen}

\section{TINKERING TOWARD WAC UTOPIA}

ABSTRACT: Writing Across the Curriculum is growing at a time of perceived crisis in education and perceived strengthening of the forces of globalization. Like composition generally and Basic Writing more specifically, the work WAC does can be influenced for good and ill by these contexts. Faced with a perceived crisis, as Basic Writing was at its birth, WAC could emphasize form in order to prepare students to take their places in the global economy. Instead, WAC should tinker with its existing techniques to promote critical thinking in even the most basic exercises. In doing so, it can help students not only to join the global economy but also to develop into thinkers who might evaluate the world and even consider ways in which they could improve it. In following the lessons of Basic Writing, WAC can offer all involved in the teaching of writing models for more inclusive pedagogies.

Like it or not, the story of American education has been and in all likelihood will continue to be a story of increasing access. -Mike Rose, "The Language of Exclusion" (541).

In a smoke-filled inn in revolutionary-era Pennsylvania, a Quaker gentleman reminds Thomas Pynchon's Mason and Dixon where the cakes and sweets that surround them come from. "A sweetness of immorality and corruption," he calls the sugar that sweetens their food and drink, "bought as it is with the lives of African slaves, untallied black lives broken upon the greedy engines of the Barbadoes" (329). An argument ensues, of the kind that the narrating Wicks Cherrycoke ascribes to the "innocent roasted berry, that has put them all in such a surly humor"(329). Pynchon reminds us of many things in this passage. One is a similar moment in Candide, when Candide comes across a maimed slave lying at a crossroads, who says of the hand and leg he lost in the cane fields of Surinam, "This is the price of the sugar you eat in Europe" (40). Candide breaks into tears and wonders for a moment if maybe this is not, as Pangloss has taught him, the best of all possible worlds. Pynchon's passage also reminds us that these substances fueled the revolutionary thinkers of the eighteenth century like those in Pynchon's inn - the coffee, sugar, and tobacco firing their dreams of

Samuel Cohen is a Ph.D. candidate in English at the Graduate Center of the City University of New York and a Writing Fellow in the University's Writing Across the Curriculum Initiative. He will be Substitute Assistant Professor of English at Baruch College, CUNY, in Spring 2003. His dissertation is on contemporary American historical novels. 
freedom, democracy, and untaxed profits - and that they also fueled empire, as the trading companies were in the New World to trade them. Linking this conversation with Voltaire's, Pynchon implies that the American dream, like Europe's imperial dream, was achieved as part of a global commerce that did not provide the best of all possible worlds for everyone.

Pynchon reminds us of this, and of something else. The Reverend Cherrycoke bears in his name another widely consumed energyproviding substance, the quintessential American beverage. One can now buy a Coke to wash down falafel in the souks of the old city in Jerusalem, frites in the cafes of Paris, and rellenos de papa in the roadside stands of Puerto Rico. The anachronism of the narrator's name points out that the globalization that has become a hot topic of late is in fact an old phenomenon. In doing so, it asks us to think about what kind of world today's globalization is bringing to us.

There is a danger, in these discussions, of being like the protestor at the 1999 Seattle World Trade Organization meeting spotted by Anthony Giddens paradoxically carrying a sign that read, "Join the worldwide movement against globalization" (Brockman 5). Being reminded of globalization's long history drives home the idea that globalization is a fact and that it will not go away. There is no turning it back, nor, if it were possible, would it make any sense. As many who have dismissed protests against the WTO and other institutions have pointed out, globalization has had benefits for those in poorer parts of the world. Still, there is much to what has been said by protestors. There may be a considerable economic price to pay for having a world where corporations no longer act within a national framework, where "What's good for General Motors is good for America" is no longer necessarily true (Danaher). The cultural costs are also formidable. One of the questions being asked as part of the current debate over globalization, as expressed by Ian Baucom in the January 2001 special issue of PMLA devoted to globalizing literary studies, is "whether globalization does and will entail the liberation or the erasure of difference" (158). It is a good question.

It is also not easily answered. Like most difficult questions, though, it is important. As do other questions about globalization, it provides a way for us to reflect on the things we do as teachers of writing. In short, these questions can help us consider what kind of world we imagine for our students, and whether that world is the best of all possible worlds for them.

One area of teaching that provides a good place to think about these questions is the loose collection of movements, curricular innovations, and pedagogical strategies and techniques known as Writing Across the Curriculum. Because it is attempting to lengthen the presence of writing instruction down the course of students' careers, it has 
the potential to change postsecondary writing instruction as a whole. Steeped in the same ideas and practices as first-year composition, however, it also provides the opportunity not just to apply them by extension but also to think again about them. As it grows, WAC can be of special importance to the readers of this journal, who stand at the head of the lengthening road of writing instruction. This road will be marked by the crossroads of familiar writing issues - issues of form, expression, academic discourse, and critical thinking. The issues those who work in Basic Writing have confronted and the lessons they have learned can be of increasing use to those working in WAC. Likewise, the issues faced by WAC programs and practitioners can provide opportunities for those in Basic Writing to reexamine these same lessons.

A good place to begin to look at WAC is the theme of the Sixth National Writing across the Curriculum Conference, as articulated on the Web site. It reads, in part,

A Conference to Place WAC in the Context of National and International Goals. In an era of international electronic networks, a global economy, and hemispheric trading partnerships, communication skill affects the success of individuals, companies, and countries. Mathematical or scientific literacy is vital, but without communication skills workers may be relegated to lower technical tasks.

This statement is a good place to start because implicit in it are assumptions about the purpose of WAC. Some of these assumptions: individual success is being a worker with a nontechnical job; WAC's job is to provide communication skills; the individual's goals, if not commensurate with the company's, can be met within them. These assumptions are important because they can be traced forward to the ways in which WAC is to be implemented in the classroom. They are also important because they can be traced backward to reveal the beliefs from which they come and, so, the connection between beliefs and daily practice. This last connection is important because it reveals the relation between our visions of the world, as it is and as we'd like it to be, and the way we think of and act in higher education.

Forward, then, from assumptions to practice: if the assumption is that individual success is a white-collar job and that the sole purpose of WAC is to teach students the communication skills they'll need to achieve this success, then WAC will be implemented as writing in the disciplines with a focus on the conventions of disciplinary discourse and formal correctness. Now, backward, from assumptions to beliefs: these assumptions are often held by those who believe that the world is in fact a place where there is no difference between the goals of the individual and the goals of the company and the country. I think it is 
becoming clear in our time that this is demonstrably not the case. As recent corporate scandals have made clear, not only can the interests of individuals and large corporations diverge but, in these days of stock market driven corporate strategy, the interests of shareholders may even differ from those of corporate management. It can also be argued that multinational corporations, in cutting their ties to one country, have shed the last of their responsibility to individuals as enforced by the nations of which they were part. Now, what's good for General Motors might be good only for General Motors - or not even for all that used to be thought part of General Motors (such as its workers). These questions should lead us to ask whether, if the interests of our students may not coincide with those of the corporations for which they wish to work, preparing them for that future by simply teaching them the communication skills they'll need to succeed in the corporate world might not be in their best interests.

While it apparently is not fashionable to use the word utopia now that history has ended and we've won the Cold War and all that, utopia-a vision of a perfect place - is what is at stake here. Educational reform, like social reform generally, is based on utopian thinking. It looks at education as it is, asks how it ought to be, and tries to figure out how to make it more like that. Utopian thinking asks what the world would look like if it were perfect. If we think of WAC as a reform movement, as Basic Writing was thought to be at its inception and is still seen to be by many of its current teachers, then when we implement it, we ought to think about our vision of utopia.

I work as a Writing Fellow in The City University of New York's new Writing Across the Curriculum initiative. It is now in its fourth year, and on many campuses, including Lehman College, where I work, this initiative is taking the form of establishing soon-to-be-required writing intensive courses. Part of my job as a Fellow (aside from taking advantage of the funding and time the fellowship provides to finish my dissertation) is to help determine what these courses will look like and to push for adoption of these characteristics into the syllabi of courses across the curriculum.

Doing this job at Lehman means dealing with a particular set of circumstances and a particular history, contexts which do not isolate our experience but rather connect it to the experiences of those working in colleges and universities across the country that are dealing with similar contexts. The particular circumstances include those affecting CUNY as whole, such as its serving a New York City population of which $65 \%$ are paradoxically labeled "minority" and of which four out of ten speak a language other than English at home (with two of these four reporting not speaking English well) ("Globalist."). Circumstances also include those specific to our campus, which serves a largely Latino, largely immigrant and first-generation college student population in 
the Bronx. An obvious ramification of these circumstances is the widespread sense among faculty that there needs to be an increased emphasis on language correctness and the forms of academic discourse.

The special history we have to face includes CUNY's place in public higher education, bearing the legacy of a number of its constituent schools that were once perceived to be of high quality yet were also inclusive of students barred from admission at the finest private universities. This is the legacy of Hunter College and Brooklyn College and Baruch College, of the City College of James Traub's City on a Hill and the documentary film Arguing the World.

This history also includes CUNY's place in the perceived crisis in education that prompted Newsweek's 1975 cover article, "Why Johnny Can't Write." The article expressed a widespread anxiety that, in its words, "the U.S. educational system is spawning a generation of semiliterates." This crisis was seen as due in part to the opening of admissions at schools like CUNY in the late sixties and early seventies under student pressure for racial inclusiveness applied, at City College, by the occupation of the admissions building and the burning of the student center in 1969. One administrator's description of his reaction to the fire could stand for that of the College's administration as a whole: "The only question in my mind was, How can we save City College? And the only answer was, Hell, let everybody in" (qtd. in Lavin 13). A less ambiguously positive reaction was that of Mina Shaughnessy, who seized the opportunity presented by an influx of new kinds of students to rethink the way writing was taught and in the process founded the field now known as Basic Writing. This reaction could stand for that of many in the College and the University who welcomed not just inclusion but the kind of institutional and pedagogical change already initiated in the 1965 birth of SEEK, a program whose aim was to assist underprepared New York high school seniors for college.

A third part of CUNY's history is what might be called the closing of open admissions, which occurred in the mid-nineties under Mayor Rudolph Giuliani and the chairman of CUNY's Board of Trustees, Herman Badillo. This closing was effected through a number of changes to admissions policy limiting the entrance of students judged unable to pass remedial exams, the capping of the number of remedial classes that students at the system's four-year colleges could take, and the eventual elimination of such classes from these campuses. The effect was to make open admissions much less open, and it was the desired effect; the goal was to raise standards, and to raise standards required exclusion. A new wave of students flooding into the university's classrooms, largely of Latino origin or descent, was felt to be dragging the university down. Badillo got specific about this wave when, at a Center for Educational Innovation luncheon, he described the Mexican and Dominican immigrants he believed to be causing a 
crisis in New York City education as "pure Indians - Incas and Mayans who are about 5 feet tall with straight hair" (Vann). Putting aside the problem of claiming Incan descent for Mexicans and Dominicans, we can see that Badillo's remarks made plain the exclusionary effects of (if not motivation for) the turn away from the university's proud legacy of inclusion. Subsequent calls for Badillo's removal were made by critics who saw not only not only the disproportionately negative effect of his policies on Blacks and Latinos but also what they claimed was the motivation for the policies, as revealed in these remarks (Arenson, "Officials").

Reviewing these circumstances and this history should lead us to consider carefully the effects of the ways in which we implement WAC at Lehman and other CUNY campuses and, as we do so, to note the parallels between the issues raised in this effort and those raised in Basic Writing. While the specific needs of student populations like CUNY's do dictate that formal correctness be addressed in some way, as with Basic Writing, we also need to think about how what we do will fit into CUNY's history of inclusion and exclusion.

Inspired in the forties and again in the late sixties and early seventies by a vision of inclusion - a utopian vision - CUNY has also been shaped by another vision, equally utopian, one of exclusion. From the Puritans onward, American history has been marked by utopian visions. The New World was ripe, in the European imagination, for cultivation as a new garden, a new Eden of innocence and plenty and moral rectitude. Many of our finest civic ideals come from this vision.

However, many of our least proud moments come from the same source, and have from the beginning. James Traub's image of the old City College as city on a hill alludes to John Winthrop's vision for the Puritan settlement of the New World. His vision was of a place that could serve as a shining example for the rest of the world to follow; with this allusion, however, comes another side of the story of America's early European settlement, the negative aspect of which it was probably not Traub's intention to invoke. Whether by conversion or killing, the Puritans made plain to the Wampanoag, Narraganset, and Nipmuc that the new American Eden had no room for their cultures. Giuliani and Badillo's vision for CUNY is often represented in terms of an Eden lost when its gates were forced open. On the occasion in 1999 of the thirtieth anniversary of the City College protests that effectively opened admissions, Badillo commented, "They lowered the standards and lowered the value of a City University diploma." He characterized the response by Mayor John Lindsay and the CUNY officials to these protests - moving up the opening of admissions five years ahead of schedule-in similar terms: "It was the days of the riots, and they caved in" (Arenson, "Returning"). Badillo's comments demonstrate that his understanding of the opening of admissions is like the understanding 
many have of the social change of the sixties as a loss of Eden; the hoped-for goal, in his vision, is a recreation of a lost place destroyed by the regrettable, radical ideas violently asserted then.

One of Pynchon's themes in Mason \& Dixon is the recurrence of a pattern of reform and reaction throughout American history. The promise of the New World, of the new nation, of Emancipation, and of the social movements of the sixties, all inspired by the vision of a new Eden, of a perfectible world, were disappointed upon the reassertion, in the name of this same vision, of exclusion, racial, cultural, and otherwise. Pynchon asks us to consider whether the danger of trying to build utopia on earth is that people will always interpret perfection as necessitating exclusion. In our small corner of the world, I would argue, it does not have to. WAC at Lehman has the chance to avoid this pitfall, and other schools facing these same demographic and institutional issues across the country have the same chance. The history of CUNY and of America can serve as reminders not just of how things can go wrong but also of the promise of their going right.

Crucial to that promise is the manner in which we try to achieve it. As David Tyack and Larry Cuban argue in their history of public school reform, Tinkering Toward Utopia, educational reform must take place within what they call a basic grammar of schooling-within the systems of administration and practice that make radical reform impossible. Richard Miller, in As if Learning Mattered, takes their lesson and applies it to higher education, arguing that the perfect university, as imagined by Paolo Freire or Peter Elbow or whomever, will not suddenly appear, and that actual reform can happen only if we slowly work toward those ideals, within the restrictions of the bureaucracy of which the university is part. Our job at Lehman can be seen in this light. We are working toward institutionalizing particular kinds of classroom practice, based on assumptions about higher education that are themselves founded on beliefs about how the world is and how it should and maybe even could be. Remembering that we are doing this in the not-so-new global economy can help us think about how the shape of our vision influences the shape classroom practice takes. Thinking about the ways Basic Writing has already and continues to deal with similar issues can help us avoid the pitfalls that we might fail to see if we assume that these issues are being confronted for the first time.

The raising of standards at CUNY is designed to make it a university that will provide workers to fill the corporate offices of Wall Street and midtown. This effort, based on its own vision of a perfect university, reflects the danger of exclusion inherent in so much utopian thinking. If we want simply to produce white-collar workers who can take their place in the global economy, we will choose practices that teach students the discourse of whatever discipline is appropriate 
to that place. And if we are successful at that, we will have really done something. Helping first generation college students achieve financial security is nothing to sneeze at. But if we stop there, we are excluding students from something.

That something has been described in different ways by different educational critics, including critics of WAC as it is currently practiced. As has been pointed out many times, WAC in practice has often amounted to what C. H. Knoblauch and Lil Brannon have called "grammar across the curriculum" or, when attention is paid to the particular forms of disciplinary writing, "packaging of information across the curriculum" (465). They argue for write-to-learn approaches that will engage students intellectually with their course material. Both writeto-learn and writing-in-the-disciplines approaches to WAC have been criticized for contributing to what Daniel Mahala calls the "formal closure of the intellectual possibilities accessible to the student," in part because the actual practice of both write-to-learn and also writing-inthe-disciplines approaches are believed to yield to "prevailing institutional divisions, faculty interests, and dominant forms of knowledge making" (782, 781). Susan McLeod and Elaine Maimon have defended existing WAC practice against criticisms that it does not work toward WAC's stated goals, saying that there are many programs whose approach to WAC is not formalist but epistemological, teaching students not just to be technically competent, to absorb course content more effectively, or to reproduce discourses but rather also to think through them ("Clearing" 580). In this and other arguments against Knoblauch, Brannon, Mahala, and others who criticize the movement with whose birth they are associated, Maimon and McLeod dismiss the criticisms as unsupported empirically and based on "myths" about WAC ("Clearing," Letters).

Rather than dismiss critiques such as these in defense of the reputation of WAC as a movement, champions of WAC should take note of them. Critics believe that WAC is falling short of its proper goals because, by focusing too narrowly on form, it is failing to encourage critical thinking. By failing to do this, they believe, WAC is falling into the trap of being satisfied with superficial correctness, content-delivery, and mimicry. It is important, in thinking about WAC, composition, and higher education at CUNY and elsewhere, to decide whether the decision to focus on form is simply a pedagogical choice or also a social choice. When our responses to error-ridden writing by underprepared students, in any context, take the form of approaches that fail to address thinking, we need to consider whether in responding in these ways, we exclude students from the world of intellectual inquiry, the world that allows students not just to enter their desired fields to but also to try to reform them if they so wish. 
The paradox inherent in the idea of teaching students to think independently is, like many paradoxes, potentially productive. It is a commonplace of the classroom practices sometimes gathered under the rubric of critical teaching, derived from the philosophies of Freire and others, that student empowerment cannot be delivered by the teacher to the student, as knowledge cannot be, but must come out of a devolution of authority from the teacher to the student. The decentered classroom, in which authority over the syllabus, classroom management, and learning itself is shifted largely or in part to students, is commonly thought to construct an environment in which students can empower themselves. Attempting instead to actively teach students to think critically would seem to fly in the face of this now common wisdom and practice; it seems not just self-contradictory but counterintuitive. These two senses of paradox - internal contradiction and opposition to common wisdom - are of course related: if two terms seem to contradict each other when joined it is because of doxa, because of commonly held understandings of the world to which the terms, joined, run counter. If it is not a contradiction to teach students to think independently, then perhaps intellectual empowerment can come from others. In fact, maybe it has to.

How, then? One valuable strategy that has been found to help students use their time writing to develop their critical faculties has involved the rethinking of thinking itself. As many in composition have incorporated into their understanding of writing the ideas of poststructuralism, in particular the idea that the individual can be seen not simply as an independent, sovereign consciousness but also as a socially constructed subject, they have changed the way they teach writing. They have tried to apply the idea of the construction of knowledge, of the inheritance of ideas and language that are socially freighted, to the teaching of writing. Seeing students as more written upon than writing, in David Bartholomae's Barthes-inspired formulation (143), has helped composition broaden its understanding of student writing from the picture of individuals creating prose work de novo to one that includes the social webs in which they compose their ideas and their expressions of them (Bartholomae, Berlin, Faigley, Susan Miller). Counter to the practice of expressivist and process pedagogies, this pedagogy has focused not on strategies that allowed student writers to free their inner voices but rather on ways that they could engage in and negotiate with preexisting discourses. There is of course a paradox in the idea that students can learn to think outside their inherited, socially constructed worldviews by learning how their worldviews are socially constructed. How can learning how your ideas are determined help you determine your ideas? The poststructuralist doxa this paradox runs counter to is the belief that social construction is total and 
inescapable. It is an idea that anyone who actually teaches cannot believe. Hidden behind the common wisdom is the realization that recognizing the social construction of discourse is the first step toward critical thought about it, and that this recognition can be shared by teachers with students. Critical thought, then, not only is possible to teach: it must be taught, precisely because the recognition that enables it is inherently so difficult to come by.

The classroom that incorporates these ideas in both reading and writing, encouraging students to see how the work they read, their own work, and even their selves are created in social contexts, is a classroom that encourages critical thinking. This classroom can be even more successful, I would argue, if the teacher spends time revealing his or her own social construction. If the teacher can discuss the limitations and possibilities inherent in his or her own position within a social, institutional, and intellectual context, he or she can help students to think critically by modeling the two-stage process of the recognition and critique of social construction. This is not a move many teachers wish to make, preferring to stay behind the lectern, above the class, demonstrating expertise. Particularly in the disciplines, and especially in disciplines in which ideas about the social dimension of knowledge have not had much impact, this just may not happen much. But when it does, when teachers delve into the history of their disciplines and show the shifts in "truths" and in modes of claiming these truths, teachers can perhaps get students thinking about where their authority and so the authority of other kinds of expertise and power come from. In doing so, they can also demonstrate how these kinds of poststructuralist ideas do not have to be seen as antihumanist (without necessarily having to use the terms). I do not give up my agency and my imagination because I admit that I am not the first to use the words I speak and write. If I let my students see how I am both restricted and enabled by the rhetorical dimensions of the discourses in which I work and even the social position I inhabit, they can begin to consider the same things about their own use of language.

An example from my own teaching experience is a class with a large number of Modern Orthodox Jewish Russian immigrants I taught a few years ago at Baruch College (CUNY). In the course of discussing an assignment which asked them to consider the ways fundamental beliefs can shape perception and action, we took up the issue of the Palestinian/Israeli conflict, and the class found itself frustrated by the views of the Russian students, one of whom repeatedly offered, as justification for Israeli settlements in occupied territory, "It's in the bible." What the class was encountering was the difficulty of stepping back from our own opinions in order to grasp the notion that other people have their own beliefs, which cause them to see the world in ways different from ours. Without asking anyone to question their own fun- 
damental beliefs (a request that assuredly would have had no effect), I asked all of us to think about the connections between identity and ideas, between where people come from and how they see what is before them. By putting myself forward as an atheist American Jew, in distinction to this group of students, Russian-American Jews citing Torah in heavy metal t-shirts and skateboard sneakers, I tried to illustrate these ideas, and encourage students to take a step back not so much from their own ideas but more from ideas themselves, to think critically about how we receive ideas and how they affect our worldviews. While many did not, as would be expected, many of them engaged in critical thinking about fundamental things (Cohen).

The benefit of this kind of teaching to writing intensive courses in the disciplines should be evident. Learning the rhetoric of disciplines not as if they were written on high but rather as historically evolved, socially implicated constructions enables students to engage with them on a more sophisticated level. Once on that level, students can think critically not just through the discourses of disciplines but about them. We can think of many common WAC practices in this light, and, rather than trying to radically alter WAC, can tinker with them to push them in this direction. The paradoxical notion of tinkering toward utopia, like the other paradoxes under discussion here, can be productive. That grand ideas require grand plans - that radical social goals necessitate massive social experiments - has been a commonly held notion. That the grand social experiments of the previous century ended in failure has been taken by many to reinforce their belief in the inevitable failure of utopian thinking. That incremental social progress has been made in the direction of utopian goals is not a contradiction but an indication that the world is not an all-or-nothing proposition. You can tinker toward utopia. Some of many possibilities for WAC, but not just for WAC:

Journals: Often used to encourage what Peter Elbow has called low-stakes writing ("High"), they are also sometimes used in more directed ways to respond to or reflect on reading or writing, and can be further directed to encourage critical thinking.

Reading journals are often little more than formalized notetaking and unfocused response. However, they can be assigned in ways that ask students to reflect on their reading in terms of disciplinary rhetoric and intellectual rhetoric generally. What claims are made? With what kind of authority? In what social context?

Writing journals can ask students to perform the same kind of operation on their own writing and the writing of oth 
ers. Rather than ask students simply to verbalize their thoughts and feelings in order to free their authentic voices, in the expressivist mode, or to reflect on the progress of their paper-writing, in the process mode, these journals can serve as places in which students consider the claims and contexts of their own writing and that of their peers. From where do they assume their own authority? In what contexts are they making their own claims?

Workshops often become exercises in proofreading and spell checking; alone or in peer groups, students go over their work and end up simply polishing surfaces. Directed exercises can encourage deeper engagement with prewriting and with revision. Students can be asked to consider the ways in which their theses are situated in larger intellectual contexts. They can be prodded to consider the unwritten rules of claim-making, of disagreement, of what is valid support and what is not (e.g., textual versus experiential, academic vs. popular). They can learn to untangle what they know about their subject from direct observation and individual deduction from what they have received from common wisdom, and they can learn to consider the same distinction when they write about others' conclusions. They can learn, in short, to think not just about filling formulas more perfectly but also about the formulas themselves.

These are only a few of the ways in which existing vehicles for writing instruction can be customized. Benefits similar to those of reading journals can be had from short response papers and even short written questions. Both can be assigned in ways that make them little more than demonstrations that students have done the reading, and relative to the pop quiz they are not so bad. They can also serve to reinforce students' grasp of content, also a worthwhile goal. But if assigned in ways that ask for critical response-examination of the assumptions behind readings, of writers' motivations, of generic conventions - these exercises can ask more of students. There are many simple, low-stakes writing techniques that, with a little reworking, can evoke high-stakes thinking. More than simple detailing, this tinkering can turn writing exercises into vehicles that can drive thinking in new directions.

I will offer one example of this kind of pedagogy from my own experience in WAC. For a course in the Lehman College Department of Latin American and Puerto Rican Studies entitled "Latinos in the United States," I ran workshops designed to help students arrive at topics, fine-tune theses, and develop and integrate support for their 
term papers. They were to write about any subject concerning the Latino experience in this country, with the requirement that they make an argument about an aspect of that experience that they could back up with data. Their professor had already begun to make the point in class discussion that there was a difference between the anything-goes rule of everyday opinion and the more stringent requirements of intellectual argument. It was clear to me that, even at the start of the semesterlong process of putting together these research essays, this point was going to need to be made a number of times. These students needed to become more familiar with the conventions of academic argumentation - thesis, support, citation - and with the finer points involved in situating an argument in a larger intellectual conversation.

The trick, however, was that any subject these students chose would be something they knew a lot about, or thought they did. This preexisting connection with the material-every single student was of Latino descent, and of course lived in the United States - posed a problem, but it also presented an opportunity. The problem was that they might not be able to separate easily the opinions formed over a lifetime spent gaining personal experience, received wisdom, and unexamined stereotypes about these subjects - about their lives - from what is accepted in academic discourse, particularly the scientistic discourse of the social sciences. A problem adjunct to this was the danger common to academic socialization in general: that their own experience would be invalidated, that they would feel that their own senses of things would have to be jettisoned if their work were to be accepted. The opportunity was that in negotiating these difficulties, they would be learning the construction of academic discourse, the rules for making and supporting truth claims, against the ever-present counterexample of simple opinion. As a result, they also gained the chance to think critically about this very distinction.

From the first elements of the first workshop, a number of sequenced free writing exercises designed to get them thinking about what they knew and how these different phenomena and concepts were related, the students were confronted with this distinction. When reviewing their clusters, for example, I asked them to think about the lines drawn between circled elements. What was the nature of the connection these lines represented? Were they causal? What were the causeeffect relationships? Were they proven or merely assumed? Over the course of our writing workshops, they engaged with what it means to use authoritative sources, what it means to argue counterintuitively, what it means to argue against received wisdom.

In the course of all this reconsidering, which was the avenue by which they improved the formal structure of their essays and which was also the form taken by their learning the discourse of their discipline, the opportunity arose to question that discourse. Why was per- 
sonal experience often seen as not valid? Why, when it was accepted, did it need to be held up by stout buttresses of empirical data? Why did the kinds of knowledge available in literature and popular culture seem to garner so little respect? Questions specific to course content also arose. Who got to speak about the Latino experience in the U.S.? Who among various players in Latino life in New York City - city councilmen and women or former members of the Young Lords, political scientists or poets - could make statements that would be received as authoritative? What kinds of explanations were given the most weight-ones that focused on the state, on political models, or those that focused on economics, or those that focused on ideology? Why?

Many students, of course, declined to seize this opportunity, probably for the reasons that students usually fail to seize such opportunities - time, energy, interest, sophistication. A few may have begun to see the outlines of the conversation emerge. Fewer still, but, still, a few, seemed to be thinking about these questions. If their writing did not always reflect this thinking (though it did reflect attempts at incorporating a variety of sources, or weaving personal experience into more traditionally academic argumentation, or questioning the motivation behind ways of thinking about these things), the thinking was still happening. Even though entire classes could have been devoted to their problems with verb endings, or argument, or to gaps in their knowledge about particular countries or political systems, these students were not steered toward the production of polished work at the perhaps unintended expense of the opportunity of critical engagement with their field.

We are said to value critical thinking very highly these days. We should not, then, treat it as a luxury for students with good English. The current perceived crisis in higher education is no different from that in the seventies or those at the turn of the last century, in the thirties, and after World War II, which were all, as David Russell has pointed out, the result of the influx of new kinds of students, and which also were all impetus for new incarnations of writing in the disciplines (271). This latest incarnation, at CUNY, has the chance to respond to the current perceived crisis in a way that fully addresses its students' needs. That many other institutions in similar situations have this same chance makes our work at this highly visible place potentially valuable. It is valuable to recognize that just as it is exclusionary to institute admission policies that label students remedial and keep them out of CUNY's senior colleges, so it is exclusionary to adopt pedagogies whose only aim is to ensure that students can attain a degree of technical competence sufficient to allow them to achieve a certain level of professional employment. These students, coming, in this global age, from around the globe to get an American education and an American job, deserve more than just that. They deserve admission, and education in 
communication skills, but they also deserve an education in critical thinking, in taking apart the rhetorical conventions of discourses, in seeing how received truths and accepted forms are social constructions. They deserve the right to receive this education in WAC, in all writing instruction, in all of their courses. They deserve the chance to ask if the world in which they live is the best of all possible worlds and whether there are ways they might change it.

This is a utopian goal worth tinkering toward. As a once optimistic young man from Westphalia who had given up looking for such a world is supposed to have said, we must cultivate our garden. Some readers interpret Candide's final words to represent Voltaire's advice that we give up all thought of utopia, accepting the world as it is, seeing it not as the best of all possible worlds, perhaps, but as the best of all possible worlds. Others insist that Candide's garden is an earthly utopia, and that, while we should be wary of the distraction of empty philosophizing and the futility of grand experiments, we must still work on improving our garden. We cannot create another El Dorado, where the streets are paved with gold and knowledge is the highest pursuit, but we can keep one in mind as a perfection to be slowly, incrementally approached. If we want to reform writing instruction, in whatever forms we practice it, we can tinker toward a more inclusive pedagogy, one that gives students the tools to tinker toward their own utopias in whatever fields in which we try to prepare them to practice. We can encourage students to see how things are made in order to allow them the possibility of remaking them. To do otherwise - to forget the lessons of Basic Writing - is to exclude students from the right to reform on which we insist for ourselves. It is to let them into the garden but make them check their spades at the gate. If we do want to improve our garden, we should want everyone to be a gardener.

\section{Works Cited}

Arenson, Karen. “Officials Back Badillo Amid Furor on Hispanic Remarks." New York Times 2 Oct. 1999: B3.

-. "Returning to City College to Revisit a 1969 Struggle." New York Times. 29 Oct. 1999: B3.

Bartholomae, David. "Inventing the University." When a Writer Can't Write: Studies in Writer's Block and Other Composing Problems. Ed. Mike Rose. New York and London: Guilford Press, 1985, 134-65.

Baucom, Ian. "Globalit, Inc.; or, The Cultural Logic of Global Literary Studies." PMLA 116.1 (2001): 158-172.

Berlin, James. "Poststructuralism, Cultural Studies, and the Composition Classroom: Postmodern Theory in Practice." Rhetoric Review 
11 (1992): 16-33.

Brockman, John. "The Second Globalization Debate: A Talk with Anthony Giddens." Edge. <http://www.edge.org/3rd_culture/ giddens/giddens_index.html>. 3 Mar. 2002.

Cohen, Samuel. "Composition and Construction: Belief, Identity, and the Teaching of Writing." Dialogue: A Journal for Writing Specialists 6.1 (1999): 30-36.

"Conference Theme." WAC 2002: Sixth National Writing across the Curriculum Conference. <http://www.ruf.rice.edu/ wac2002/ ctheme.htm>. 1 Mar 2002.

Danaher, Kevin. "Globalization and the Downsizing of the American Dream," Global Exchange.<http://www.globalexchange.org/ economy/econ101/americanDream.html>. 3 Mar. 2002.

Dorman, Joseph, dir. Arguing the World: The New York Intellectuals in Their Own Words. First Run/Icarus Films, 1997.

Elbow, Peter. "High Stakes and Low Stakes in Assigning and Responding to Writing." New Directions for Teaching and Learning 69 (1997): $5-13$.

-. Writing Without Teachers. New York: Oxford U P, 1975.

Faigley, Lester. Fragments of Rationality: Postmodernity and the Subject of Composition. Pittsburgh: U of Pittsburgh P, 1992.

Freire, Paolo. Pedagogy of the Oppressed. New York: Seabury Press, 1971.

"Globalist Factsheet: New York-City of Extremes." The Globalist. <http://www.theglobalist.com/nor/factsheets/2001/06-2601.shtml>. 4 Mar. 2002.

Knoblauch, C. H., and Lil Brannon. "Writing as Learning Through the Curriculum." College English 45 (1983): 465-74.

Lavin, David E., Richard D. Alba, Richard A. Silberstein. Right Versus Privilege: the Open-Admissions Experiment at the City University of New York. New York: Free Press, 1981.

Mahala, Daniel. "Writing Utopias: Writing Across the Curriculum and the Promise of Reform." CE 53 (1991): 773-89.

Maimon, Elaine, and Susan H. McLeod, "Clearing the Air: WAC Myths and Realities." CE 62 (2000): 573-84.

-. Letter. $C E 46$, Oct. 1984; 615-20.

-. Letter. CE 54, Oct. 1992; 729-35.

Miller, Richard. As If Learning Mattered: Reforming Higher Education. Ithaca: Cornell UP, 1998.

Miller, Susan. Textual Carnivals: The Politics of Composition. Carbondale, IL: Southern Illinois UP, 1991.

Pynchon, Thomas. Mason EDixon. New York: Holt, 1997.

Rose, Mike. "The Language of Exclusion." College English 47 (1985):

341-59. Rpt. in Cross-Talk in Comp Theory: A Reader. Ed. Victor

Villanueva, Jr., Urbana, IL: NCTE, 1997, 525-47.

Russell, David R. Writing in the Academic Disciplines, 1870-1990: A Cur- 
ricular History. Carbondale: Southern Illinois UP, 1991.

Shaughnessy, Mina P. Errors and Expectations: A Guide for the Teacher of Basic Writing. New York: Oxford UP, 1977.

Shiels, Merrill. “Why Johnny Can't Write." Newsweek 8 Dec. 1975: 5865.

Traub, James. City on a Hill: Testing the American Dream at City College. Reading, MA: Addison-Wesley, 1994.

Tyack, David, and Larry Cuban, Tinkering Toward Utopia: A Century of Public School Reform. Cambridge, MA: Harvard UP, 1995.

Vann, Bill. "New York Protests Continue over City University Chief's Racist Diatribe." World Socialist Web Site 12 Oct. 1999. <http:// www.wsws.org/articles/1999/oct1999/badi-o12.shtml>. 3 Mar. 2002.

Voltaire. Candide, or, Optimism: A Fresh Translation, Backgrounds, Criticism. 2nd ed. Trans. and ed. Robert M. Adams. New York and London: Norton, 1991. 


\section{UNDERGRADUATE SECOND LANGUAGE WRITERS IN THE WRITING CENTER}

ABSTRACT: The number of second language writers in composition classes and seeking assistance at university writing centers is growing every year. Yet, relatively little attention has been paid in composition studies or the writing center literature to the challenges that these writers face. In the writing center, tutors who work with these writers also face an enormous challenge if they do so without adequate preparation and knowledge. This article explores some important insights offered by second language acquisition research, focusing in particular on the findings of interactional and Vygotskyan approaches. Finally, it argues that writing centers may be an ideal place for second language writers to work on their writing.

Sue Kang's psychology professor advised her to come to the writing center for "help with prepositions and articles." Lu's composition instructor wondered if she were in the right class and suggested she go to the writing center for "extra help." Farad came in on his own for help with "ideas and grammar." Writers like these often come or are sent to the writing center when their instructors simply do not know what else do with them. In part, this may be due to the fact that, at many institutions, composition instructors receive little preparation in how to work with second language writers and still less, any background in theories of second language learning (Kennedy; Williams, "Program Administration"). Instructors may send their undergraduate second language writers to the writing center at best, out of frustration, (Thonus, "Tutors" 14; Zamel 506) and at worst, because they don't think dealing with second language problems is part of their job (Zamel 509). It may be assumed that, since second language writers are in college, their language proficiency is no longer an issue; their language problems have somehow been taken care of before matriculation.

In spite of their visibility at writing centers, second language writers do not get much attention in the writing center literature. Indeed, they are not even mentioned in Boquet's recent history of writing centers. There has been a handful of articles on the topic in the

Jessica Williams teaches in the M.A.TESOL program at the University of Illinois at Chicago, where she also directs the ESL composition program. She was faculty director of the Writing Center from 1999-2001. She has published articles on variety of topics in second language acquisition, including second language writing, lexical acquisition, and the effect of focus on form. 
past fifteen years (e.g., Cogie, Strain and Lorinksas; Friedlander; Gadbow; Harris and Silva; Kennedy; Moser; Powers; Ronesi; Thonus "Tutors"), but most of these are limited to cautious advice or do's and don'ts for working with second language writers. Very few give second language acquisition research more than a passing mention. Nor has ESL writing research received much attention in the mainstream composition literature (see Matsuda; Silva, Leki and Carson). This article explores some of the problems faced by second language writers, identifies some fundamental findings from the field of second language acquisition, and argues that this knowledge can inform interactions between these learners and their teachers and tutors.

It has been suggested that the writing center is an ideal place to address the problems and challenges of second language writing. Ronesi points to the common theory, goals and approaches of composition pedagogy and writing center practice. She also suggests that the extra time and attention that second language writers need to complete assignments are often not available in class or from their teachers, and that writing centers are by nature, focused on the individual. Muriel Harris, in a study of second language writers in the writing center, reported that they perceived tutors to be "immediately more helpful, more approachable, more practical and more personal than teachers" ("Cultural Conflicts" 223). Recent thinking points to a central role for writing centers, one that suggests a reciprocal relationship with composition instructors. Tassoni and Harris ("Middle") both argue that the writing center does not simply provide supplementary instruction; often it is a site of primary learning. This may be a particularly fruitful perspective for second language writers.

Regardless of whether it is, in principle, appropriate or effective for second language writers to use the resources of the writing center, they are an inevitable and significant part of the writing center clientele. According to many in the field, second language writers are coming in increasing numbers and there is no indication that this trend will end soon (Carter-Tod; Powers; Ronesi). It is therefore essential for writing center professionals to review what is known about their second language writer clients and to inform themselves about how they might better serve this population. The first and most important step is to acknowledge openly that second language writers are not only learning to write in a second language, they are learning a second language (Kroll; Harris and Silva 528-9). Although these are intertwined in practice, in fact, they are different processes. Learning a language is not the same thing as learning to write in that language. 


\section{The Writers}

The second language writers who come to writing centers do not have a monolithic profile. They come from a variety of social, linguistic, cultural and educational backgrounds; and they have different goals for their long-term educational and professional development and for their sessions in the writing center. However, a broad and crucial distinction can be made between international students and permanent residents/citizens (Leki, Understanding; Reid). Harklau, Losey and Siegal maintain that it is the second group that has been the major source of the increasing linguistic and cultural diversity on today's college campuses (2), and by extension, at writing centers. At some universities and colleges, the majority of second language writers are international students who, ostensibly, will return to their own countries when their education is complete. Some, though by no means all, have good educational backgrounds and considerable experience writing in their first language. In contrast, at a large number of universities and colleges, especially urban public institutions, permanent residents and citizens predominate. Many of these bilingual and second language writers are members of what has been characterized as Generation 1.5 because of "traits and experiences that lie somewhere between those associated with the first and second generation." (Harklau, Losey and Siegal, vii). Perhaps the most important point about this group is that the United States is their home, and for many, the only home they remember. Some are fluent in spoken English; many have little literacy experience in their home language, over which some have uncertain command. Their educational background and experience may overlap with those of their native English writer classmates. Yet, their writing shows many characteristics typical of second language learners.

Why do second language writers come to the writing center? First, there are the obvious reasons: either they or their instructors perceive that they need to improve their writing skills and/or their second language ability. Although in the writing center we are largely concerned with the former, it is important that the latter be addressed as well. Tutors tend to be more knowledgeable and confident about dealing with writing issues than language problems. For the latter, some tutors may refer second language writers to handbooks, which generally contain explanations of troublesome grammatical forms and sentencelevel exercises. These measures are frequently frustratingly ineffective. Many second language writers are often already experts at the sentence-level drill, but this may have no apparent effect on their writing (Williams and Evans). Tutors may think that if they simply provide 
an explanation, the student's performance should improve, and they become frustrated when this does not happen. There are several reasons for this.

- Second language acquisition, that is, the internalization and automization of new linguistic knowledge, takes time, lots of time. It is unlikely to take place during a 50-minute writing center conference. Learning a new language is a slow, and like learning to write, a non-linear, sometimes recursive process.

- Learners must be developmentally ready to acquire what is being presented to them; teaching is no guarantee of learning.

- Metalinguistic knowledge, or rule knowledge, which is what often guides second language writers through sentence-level drills, does not guarantee implicit knowledge, which is what underlies accurate spontaneous language use.

- Not all aspects of language are learned in the same way; therefore, not all language errors are the same.

In addition to acquiring a new language, second language writers are entering a new discourse community, in which they must master many other skills. We witness their struggles with writing at the writing center, but depending on the background of the student, there may be other required tasks that are relatively unfamiliar. The biggest challenge at college for all second language writers is probably reading and engaging unfamiliar texts, extracting information and using it in creating their own texts (Spack "Acquisition," "Student"). At the writing center, tutors see the end, or sometimes, interim product of their struggle; however, it begins much earlier. For second language writers, academic reading itself can be an enormous challenge. Theories of interactive reading point to the interplay between top-down and bottom-up reading strategies. Bottom-up processing refers to the text-driven decoding of surface structures, in contrast to top-down processing, which emphasizes the overall construction of meaning, including the application of prior knowledge. Good readers use both strategies. Unfortunately, the bottom-up decoding skills of second language learners may be insufficient for the fluent reading that academic work requires (Grabe and Stoller, "Teaching"). They may decode slowly, word-by-word, often failing to make sense of the entire text. This is due in large part to their limited vocabulary, particularly, lower frequency academic vocabulary.

The connection between vocabulary and reading comprehension 
in a second language is widely attested (Coady; Grabe and Stoller, "Reading"). Zeichmeister, D'Ana, Hall, Paus and Smith conservatively estimate that the average native speaking undergraduate has a vocabulary in the range of 14,000 to 17,000 words (203), suggesting that second language writers may need to increase their vocabulary size considerably in order to achieve academic success. One acknowledged way of increasing vocabulary in both the first and second language is through extensive reading. During reading, vocabulary is acquired incidentally, through inferencing and repeated exposure. However, the inferencing process is unlikely to be successful unless much of the text surrounding the unknown word is understood. It has been estimated that successful word inferencing from context occurs only when $98 \%$ of the other words in a text are familiar to the reader (Laufer; Nation and Coady). For second language learners, this ideal situation may be infrequent. Participants in a study by Parry, for example, guessed accurately only $12 \%-33 \%$ of the words from a college anthropology text that they listed as unfamiliar (639). In some cases, they listed words as unfamiliar, but did not bother to guess at all. This creates a cycle from which it is difficult for second language writers to break free: academic reading loads are onerous and completed slowly, and vocabulary acquisition is slow and erratic. Writing tasks based on such reading assignments can pose a tremendous challenge for these second language writers.

Once students have read assigned texts, they are often asked to respond to them, analyzing and synthesizing information, and constructing arguments. Numerous studies demonstrate the difficulty of this work, as well as the struggle that can result in charges of plagiarism against many second language writers (Currie). Second language writers often do not understand the difference between summary and analysis (Spack, "Acquisition" 31), and which and how much text can safely be included in their own writing. Indeed, second language writers receive conflicting messages regarding their reliance on material written by others. On the one hand, they are told to use their own words, but then are often penalized when they do so, leading them to pursue a strategy of' "textual borrowing" (Currie 7). Such a strategy is often attributed to cultural differences in attitudes toward intellectual property, an aspect of contrastive rhetoric (Deckert; Matalene). Yet, this perspective is unlikely to explain the phenomenon in the writing of permanent residents, whose perceptions have been shaped by their American education. It is far more likely to be a result of second language writers' inexperience with the task, a lack of awareness of expectations, and their desire, in Currie's words "to stay out of trouble" (7). Nevertheless, the notion that second language writers' writing reflects practices and beliefs influenced by their native culture has found its way into the writing center literature, where it appears to be widely 
accepted (Costello; Friedlander; Gadbow; Harris and Silva; Powers; Thonus, "Tutors"). Although it is evident that educational and cultural experience affect a writer's process and product, uncritical embrace of contrastive rhetoric in the writing center is problematic for several reasons. Most generally, contrastive rhetoric has been criticized as reductionist, that it unfairly constructs identities and practices for second language writers that may or may not apply (Cahill; Kubota; Leki, "Crosstalk;" Severino, "Doodles;" Spack, "Rhetorical"). It has been applied especially frequently to Asian writers. Cahill argues persuasively that much of the contrastive rhetoric literature, which characterizes Asian writing as indirect, non-linear, and lacking explicitness, as measured against the logical, linear west, is quite simply, orientalism. In fact, inexperienced writers can often be indirect, non-linear and inexplicit in their written expression as well. This does not mean, of course, that cultural differences do not exist, but simply that they may not always explain the features of the majority of second language writers' texts. It is important to examine such claims critically before using them to prepare tutors of second language writers.

\section{Learner language}

Characterizations of learner language are necessarily generalizations, but even a cursory knowledge of second language learning processes and how they affect learner production can be helpful to writing center tutors (see Carson for a review). The texts produced by second language writers often diverge markedly from standard edited English; both second language writers and their tutors have to confront second language writers' linguistic errors. These may be of several types. First, there are many rules, such as subject-verb agreement, that most second language writers do know and can apply under the right circumstances. This is often the case with highly systematic rules that have a clear and predictable form-meaning relationship. Yet, second language writers may apply their knowledge unevenly because their attention is directed elsewhere during the writing process, namely, to the content of their texts. These are errors that second language writers can self-correct and they should be encouraged to do so (see Cogie, Strain and Lorinksas; Ferris; Williams and Evans). Other errors, ones that result from lack of knowledge or incomplete knowledge, are more difficult to assess. There are two issues to consider. First, although there is some controversy on this point, most applied linguists agree that linguistic knowledge may be acquired systematically or one item at a time. ${ }^{1}$ This has implications for the kind of feedback tutors can give. An example of system learning is regular past tense marking with $e d$, or that the verb wish must be followed by a subjunc- 
tive form of the verb (usually more simply explained as a past form) in the next clause. Javier wishes he had a dog. Because these structures can be described as part of a system, current knowledge can be projected onto new forms, e.g., I wish I owned a Porsche. Thus, feedback on one example might become useful in other contexts. Alternatively, learners can be encouraged to apply their own developing knowledge to new contexts. Item learning is, by definition, less efficient. For example, the fact that the word iota appears almost exclusively in negative sentences or the knowledge of which particle (e.g., at, up, out, on, etc.) should follow work in the sentence I can't work out this problem, is unlikely to extend much beyond these specific contexts. If second language writers do not have this knowledge, there is very little tutors can do other than simply tell them.

The second issue pertains to the type of knowledge source on which the second language writers can be expected to draw in order to improve linguistic accuracy. Implicit knowledge of a second language is much like knowledge of a native language: it is tacit and abstract. It is knowledge on which a user can draw without thinking in order to produce or understand language. Returning to the wish example above, most native speakers will accept I wish I owned a Porsche but reject *I wish I bought a Porsche. This knowledge is part of a native speaker's linguistic competence, yet most of us would have difficulty explaining why the first sentence is acceptable but the second is not. Although the goal of second language learning is the development of this implicit knowledge, writers, because they have the luxury of time and planning opportunity, can also take advantage of their explicit knowledge. This is knowledge that they can articulate, but cannot always use when speaking or writing quickly or under pressure. Many second language writers can provide linguistic rules and reasons for why and how a certain form is used, often more readily than native speakers. Tutors should encourage writers to draw on both sources as they write and revise. They can consult implicit knowledge (This doesn't sound right.) or explicit knowledge (Prepositions can only be followed by gerund complements). Finally, it is clear that native speaking tutors have complete implicit knowledge of English. However, in order to assist second language writers in the development of their explicit knowledge, tutors would do well to make some of their own linguistic knowledge more explicit. In other words, they need to know English grammar rules in order to explain them to others (Ferris; Harris and Silva).

\section{The tutors}

Tutors in the writing center, like teachers of writing, are often unprepared to deal with second language writers (Moser; Ronesi), in 
spite of the fact that at some centers, the majority of sessions are with second language writers. What tutors are prepared to do is collaborate: "to guide, ask questions, listen and make suggestions, but they are neither authority figures nor evaluators" (Harris "Conflicts" 221). In short, they act as peer advisors. Studies of interaction among peers in second language writer classes have yielded mixed findings (see Liu and Hanson for a review). Some have found peer feedback to be as effective as teacher feedback (Hedgcock and Lefkowitz; Villamil and De Guerrero), others found that writers incorporated very little of what their peers suggested (Allaei and Connor; Connor and Asenavage), while still others found that writers were selective in what suggestions they chose to follow (Mendonça and Johnson; Nelson and Murphy). The uneven effectiveness of peer response may be rooted in the writers' perception that their classmates are, in fact, peers, and perhaps no more knowledgeable than they. Harris ("Collaboration") points to many important differences between peer collaboration and peer tutoring, including the roles, goals and methods. In fact, writing center tutors are not always the peers in practice that they are in theory (Dyehouse), especially when working with second language writers. Thonus ("Dominance") and Williams ("Institutional discourse") found consistent evidence for institutionally dependent markers of conversational dominance by tutors, in the form of turn length, directives, interruptions, and unmitigated suggestions. Thonus also found that second language writers wanted their tutors to behave as higher-status interlocutors, and that they found the tutors' dominant behavior to be consistent with their view of the tutors as authorities (Thonus, "NSNNS Interaction;" Young). This view is echoed by the participants in the Harris study, who saw the writing center tutor as someone who could help solve problems ("Cultural Conflicts,"223).

\section{Interaction}

If we acknowledge that writing center tutors and the second language writers who seek their assistance are perhaps not peers, that tutors demonstrate conversational dominance and that second language writers want and expect this, what implications does this have for tutoring second language writers? How does this perspective intersect with what is known about effectiveness of collaboration among peers in the second language writing classroom? Powers has suggested that it might well be appropriate for tutors to be somewhat more directive with second language writers than with native English writers. Yet, as Cogie, Strain and Lorinskas note, it is easy for such a policy to veer into tutor editing of second language writers' papers (7). How can tutors strike a balance between providing the guidance that second lan- 
guage writers often seek and not providing so much that they are either editing or appropriating students' texts? The key, I believe, is in the interaction. Here, we may usefully draw on two related areas of second language acquisition research, both concerned with the interactions in which learners are engaged. The first is often referred to as the Interaction Hypothesis, which focuses on the role of negotiation of meaning in language acquisition, and the second, a sociocultural approach, much cited in other areas of education, which draws heavily on the work of Lev Vygotsky.

The Interaction Hypothesis refers to a body of research that addresses, among other things, the input-interaction-output sequence in second language acquisition. The discussion that follows draws primarily on the work of Michael Long, Teresa Pica, and Susan Gass. In particular, the Interaction Hypothesis explores how negotiation of meaning among learners and their interlocutors aids in the acquisition of language. Negotiation has a specific meaning in second language acquisition research. It is narrowly understood as taking place when there is some problem in communication, which results from a combination of limited linguistic resources of the learner(s) and the cognitive demands of the task. It can occur when interlocutors are unable to express themselves with sufficient clarity to be understood or are unable to comprehend what is addressed to them. Ideally, in order to resolve the situation, the interlocutors negotiate until mutual comprehension is reached. The following is a brief example of a negotiated sequence between a native speaker and a nonnative speaker. It revolves around the meaning of the word facing.

NS: Are they facing one another?

NNS: Facing?

NS: Um. Are the chairs at the opposite ends of the table or-

NNS: Yeah (Pica 515)

One of the first advantages attributed to negotiation is the increased comprehension of input, as in the example above. When learners participate in interaction, they are able to tailor the input to their own level of proficiency by signaling their interlocutors about language they do not understand. This is essential since comprehensible input is thought to be a prerequisite for acquisition. Second language writers are likely to have more access to such tailored input in a tutoring session than in a class since the input is addressed uniquely to them. Negotiation may facilitate second language acquisition in at least three other ways. First, it can call attention to aspects of what is called positive evidence, that is, information about what is possible in the target language. Since it is widely believed that only input that comes into 
focal attention is likely to be acquired (Schmidt), this is a crucial function of negotiation. Learner participation in negotiated interaction can assist in the segmentation and analysis of input, and make specific, often problematic items in the input more noticeable. For instance, where problem areas emerge in negotiation, not just the meaning of the message but also its form may be brought into focus, pushing learners to pay more attention to those formal features. Second, negotiation can trigger the provision of precious negative evidence, or information about what is not possible in the target language, in the form of feedback from interlocutors. This process can help learners find out what they are doing wrong, either implicitly, when their interlocutors signal problems in comprehension, or more explicitly, through corrective feedback. Importantly, research suggests that learners are more likely to correct errors in their production when they are pushed to make their own contributions clearer (e.g., Lyster and Ranta; Pica, Holliday, Lewis, and Morganthaler). This opportunity for learners to shape their output toward comprehensibility and accuracy is a third advantage of negotiated interaction.

These findings may have important implications for second language writing, particularly in interactive settings such as the writing center conference. Thonus ("Tutors") has noted, during conferences, the presence of the interactional modifications thought to facilitate comprehension, such as confirmation requests (e.g., Did you say the first one?) and clarification requests (e.g., Where did you want to put in that example?), comprehension checks (e.g., See what I mean?), decomposition and segmentation (e.g., The thesis statement, shall we start with that?). These occur naturally during writing center sessions, but once tutors become aware of their importance, they can exploit them more effectively. In particular, they may be able to modify interaction in such a way that comprehension is enhanced. However, to be effective, it is essential that negotiation be two-sided, that not only the tutor, but also the writer engage in the interaction. Numerous second language acquisition studies have found that it is not simply the outcome of negotiation, that is, modified and presumably more comprehensible input, but the actual participation in the negotiation, that facilitates acquisition (see Long; Mackey, for reviews). Similar results can be found in second language writing research. Pathey-Chavez and Ferris found that active participants in student-teacher writing conferences made revisions that are more substantial in their drafts, and that they were able to appropriate and transform what was discussed in the session to create their own text. Weaker participants were inclined simply to transfer verbatim what the teacher said during the session into the revised draft. Conrad and Goldstein, in their study of writing conferences with second language writers, obtained similar results: that those students who participated in negotiation during conferences were more 
likely to make meaningful revisions in their drafts. Here, negotiation is understood somewhat more broadly than in the second language acquisition literature, in that it does not necessarily involve communicative breakdown. It simply means that the interlocutors may begin with different understandings and, through negotiation, arrive at a mutual one.

Several studies of peer interaction in the second language writer classroom have shown results similar to those of Pathey-Chavez and Ferris and Conrad and Goldstein: negotiated points in student texts are more likely to be incorporated into final revisions. Villamil and De Guerrero found this to be the case for $74 \%$ of the trouble sources revised during peer sessions (501). Mendonça and Johnson found a lower $(53 \%)$ but still substantial portion of peer-discussed revisions in final drafts (758). Suggestions that were not used were often explicitly rejected; in other words, the negotiation resulted in drafts that involved thoughtful and conscious choices regarding advice from their peers. In writing center research, a small-scale study has also shown the effectiveness of negotiation. In a comparative study of second language writer and native English writer sessions, Frank showed that the portions of student texts that were negotiated in the session were most likely to be revised in the final draft. This trend was consistent across second language writers and native English writers and focus of revision (i.e., whether it was a local problem, such as word choice or a more global issue, such as a major organizational revision). The lower proficiency speakers participated in the interaction with more difficulty, presumably because of their limited oral skills and tended to revise less. Interestingly though, Frank found that one lower proficiency student vigorously negotiated in the session, in spite of her modest language skills. That student's revisions were as substantial and effective as those of some of the native English writers who negotiated less. Frank concluded that second language writers could compensate for their lack of proficiency by actively negotiating meaning during sessions.

\section{A sociocultural approach to second language writers}

The significance of negotiation of meaning is supported by research in second language acquisition in general and in second language writer and native English writer classrooms in particular. It has been shown to be helpful in the acquisition of both language and academic literacy skills. However, some in the field of second language acquisition have criticized this approach, claiming that it focuses too much on the individual and that it fails to take into account the very important role of social context. Sociocultural theory sees interaction as a social process that can result in the joint construction of new knowl- 
edge (Vygotsky). Much of the work in this area is based on Vygotskyan views of first language learning and education, in which learners first depend on other-regulation, that is, the guidance of more skilled individuals, to perform new and difficult tasks. Dialogue is a way for the novice to stretch current knowledge, as initial reliance on the expert yields to internalization of new knowledge by the novice and subsequent self-regulation. This is most likely to occur in the learner's zone of proximal development, the domain in which the learner is not yet capable of self-regulated activity, but can accomplish tasks under the guidance of experts or in collaboration with a peer. The zone of proximal development is not simply a predetermined next stage of readiness. Rather, it is mutually constructed and can only be determined dialogically, suggesting that knowledge creation is a socially mediated activity. The role of talk is particularly important here because concept and knowledge construction is mediated by language; articulation makes the new knowledge available for inspection and discussion. This is a precursor to the internalization of knowledge, which can then become automatic. Swain concludes that "verbalization mediates the internalization of external activity (109);" in other words, talking helps build linguistic competence. Thus, in writing centers, the dialogue may not only help learners to become better writers, but may facilitate language learning as well.

A growing body of second language acquisition classroom research, has investigated the possibility of novices, or peers, assisting one another through the zone of proximal development toward the construction and internalization of new knowledge (Aljaafreh and Lantolf; Pathey-Chavez and Ferris; Di Camilla and Antón; Donato; Ohta; Storch; Swain). Research on second language writers within a sociocultural framework demonstrates that novice second language writers, working collaboratively within their zone of proximal development, can move beyond their current level of competence by jointly constructing new knowledge in collaboration with peers (Storch; Villamil and De Guerrero). The zone of proximal development in these studies refers to their development of academic literacy rather than linguistic knowledge.

It is important to stress here the role that sociocultural theory gives to other experts in the development of new knowledge by novices. In the writing center, again, the question arises as to whether it is more useful to consider tutors who work with second language writers as peers, or as relative experts, who can provide other-regulation while the second language writers continue to build and internalize new knowledge. Cumming and So investigated the relative effectiveness on second language writing of procedural facilitation (Bereiter and Scardamalia) and error correction during tutoring sessions. Like Thonus ("Dominance"), Cumming and So found that the specific ap- 
proach to tutoring had little effect on the participation levels of the second language writers, and that institutional roles overwhelmed any effect it might have had. This interaction is consistent with what Storch calls an expert-novice pattern, in which one interlocutor (the tutor) controls the flow of discourse, but there is moderate mutuality, that is, the expert actively encourages the participation of the novice. In prompting learners to adopt specific strategies, Cumming and So may have missed an important insight of sociocultural theory, that is, that effective feedback cannot be predetermined. The zone of proximal development emerges collaboratively and individually and is subject to constant change. Some learners may be almost ready for self-regulated activity, requiring only the most implicit guidance. Other learners may need far more-and more explicit-assistance and continued reliance on an expert for scaffolding of new knowledge. Scaffolding is the support provided by the expert that allows the learner to perform the new task. In the following excerpt of a writing center session, $\mathrm{O}$, the tutor, scaffolds the writer's (L) language and task in several ways. He recasts her incorrect utterances with target language accuracy $(2,8$, 14). He extends and elaborates her utterances $(4,6,16)$. He takes the lead in the interaction and points to places in her text that may need revision $(10,12)$. In the transcription, each [.] represents .5 seconds.

1. L: This paragraph it's about ... he discover his father ex perience.

2. O: $\mathrm{mmhm}$. The discovery of his experience, right?

3. L: His father life . in the past.

4. O: He finds out the truth about his father's past?

5. L: The truth about Japanese.

6. O: About Japanese-Americans?

7. L: uh huh . . being. It's about his father life.

8. O: $\mathrm{mmhm}$. His father's life.

9. L: . . um .. (writes). The father's life.

10. O: $\mathrm{mmhm}$. So what's next? . So all of this is about that one sentence?

11. L: $\mathrm{mmhm}$.

12. O: Kay. And this one is about?

13. L: Relationship between . father. Of his father and him self.

14. O: About his father and his father's father?

15. L: uh huh. So, it's .. well . his father treated him like . his grandfather treated his father .. so it's like.relationship?

16. O: $\mathrm{mmhm}$. Mkay. So, his father had a similar relationship with his own father?

(Williams, Transcript) 
Thus, it is not a question of being more or less directive for second language writers as a group; rather, it is a matter or providing the level of directedness that is appropriate for each learner. Aljaafreh and Lantolf offer two important principles for experts to follow in providing guidance to novices, both of which read like a writing center primer:

Intervention should be graduated and contingent. It should begin at a highly strategic, or implicit level and progressively become more specific, more concrete, until the appropriate level is reached as determined by the novice's response. [...]Second [...] it should be offered only when it is needed and withdrawn as soon as the novice shows signs of self-control and ability to function independently (468).

If this is indeed the ideal learning situation for second language writers, there can be no better place for this to take place than a writing center, where dialogue is at the heart of every session.

Second language acquisition theory and research can provide a useful perspective for tutors in the writing center. Tutors who are aware of the processes involved in the development of second language and second language writing competence can be more effective in their conferences. In particular, knowledge of the role of input, interaction, output, and interlocutor scaffolding can guide their work with second language writers. The writing center can also be an important site for research into second language learning processes and the development of second language writing (Severino, "Cross-Language"). It is a unique place where talk and writing come together, where interaction nearly always focuses on meaningful communication, and writers work on authentic academic tasks. Indeed, the importance placed on the role of interaction in second language learning suggests that the writing center may sometimes be an even better place for second language writers to learn than the classroom.

Note

1. This is a deliberate simplification and does not take into account connectionist views of second language learning (Ellis, 2002).

\section{Author's Acknowledgements}

This paper has greatly benefited from suggestions made by Vainis 
Alexsa, Patricia Harkin, David Shaafsma and several anonymous reviewers on earlier drafts.

\section{Works Cited}

Aljaafreh, Ali and James Lantolf. "Negative Feedback as Regulation and Second Language Learning in the Zone of Proximal Development." Modern Language Journal 78 (1994): 465-83.

Allaei, Sara and Ulla Connor. "Exploring the Dynamics of Cross-Cultural Collaboration "Writing Instructor 10 (1990): 19-28.

Bereiter, Carl and Marlene Scardamalia. The Psychology of Written Composition. Hillside, NJ: Erlbaum, 1987.

Boquet, Elizabeth. "'Our Little Secret:' A History of Writing Centers, Pre-to Post-Open Admissions." College Composition and Communication 50 (1999): 462-483.

Cahill, David. Contrastive Rhetoric, Orientalism, and the Chinese Second Language Writer. Diss. University of Illinois at Chicago. 1999. DAI 60 (1999) : 2901A.

Carson, Joan. "Second Language Writing and Second Language Acquisition." On Second Language Writing. Eds. Tony Silva and Paul Kei Matsuda. Mahwah, NJ: Erlbaum. 2001. 191-199.

Carter-Tod, Sheila. The Role of the Writing Center in the Writing Practices of L2 Students. Diss. Virginia Polytechnic Institute. 1995. DAI 56 (1995) : 4262A.

Coady, James. "L2 Acquisition through Extensive Reading." Second Language Vocabulary Acquisition. Eds. James Coady and Thomas Huckin. Cambridge: Cambridge University Press. 1997. 273-290.

Cogie, Jane, Kim Strain, and Sharon Lorinskas. "Avoiding the Proofreading Trap: The Value of Error Correction Strategies." Writing Center Journal 19 (1999): 19-39.

Connor, Ulla and Assevenage, Karen. "Peer Response Groups in ESL Writing Classes: How Much Impact on Revision?" Journal of Second Language Writing 3 (1994): 257-75.

Conrad, Susan, and Lynn Goldstein. "Student Input and Negotiation of Meaning in ESL Writing Conferences." TESOL Quarterly 24 (1990): 443-460.

Costello, Jacqueline. "'Because it is Suitable for Me:' Eliciting Support and Specificity in ESL Writing." Language Quarterly 28 (1990): 6874.

Cumming, Alister and Sufumi So. "Tutoring Second Language Text Revision: Does the Approach to Instruction and the Language of Communication Make a Difference?" Journal of Second Language Writing 5 (1996): 197-225.

Currie, Pat. "Staying out of Trouble: Apparent Plagiarism and Aca- 
demic Survival." Journal of Second Language Writing 7 (1998): 1-18. Deckert, Glenn. "Perspectives on Plagiarism from ESL Students in Hong Kong." Journal of Second Language Writing 2 (1993): 131-148.

DiCamilla, Frederick and Marta Antón. "Repetition in the Collaborative Discourse of L2 Learners." Canadian Modern Language Review 53 (1997): 609-33.

Donato, Richard. "Collective Scaffolding in Second Language Acquisition." Vygotskian Approaches to Second Language Research. Eds. James Lantolf and Gabrielle Appel. Norwood, NJ: Ablex, 1994. 3356.

Dyehouse, Jeremiah. "Peer Tutors and Institutional Authority." Working with Student Writers: Essays on Tutoring and Teaching. Eds. Leonard Podis and JoAnne Podis. New York: Peter Lang, 1999. 5358.

Ellis, Nick. "Frequency Effects in Language Processing: A Review with Implications for Theories of Implicit and Explicit Language Acquisition." Studies in Second Language Acquisition 24 (2002): 143-188.

Ferris, Dana. Treatment of Error in Second Language Student Writing. Mahwah, NJ: Erlbaum, 2002.

Frank. Lori. "Negotiating Meaning at the Writing Center." Paper. Annual TESOL Conference, Vancouver, British Columbia. (2000).

Friedlander, Alexander. "Meeting the Needs of Foreign Students in the Writing Center." Writing Centers: Theory and Administration. Ed. Gary Olson. Urbana IL: NCTE, 1984. 206-214.

Gadbow, Kate. "Foreign Students in the Writing Lab: Some Ethical and Practical Considerations." Writing Lab Newsletter 17 (1992): 1-5.

Gass, Susan. Input, Interaction and the Second Language Learner. Mahwah, NJ: Erlbaum, 1997.

Grabe, William and Frederica Stoller. "Reading and Vocabulary Development in a Second Language: A Case Study." Second Language Vocabulary Acquisition. Eds. James Coady and Thomas Huckin. Cambridge: Cambridge University Press, 1997. 98-122.

Grabe, William and Frederica Stoller. Teaching and Researching Reading. Harlow, UK: Addison Wesley, 2002.

Harklau, Linda, Kay Losey and Meryl Siegal. “Linguistically Diverse Students and College Writing: What is Equitable and Appropriate?" Generation 1.5 Meets College Composition. Eds. Linda Harklau, Kay Losey, and Meryl Siegal. Mahwah, NJ: Erlbaum, 1999. 1-14.

Harris, Muriel. "Cultural Conflicts in the Writing Center: Expectations and Assumptions of ESL Students." Writing in Multicultural Settings. Eds. Carol Severino, Juan Guerra, and Johnella Butler. New York: Modern Language Association, 1997. 220-233.

-. "Talking in the Middle: Why Writers Need Writing Tutors." College English 57 (1995): 29-42.

-. "Collaboration is not Collaboration is not Collaboration: Writing 
Center Tutorials vs. Peer Response Groups." College Composition and Communication 43 (1992): 369-383.

Harris, Muriel and Tony Silva. "Tutoring ESL students: Issues and Options." College Composition and Communication 44 (1993): 525-537. Hedgcock, John and Natalie Lefkowitz. "Collaborative Oral/Aural Revision in Foreign Language Writing Instruction." Journal of Second Language Writing 1 (1992): 255-76.

Kennedy, Barbara. "Non-Native Speakers as Students in First-Year Composition Classes with Native Speakers: Can Writing Tutors Help?" Writing Center Journal, 13 (1993): 27-38.

Kroll, Barbara. "The Rhetoric and Syntax Split: Designing a Curriculum for ESL Students." Journal of Basic Writing 9 (1990): 40-45.

Kubota, Ryuko. "Japanese Culture Constructed by Discourses: Implications for Applied Linguistics Research and ELT." TESOL Quarterly 33 (1999): 9-35.

Laufer, Batia. "The Lexical Plight in Second Language Reading: Words You Don't Know, Words You Think You Know, and Words You Can't Guess." Second Language Vocabulary Acquisition. Eds. James Coady and Thomas Huckin. Cambridge: Cambridge University Press, 1997. 20-34.

Leki, Ilona. Understanding ESL Writers. Portsmouth, NH: Boynton-Cook, 1992.

-. "Cross-Talk: ESL Issues and Contrastive Rhetoric." Writing in Multicultural Settings. Eds. Carol Severino, Juan Guerra, and Johnella Butler. New York: Modern Language Association, 1997. 234-244.

Liu, Jun and Jette Hansen. Peer Response in Second Language Writing Classrooms. Mahwah, NJ: Erlbaum, 2002.

Long, Michael. "The Role of the Linguistic Environment in Second Language Acquisition." Handbook of Research on Second Language Acquisition. Eds. William Ritchie and Tej Bhatia. New York: Academic Press, 1996. 413-468.

Lyster, Roy and Leila Ranta. "Corrective Feedback and Learner Uptake: Negotiation of Form in Communicative Classrooms." Studies in Second Language Acquisition 19 (1997): 37-66.

Mackey, Alison. "Input, Interaction and Second Language Development." Studies in Second Language Acquisition 21 (1999): 557-587.

Matalene, Carolyn. "Contrastive Rhetoric: An American Writing Teacher in China." College English 47 (1985): 789-808.

Matsuda, Paul Kei. "Situating ESL Writing in a Cross-Disciplinary Context." Written Communication 15 (1998): 99-121.

Mendonça, Cassía and Karen Johnson. "Peer Review Negotiations: Revision Activities and ESL Writing Instruction." TESOL Quarterly 28 (1994): 745-69.

Moser, Janet. "Crossed Currents: ESL Students and their Peer Tutors." Research and Teaching in Developmental Education 9 (1993): 37-43. 
Nation, I.S.P. and James Coady. "Vocabulary and Reading." Vocabulary and Language Teaching. Eds. Ronald Carter and Michael McCarthy. London: Longman, 1988. 97-110.

Nelson, Gayle and John Murphy. "Peer Response Groups: Do L2 Writers Use Peer Comments in Revising Their Drafts?" TESOL Quarterly 27 (1993): 135-41.

Ohta, A. Second Language Acquisition Processes in the Classroom. Mahwah, NJ: Erlbaum, 2001.

Parry, Kate. "Building a Vocabulary through Academic Reading." TESOL Quarterly 25 (1991): 629-653.

Pathey-Chavez, G.G., and Dana Ferris. "Writing Conferences and the Weaving of Multi-Voiced Texts in College Composition." Research in the Teaching of English, 31 (1997): 51-90.

Pica, Teresa. "Research on Negotiation: What Does it Reveal about Second Language Acquisition?" Language Learning 44 (1994): 493527.

Pica, Teresa, Lloyd Holliday, Nora Lewis, and Lynelle Morgenthaler. "Comprehensible Input as an Outcome of Linguistic Demands on the Learner." Studies in Second Language Acquisition 11 (1989): 6390.

Powers, Judith. "Rethinking Writing Center Conferencing Strategies for the ESL Writer." Writing Center Journal 13 (1993): 39-47.

Reid, Joy. "Which Non-Native Speaker? Differences between International Students and U.S. Resident Students." New Directions in Teaching \& Learning 7 (1997): 17-27.

Ronesi, Lynne. "Meeting in the Writing Center: The Field of ESL." TESLEJ1.3 (1995).

Schmidt, Richard. "Attention." Cognition and Second Language Instruction. Ed. Peter Robinson. Cambridge: Cambridge University Press, 2001. 3-32.

Silva, Tony, Ilona Leki and Joan Carson. "Broadening the Perspective of Mainstream Composition Studies." Written Communication 14 (1997): 398-428.

Severino, Carol. "The Writing Center as a Site for Cross-Language Research." Writing Center Journal 15 (1994): 51-61.

Severino, Carol. "The 'Doodles' in Context: Qualifying Claims about Contrastive Rhetoric." Writing Center Journal, 14 (1993): 44-61.

Spack, Ruth. "The Acquisition of Academic Literacy in a Second Language." Written Communication 14 (1997): 3-62.

Spack, Ruth. "The Rhetorical Construction of Multilingual Students." TESOL Quarterly 31 (1997): 765-774.

-. "Student Meets Text, Text Meets Student: Finding a Way into Academic Discourse." Reading in the Composition Classroom. Eds. Joan Carson and Ilona Leki. Boston: Heinle, 1993. 183-196.

Storch, Neomy. "Patterns of Interaction in ESL Pair Work." Language Learning 52 (2002): 119-158. 
Swain, Merrill. "The Output Hypothesis and Beyond: Mediating Acquisition through Collaborative Dialogue." Sociocultural Theory and Second Language Learning. Ed. James Lantolf. Oxford: Oxford University Press, 2001. 97-114.

Tassoni, John. "The Liberatory Composition Teacher's Obligation to Writing Centers at Two-Year Colleges." Teaching English in the TwoYear College 25 (1998): 34-43.

Thonus, Therese. "Tutors as Teachers: Assisting ESL/EFL Students in the Writing Center." Writing Center Journal 13 (1993): 102-114.

-. "NS-NNS Interaction in Academic Writing Tutorials: Discourse Analysis and its Interpretations." Annual Meeting of the American Association of Applied Linguistics. Stamford, CT., 1999.

-. "Dominance in Academic Writing Tutorials: Gender, Language Proficiency and the Offering of Suggestions." Discourse and Society 10 (1999): 225-248.

Villamil, Olga and María De Guerrero. "Assessing the Impact of Peer Revision on L2 Writing." Applied Linguistics 19 (1998): 491-514.

Vygotsky, Lev. Thought and Language. Cambridge, MA: MIT Press, 1986.

Williams, Jessica. "ESL Composition Program Administration in the United States." Journal of Second Language Writing 4 (1995): 157179.

-. Transcript of tutor-writer interaction. Unpublished raw data. 2000.

-. "Writing Center Interaction: Institutional Discourse and the Role of Peer Tutors." Institutional Talk and Interlanguage Pragmatics Research. Eds. Kathleen Bardovi-Harlig and Beverly Hartford. Unpublished manuscript.

Williams, Jessica and Jacqueline Evans. "How Useful are Handbooks for Second language writers?" Writing Program Administration 10 (2001): 59-75.

Young, Virginia. Politeness Phenomena in the University Writing Conference. Diss. University of Illinois at Chicago, 1992. DAI53 (1992) : 42236A.

Zamel, Vivian. "Strangers in Academia: The Experiences of Faculty and ESL Students across the Curriculum." College Composition and Communication 46 (1995): 506-521.

Zeichmeister, Eugene, Catherine D'Ana, James Hall, Cynthia Paus, and Julie Smith. "Metacognitive and Other Knowledge about the Mental Lexicon: Do We Know How Many Words We Know? "Applied Linguistics 14 (1993): 188-206. 


\section{David Miller}

\section{DEVELOPMENTAL WRITING: TRUST, CHALLENGE, AND CRITICAL THINKING}

ABSTRACT: This article explores the idea that basic writing students, when positioned in a classroom setting where safety and trust are paramount, will be willing to take risks that, when successful, will lead them into a more positive relationship with their own writing abilities. Success in writing leads to a more open-minded approach wherein they are willing to accept the challenges brought on by the struggle to become critical thinkers capable of functioning effectively in the academy.

In any case - and this is why formal logic always failed in the composition classroom - "thinking skills" must not be taught as a set of abstract exercises (which, of course, they will be if they are not conceived of as being part of writing), but must be intimately connected to composition instruction. Otherwise students hear one more lecture on isolated mental arabesques. (Rose, "Remedial Writing Courses: A Critique and a Proposal" 113)

Mike Rose's concept of "mental arabesques" is particularly intriguing. When my two daughters were learning basic ballet positions, they both found the arabesque an extremely difficult position to master. This complex move requires acute balance as well as mental and physical control of the torso, head, and all four limbs. The mind must also control all of the muscles that make all the various body parts move into and hold the position, sometimes for a protracted length of time. Furthermore, the body must execute the various commands sent by the mind. Their dance instructors introduced this position very early - in the basic stages of the learning process - but not before other basic moves and positions were introduced. The arabesque continues to be a difficult move for both, but practice and maturity have made it not as daunting as it once was. The most important aspect of teaching the arabesque was that it was part of an integrated approach including familiarity, practice, and application.

David Miller is an adjunct professor of Developmental Writing at Tomball College, a part of the North Harris Montgomery Community College District, located in the Greater Houston area. 
Like teaching the arabesque to beginning students of ballet, teaching critical thinking skills to developmental writers should begin at the earliest stages of instruction and should continue throughout all phases of writing instruction. But is it necessary to actually address and teach skills as though they were addition facts or events in an historical sequence, or are critical thinking skills and strategies part of the things students do every day? Are they not merely extensions and abstractions of cognitive and metacognitive functions that permeate our lives? If this is the case, then students already know how to think critically. It could be that they are fully capable of employing metacognition when they truly do not even realize it. If so, our task as teachers of developmental writing is more one of making students aware that they have these skills and showing them how to employ them in the study of writing.

In his textbook/workbook Becoming a Critical Thinker, Vincent Ruggiero draws an interesting distinction between two methods of thinking: "the production of ideas (creative thinking) [that is] accomplished by widening your focus and looking at many possibilities," and "the evaluation of ideas (critical thinking) [that is] accomplished by narrowing your focus, sorting out the ideas you' ve generated, and identifying the almost reasonable ones." He goes on to assert that "both processes are natural activities for human beings" (3). If both of these practices are natural activities, why, then, do so many developmental students find it difficult to think either creatively or critically? I must contend that most of these students are fully capable of thinking at a critical level. However, in many cases, I feel that they are not fully aware of the fact that they are able to think this way; furthermore, they do not understand how they can get from the superficial state in which we most often function to the metacognitive state they must acquire to function in the academy. We tell them all the time that they need to "think critically." What we often fail to do is show them how.

\section{Critical Thinking}

The concept of teaching critical thinking through writing across the board to a broad spectrum of the student body, especially those students who find themselves marginalized before they even begin their academic careers, is a daunting, yet essential, task. In "Teaching Critical Thinking in First-Year Composition: Sometimes More is More," Ruth Stewart states that "the teaching of critical thinking in composition needs a paradigm that more accurately reflects the demands of college and career" (170). From placement scores alone, it would appear that many students actually conform to the parameters of the humanistic "Great Cognitive Divide" theory, and early in-class essay 
assessments would corroborate this possibility. Many find it difficult to write more than a few simple, unconnected sentences when asked to write an essay that discusses, for instance, their reasons for deciding to attend college. As a rule, their verbal skills are excellent in both spoken English and in the vernacular that best suits their cultural background. This evidence would lead some to believe that these developmental students are functioning primarily on a verbal level, what Patricia Bizzell calls "parataxis" ("Arguing About Literacy" 240). However, a companion assessment that requires students to identify various components and strategies within a written text yields very different results.

Most students easily identify introduction, body, conclusion, thesis statement and a host of other components. They are also able to pick out rhetorical strategies buried within the text and can find the resolution to the problem posed by the thesis. This presents an interesting dilemma: Why are they familiar with all the parts of an essay yet unable to write one? Why are they able to make connections regarding abstract concepts with someone else's text, yet unable to create their own text, even with a model right before their eyes? (The essay they must dissect for parts is entitled "The Essay" - a short piece that explains the necessity of knowing how to write essays for college classes.) In this respect, they do appear to embrace what Bizzell refers to as "hypotaxis, the subordination of one idea to another in a logical hierarchy" and "generalizations that appeal to reason and text-assisted memory for validation" (241). The third criterion Bizzell notes, "a dialectical relation to authority, encouraging the ongoing, disinterested criticism of ideas" (241), is addressed indirectly through the writing sample with which so many students have problems. They do not appear to be able to synthesize, to put "together the parts ... analyzed with other information to create something original" (Reichenbach 25). In the case of developmental writing students, the "other information" Reichenbach refers to would most often be personal experience. I have found that developmental writing students, in general, often question the validity of their personal experience and find it difficult to accept that it is as valid as anyone else's first-hand experience - in short, they do not trust the knowledge they already possess. This phenomenon leads me to conclude that many developmental students are orally and alphabetically literate (and in the case of the latter, literate in both the vernacular and in Standard English); however, they lack the skills needed to synthesize the information they readily have at hand into new information. If they can not synthesize the information, they are left with scattered bits of data and concepts they have gleaned from their reading and nothing to which they can relate any of it.

What does it mean, then, to be a critically thinking human being? Lauren B. Resnick of the National Research Council outlines higher 
order thinking and states that "we can recognize [it] when it occurs" (3). Critical thinking

(1) is nonalgorithmic. That is the path of action is not fully specified in advance.

(2) tends to be complex. The total path is not "visible" (mentally speaking) from any single vantage point.

(3) often yields multiple solutions...rather than unique solutions.

(4) involves nuanced judgement and interpretation.

(5) involves the application of multiple criteria, which sometimes conflict with one another.

(6) often involves uncertainty. Not everything that bears on the task at hand is known.

(7) involves self-regulation of the thinking process. We do not recognize higher order thinking in an individual when someone else "calls the plays" at every step.

(8) involves imposing meaning, finding structure in apparent disorder.

(9) is effortful. There is considerable mental work involved in the kind of elaborations and judgements required. (3)

For academics, these criteria make complete sense and are easily applied to almost any field of study. But to a developmental student, they mean little more than a wild goose chase combined with a snipe hunt followed by a fishing expedition in uncharted waters. Students need guidance and in-depth explanation of these processes as much as they need guidance with rhetorical strategies. But perhaps what they need more is the assurance that they will not develop any new, or reopen any existing "writing scars." I have found and will discuss throughout this paper a number of very practical ways to engage students in the critical thinking process.

One of the best practical definitions of critical thinking, addressed directly to students, comes from The Little, Brown Handbook:

Throughout college and beyond, you will be expected to think, read, and write critically. Critical here means "skeptical," "exacting," "creative." When you operate critically, you ques- 
tion, test, and build on what others say and what you yourself think. The word critical does not mean "negative" in this context. It comes from Greek words meaning "to separate" and "to discern" [...]. (118)

Students become intimately involved with this definition because it is introduced during the first week of the course and referenced repeatedly throughout the semester. For practical application and understanding of the term "criticism," early in the semester, we look at film, book, and restaurant reviews to show that being "critical" has positive, negative, and ambivalent aspects that are all based in personal reaction to external stimuli.

\section{Safety, Trust, and Application}

The relationship that beginning students of dance have with their instructors is one of implied trust, a trust that allows them to take risks and attempt difficult moves such as the arabesque. Similarly, the "mental arabesques" writing teachers ask developmental writers to perform can not be accomplished if students do not trust themselves or their instructors. Developmental writing students are a diverse lot, but one thing they all have in common is that they are told they must enroll in developmental writing because their placement scores indicate that they are writing below college level. Many have failed past English courses; many blatantly state that they "can't write." Overall, they feel frustration based on previous negative experiences with writing. Stewart's experience shows her that it is important that students "know their frustration is a shared experience" (167). A few are confident, even cocky, but this demeanor almost always proves to be merely false bravado. Most are afraid. Some are terrified. Some make no sounds or movements until mid-term. Most will not trust me until then, but building trust and retaining it is crucial to their success: they can not progress until they feel safe enough to take risks. And they will not take risks until they feel assured that I will not hurt them. Citing the work of Maxine Hairston (1997), Anmarie Eves-Bowden creates a "lowrisk, student-centered classroom where the emphasis is on communicating in writing" (74). In an effort to establish trust and foster risktaking, the in-class assessment my students take the first week of class receives no grade; it merely tells me where I need to start. Early semester writing assignments receive little weight, if any, toward the final grade. In short, they soon know that in their developmental writing class, recursive process is more important than initial product, and not only will they learn how to write an essay, they will also learn to think critically about what they are writing and what they are trying to say. 
Developing an environment of trust within the confines of the writing classroom is pivotal when dealing with developmental students. Many have been "burned" in the past; all can relate stories that indicate failure leading to alienation from, or abject fear of, "putting pencil to paper." Indeed, some have such an aversion to writing that they initially refuse to take even the most elemental notes. The semester begins with an introduction to the course followed by an ungraded assessment that the students never see again. The next two assignments, a short narrative piece and a short descriptive piece, are intended not only to allay student fears about writing but also to help me continue to assess the overall tenor of the class' strengths and weaknesses. Marilyn B. DeMario states that she is "markedly inattentive to errors in student papers in the first part of the term" ("Teaching the Course" 97). David Bartholomae agrees with DeMario when he states that "cover[ing] their papers with red circles would be a betrayal of this trust, and yet it would be irresponsible to act as though error didn't matter" ("Teaching Basic Writing"). I, too, feel that too much attention paid to grammatical structures found in early student writings is counterproductive to the process. Certainly, many of these papers are rife with error, but drafts that are covered in editing marks merely reinforce the cycle of failure that many developmental students have faced for years. It is my opinion, then, that students need to feel a modicum of success in one area before they can begin to address additional problems. First drafts and early revisions receive only comments, no grades. Comments are limited to critical questions intended to make students reflect on what they have written and what they could do to make their meaning more clear. Little attention is paid to grammatical structures during this procedure other than general comments that indicate to students that grammatical errors exist that will need attention in the future. The class knows they will have the entire semester to work on revising these pieces. It is not until the revisions begin to show significant improvement that grades are assigned.

To some, this is an entirely new concept. Students begin to ask questions about the comments they receive, essentially asking for clarification, a basic step toward philosophical inquiry and a first tentative step in critically thinking about what they have written and what they are trying to say. This questioning leads to additional revisions through which students typically become more analytical toward content and style. They begin to question their own motivations and the conclusions they are attempting to draw.

Developmental students are not stupid; however, they may carry around this perception from years of failure. It is imperative to dispel this myth in the earliest stages of the semester. In a lengthy discussion regarding the "inherent knowledge" that students bring to the classroom, Gregory Shafer, president of the Michigan Council of Teachers 
of English, cites numerous sources that substantiate "the amazing skill that students bring to class. Rather than being the deficient, developmental students that seem forever to be missing basic skills, writers [...] are competent and linguistically sophisticated when they enter our classrooms" (8-9). The problem then becomes one of convincing students that they are capable of success regardless of past failures. During a class discussion over the characteristics of description, the concepts of denotation and connotation always arise. We select almost any noun, for instance, "dog," and it is written on the board. We define it using a dictionary and determine that this is the denotative quality of the noun. I then ask students to tell me what the noun makes them think about and their responses comprise a lengthy list of words and phrases under the heading connotation. We discuss the practical uses of connotation and denotation as they would apply to students' writing and orally construct some highly descriptive, and often very humorous, sentences using the words and phrases on the board, comparing them to a strictly denotative sentence about the chosen noun. (The exercise can also be a wonderful springboard to a discussion of generality and specificity.)

These tasks accomplished, we move into a slightly different realm, still using the materials on the board. The denotative definition becomes the "form." The connotations are the individual perceptions and variations created by the form. Students are surprised to realize that they have the inherent ability to think like Plato-what effect this type of revelation might have on a student's overall academic performance may indeed be negligible, but in class, the resultant boost in self esteem is palpable. ${ }^{1}$ To know that they are able to think like one of the world's greatest thinkers empowers them to progress despite past failures. In short, it may be possible that no one has ever patted them on the back or given them an "attaboy." Developing an environment where students feel confident in their abilities leads to a sense of trust that allows them to take those risks they have been hesitant to take in the past.

\section{Challenge and Application}

Even if developmental writing students are unsure of themselves, keeping them too "safe" can also be counterproductive, just as teaching only the safest ballet positions would be counterproductive to an aspiring dancer. Stewart states that "[...] research in educational psychology suggests that struggle is integral to higher-level learning" (167). In describing his Basic Reading and Writing course, David Bartholomae states the importance of introducing longer, more involved texts into the curriculum: "[We] felt in designing the course, that our concern 
should be with acts of comprehension beyond the sentence or the paragraph, and our bias towards larger units of discourse was justified by later findings from the research we did on the course" (97). Stewart agrees: "Much can be gained by challenging students with material assumed to be 'too difficult' for them. ...And as a result, they develop analytical skills at a level that comes from doing academic work as opposed to being prepared to do academic work" (162). Shafer concurs in his outline of curriculum revision: "[...] it seems more natural to pose problems, which induce critical thinking and original approaches to composition" (14).

My students are challenged from the outset with a difficult text that we work through over the course of the semester - one that lends itself to a multitude of activities that enhance their ability to critically assess this and other texts they will encounter. Early in the semester, students read chapter three of Annie Dillard's The Writing Life. Dealing with the problems even the professional writer encounters in developing a text, this selection is far from academic in structure; however, its surface meaning is clear: writing, in any form, is extremely difficult and the demands placed on the writer can often be very disconcerting. But acknowledging as much can help to relieve some of the pressure. Bartholomae notes that "it is liberating to hear others [...]talk about how sloppy the process is, or about ways others have dealt with the anxiety and chaos that so often accompany writing" (88). Students must keep notes while reading this piece and must write at least a paragraph about what they understand the purpose of the chapter to be. Over the course of the semester, the class often returns to relevant sections of the chapter (narrative, descriptive, comparative, causal, and argumentative) to delve more deeply into the writer's motivations and results. Students try to determine why Dillard uses some of the tactics she does and what effects these tactics have on the conclusions she draws. Students locate and identify the strategies she uses to develop her ideas. Through this inquiry, it becomes obvious that Dillard spends much more of her time thinking about development of ideas, purpose, audience, organization, style, and revision than she spends actually writing. Not only does this show students the importance of process, it also forces them to be more aware, and more critical, of their own writing processes. A simple exercise in analyzing process becomes a catalyst for understanding objectivity.

One feature of our developmental writing requirement is that students must fulfill a weekly lab requirement; fortunately, the form these labs must take is left to the discretion of the instructor. I have chosen to structure my labs around the Dillard selection and other writings that I vary from time to time. ${ }^{2}$ Labs involve topics as varied as vocabulary development, identification and decoding of simile and metaphor, interpreting implicit meaning, and finding the connections 
between the extended metaphors. Students are also asked to develop a profile of the writer after reading the text and a short biographical sketch - conjecture is welcomed, always with varied and often humorous results. Students come to understand that often there are no right or wrong answers and that contradiction and paradox are integral parts of academics, an observation made by Bartholomae: "Ambiguity, contradiction, uncertainty - those qualities that are most attractive to academics - are simply 'wrong' in the minds of students whose primary goal is to produce controlled and safe essays" (92).

Finding ways to make sense of what does not initially appear to make sense is crucial to understanding an author's intent, but it requires effortful, complex thought that often leads to further uncertainty and multiple solutions. It requires creating new meaning from disorder. Students need to know that from the ambiguities and uncertainties come the most fertile ground for expressing their opinions through academic argument. I write the word "WHY?" in huge letters on the board every day. It sometimes takes two weeks for someone to ask what it means, but when someone does, the real work soon starts. It becomes the operative word - the word that will lead them past the literal and into the realm of academia as critical thinkers.

In an effort to show students the importance of implicit meaning in their writing, they are required to critically analyze their own early writings. The non-confrontational narrative and descriptive essays, initially intended as safe, trust-building activities, become the catalyst for reflection and initial steps into the realm of critical thought. From these two "safe" essays, a comparative analysis of both writings soon evolves. To most developmental students, this concept is completely foreign (certainly a mental arabesque) and many are openly mystified; therefore, most of the early part of this process is completed in class.

We begin by covering the theoretical material and examples in the textbook and reading ancillaries such as Mark Twain's "Two Views of the Mississippi." I point out the relative futility in comparing two things simply to compare them, and draw their attention especially to the numerous conclusions we can draw from an analysis of Twain's writing. Comparing for the sake of comparison becomes another exercise in descriptive strategy, something we have already done. The purpose here is to elicit a critical, third-person response to earlier texts, much like the analyses they will have to perform in freshman composition. But in this scenario, there is safety as well as challenge. Since they are intimately involved with the writer, there is safety in that everything they need to know about the writer they already know - biography, preferences, cultural background, socio-economic background-making research into the author unnecessary to understand the writer's motivation. The challenge is to analyze the material and draw conclusions about a singular aspect of the writing - to create new 
meaning from the two texts. Bringing these two concepts together in order to draw relevant conclusions about the writing itself carries with it the potential to open pathways of thought that for some, have never been traveled.

In class, students first write synopses of both papers. (This forces some students to scramble and quickly write one or both of the required essays.) From the synopses, they look for commonality, contradiction, paradox, similarities in point of view, subject matter, voice, or any of a host of other possibilities. They assume the role of an objective, third-person critic whose task it is to formulate an opinion about the writings. During this entire process, I circulate, working individually with students, answering questions and generally guiding the composition. They are encouraged to work in pairs or small groups to get feedback from their peers. Perhaps more importantly, I ask probing, open-ended questions intended to make students consider all aspects of what they have previously written. It is from these probing questions that opinions begin to develop, opinions that become pointed arguments developed out of the materials students have at hand. Whether the opinion is that the grammar needs revision in both papers, or that the writer used similar tactics in both papers, or that the writer treasures family values, the important point is that the student has thoroughly analyzed two pieces of writing and through a process including reflection, inference, and synthesis, has successfully formed an opinion that has led to an arguable conclusion about the two pieces of writing in question.

Many students have expressed surprise and elation at what they have been able to accomplish. It has required guidance, patience, and in-depth thought. As they go through this process, they become aware of the concept that they are thinking about what they have already written as they would any given text, taking into consideration all the known facts and forming opinions regarding what they know and what they have deduced. Many feel that, for the first time, they have been able to accomplish something through writing. This further success provides them with the assurance that they can take risks and that they can be successful.

Another successful strategy is to have students write a journal entry for each class day. A portion of the entry must reflect class procedure for that day; a portion must attempt to assess the impact the class session had on the student's understanding of academic writing; and a portion may voice opinions or questions raised during reflection. Sometimes there are no questions, but more often, students who diligently follow this process openly or privately seek clarification, actively opening a dialogue that helps to further clarify a concept or strategy. These class discussions sometimes wreak havoc on class schedules, so it is imperative to be flexible. The most important aspect of this process is reflection leading to dialogue. 
Students are often unaware that they already think critically in most situations, but that often the thinking happens so fast that they do not even realize it. I ask if they have ever been in a situation that required an immediate defensive driving maneuver and ask what their reaction was. The immediate answer is that they swore, swerved, and/ or applied the brakes heavily. I point out that this type of thinking, however immediate, is a process of recognizing a problem, determining a logical course of action, and employing a strategy that suits the situation, hopefully arriving at a solution that avoids serious damage, and without certainty that the solution will work. Expressed in this manner, such everyday problem-solving helps students start to see the metacognitive possibilities they already possess; the task then becomes harnessing and slowing down the thought process so students are aware of it. On a similar note, we discuss commercials, coming to the same conclusion: we employ our critical thinking skills at all times, even if we do not realize we are doing so.

In an effort to heighten awareness of external stimuli, to discern meaning and to learn descriptive strategy, students watch a short video entitled "It's in Every One of Us." This video is a series of still photographs with musical accompaniment. There is no action nor is there dialogue, but the multi-faceted argument is very evident. Musically and visually, the video follows a fugue pattern, regularly adding instrumentation to the sound track and adding different people and groups as it progresses. The faces portrayed are multi-cultural and the settings are obviously shot at various locations around the world. After watching the video one time, I ask students to give me their impressions. Initial responses are "people, faces, groups, smiles, frowns" and the like - only the superficial visual aspects. They then watch it a second time after I have asked them to use all their senses, hinting that there are patterns that evolve in both the visual and audio portions. Reactions become more concise. They notice more nuance, such as emotions and background settings, but the patterns still elude them. It is not until the third viewing that students begin to notice the patterns: one voice, one instrument, one person; two voices, two instruments, two people; several voices, several instruments, groups of people. They quickly come to understand that watching the video more than once is analogous to reading a text more than once. When asked what the video means, most will agree on an overall meaning, but as we discuss and brainstorm further, even deeper meaning becomes evident. The result is that students realize that the deeper they probe into a text, the more meaning they will be able to create from it. 


\section{Conclusions}

Performing the arabesque, a complex, mentally and physically challenging maneuver, can become simple with practice-so simple that, perhaps, it is no longer an acquired skill. It becomes second nature, something one performs without hesitation. Like the arabesque, critical thinking can become second nature, as Rose has stated, a mental arabesque. Ruggerio says that it is a "natural activity" achieved by narrowing the focus. But many, perhaps most, developmental writers have been "under-exposed" to ways of thinking beyond the literal, surface level meaning of a text. I "over-expose" students in the sense that instruction in writing and instruction in critical thinking can not be separated in most instances. Certainly, they learn how, when, and where to apply any of the various rhetorical strategies we study, but this is not enough. They learn to habitually ask and attempt to answer the question "why?" regarding all aspects of writing. I do not expect that they will all exit the program as philosophers, but they will be much better equipped to face their impending challenges than they were when they arrived. In "What Happens When Basic Writers Come to College," Bizzell states that there are three approaches to understanding basic writers in college: recognizing "differences in dialects, discourse conventions, and ways of thinking" (167). I fully agree that the dialects and discourse conventions normally attributed to developmental writers differ radically from those found in academia. However, different ways of thinking, especially ways of thinking about thinking, are more a result of under-exposure in earlier grades rather than of "cognitive dysfunctions" or of an inattention to "the cultural bases of differences in thinking" (Bizzell 167). Although developmental writers initially struggle to master critical thinking, once they are aware of its possibilities, they are, with practice and guidance, willing to accept new and different ways of thinking and are fully capable of functioning at or near (and in some cases, above) a level that will allow them to compete with their academic peers. I have found that overexposing students to situations that force them to think critically about their own texts, and those of others, tends to make critical thinking a more natural process, one that can be accessed at any time.

What, then, do safety and challenge have to do with becoming more adept at thinking critically? Feeling secure in an unfamiliar environment is a notion everyone would prefer in all situations. Being challenged is what often forces us to progress. But the challenge is easier faced knowing that there is a safety net in place, one that will cushion the fall. Moving into the realm of critical thinking is a risk that many developmental students would prefer to avoid. Previous situations have often allowed them to fall into the safety net of "touchyfeely" writing that will not support them in the academy. Mike Rose 
has said that "error marks the place where education begins" (Rose, Lives on the Boundary 189), and developmental students are going to make numerous errors, despite the best intentions of their instructors. They must believe that the errors they make are not going to elicit the types of failures they have previously encountered. Learning to become a critical thinker is a challenge that will beget error, but avoiding the pain usually associated with error is paramount.

There are numerous tactical devices that can elicit critical thought in developmental writers. Exposure, perhaps over-exposure, is the key. Experience has taught me that merely telling developmental students to think critically about what they read and write is a waste of time. Showing them that they already have the inherent ability to think critically and explaining how the process can work for them may be time-consuming, but it can be combined with regular classroom instruction in academic writing to give them that critical edge they need to succeed in their future endeavors. We can, indeed, teach them to perform those "mental arabesques" that have been too risky to try in the past.

\section{Notes}

1. Plato and dialectic are discussed at various times during the semester. We also discuss a simplified version of Hegelian dialectic, and Descarte's cogito is discussed when we look at proper application and punctuation of the conjunctive adverb.

2. Other selections have included the introduction to Tom Brokaw's book, The Greatest Generation, and a comparison of the text and film versions of Katherine Anne Porter's "The Jilting of Granny Weatherall." I am currently developing additional selections to use in the future.

\section{Works Cited}

Bartholomae, David. "Teaching Basic Writing: An Alternative to Basic Skills." A Sourcebook for Basic Writing Teachers. Ed. Theresa Enos. New York: McGraw-Hill, 1987, 84-103.

Bizzell, Patricia. "Arguing About Literacy." Academic Discourse and Critical Consciousness. Pittsburgh: U Pittsburgh P, 1992, 238-255.

-. "When Basic Writers Come to College." AcademicDiscourse, 164-174. DeMario, Marilyn B. "Teaching the Course." Facts, Artifacts and Counterfacts. David Bartholomae and Anthony Petrosky. Pourtsmouth: Boynton/Cook Publishers, 1986. 87-102. 
Dillard, Annie. The Writing Life. New York: HarperCollins Publ., 1989. Eves-Bowden, Anmarie. "What Basic Writers Think About Writing." Journal of Basic Writing 20:2 (2001): 71-87.

Fowler, H. Ramsey, and Jane E. Aaron, et. al. The Little, Brown Handbook. New York: Addison-Wesley, 2001.

Krutein, Wernher, and David Pomeranz. "It's in Every One of Us." San Francisco: New Era Media, 1987.

Resnick, Lauren B. Education and Learning to Think. Washington: National Academy Press, 1987.

Reichenbach, Bruce R. Introduction to Critical Thinking. Boston: McGraw Hill, 2001.

Rose, Mike. Lives on the Boundary. New York: Penguin, 1990.

-. "Remedial Writing Courses: A Critique and a Proposal." $A$ Sourcebook, 104-124.

Shafer, Gregory. "The Process of Change in a Community College Writing Program." Teaching English in the Two-Year College 29 (2001): 7-15.

Stewart, Ruth. "Teaching Critical Thinking in First-year Composition: Sometimes More Is More." Teaching English in the Two-Year College. 29 (2001): 162-71. 


\section{George Otte}

\section{HIGH SCHOOLS AS CRUCIBLES OF COLLEGE PREP: WHAT MORE DO WE NEED TO KNOW?}

ABSTRACT: $A$ departing co-editor's thoughts turn to one thing in particular: the increasing pressure exerted on high schools to ensure adequate preparation for college (and thereby eliminate the need for remediation), pressure exerted above all in the form of state-mandated tests. Hopes of coping with such pressure rest on understanding whence it comes, but also on collaborative ventures between colleges and high schools that are true partnerships, transcending a fixation on state mandates and quick fixes.

I'm leaving as co-editor of $J B W$ just one volume year after Trudy Smoke left. Trudy's valedictory was an impressive review of the journal's publication history during her tenure as co-editor. Starting not long after Trudy (we worked together for a full half decade), I see little point in doing the same sort of retrospective. We would be covering the same ground. It occurred to me instead to say something about what editors often think about: the kinds of submissions they wish they would get but don't. That too seemed a chastening prospect, partly because it might degenerate into an idiosyncratic wish list, partly because the best intentions could hardly transcend a combination of blindness to absences and a reluctance to note them.

But for a few years now one issue has loomed ever larger for me as a research question - actually, a whole nexus of research questions (one whose answers, moreover, outline an agenda for action). This issue scarcely seems to register on our radar. We fail to give it significant attention even as the forces behind it significantly reshape the educational landscape-our topography in particular. And so, as I leave JBW, I would like at least to draw a crude map of that relatively uncharted territory.

My initial demarcation of it is my title. The question in it can be

Formerly a writing program administrator at Baruch College (from 1986-1998), George Otte has been co-editor of JBW since the Fall 1996 issue. He is currently Director of Instructional Technology for the City University of New York (CUNY) and is also a member of the doctoral faculty at the CUNY Graduate Center (in the Ph.D. Programs in English, Urban Education, and Technology \& Pedagogy). From 1998-2000, he was Baruch's Executive Director of Enrichment Programs, which included presiding over high school outreach programs (even teaching in a high school for a term). And since 1998, he has served as co-director of Looking Both Ways, a project bringing college and high school teachers together to discuss issues of literacy and learning. 
read in different ways: dismissively (as if, hey, facts are facts, and we need to get on with the work staring us in the face); desperately (as if to set off alarms about a state of crisis and confusion); earnestly (as if there are important questions to be asked, questions we need answers to if we are to serve our students well). You probably have guessed what is in fact the case: I' $m$ inclined to ask that question in earnest. But I won't be coy and act as if I haven't arrived at some answers as well. One is implicit in my title: attention to the academic readiness and success of students is shifting from a variety of experiments and experiences with open admissions in colleges and universities to growing pressure on the high schools. Increasingly, high schools are becoming the crucibles of college prep.

Why is this so, and to what extent? Let me start with the question of extent. The single most obvious fact about the relationship between high school and college is that many more high school students are college-bound than ever before. Fewer than half of all the students who completed high school went on to college as recently as the seventies. In the quarter century from 1972 to 1997, the United States went from having fewer than half of its high school graduates going on to college to having more than two thirds. ${ }^{1}$ This dramatic shift in expectations over the last several decades - that many more high school students are supposed to go on to college (that, in fact, the success of high schools is measured by what proportion they send on) - has occurred without a corresponding shift in resources given to high schools, in the status or rewards accorded high school teachers and administrators. If we reap what we sow, we must realize we're plowing and planting the same field yet expecting a much bigger and better crop. To a remarkable degree, the high schools have been meeting that expectation. But now it's crunch time.

How did we get to this pass? The answer is mostly basic economics. As we tell our kids all the time (whether as parents or teachers), the earning power of a college degree is considerably higher for a college grad than a high school grad - in fact, nearly $\$ 20,000$ a year higher. In 1999 (the last year for which figures are provided in the most recent Digest of Educational Statistics), the median annual income of male high school graduates working full-time year round was $\$ 33,184$, while it was $\$ 52,985$ for those with a bachelor's degree. For female full-time workers (the glass ceiling still being what it is), the average 1999 median annual income was $\$ 23,061$ for high school graduates, $\$ 37,993$ for those with a bachelor's degree. ${ }^{2}$

We all have some sense of why this is happening: in a more technologically advanced society and information-based economy, a college degree is increasingly important as a ticket to (or a voucher to remain in) the middle class. In this post-industrial economy, a college education does not promise upward mobility so much as economic 
stability and security. The increasing democratization of higher education that started with the GI Bill after World War II and gathered still greater momentum with the reforms of the seventies (reforms that had so much to do with shaping Basic Writing) has created a society that sees college education more as a requirement than an option, more as a right than a privilege. Students have for some time been voting with their feet. As I said-as we know-more and more of them are going to college.

So we need to look at the college end. And what's happening there is just what you would expect: we have many more students on the doorstep, very nearly double the number a few decades ago. (In 1969 , undergraduate enrollment totaled 6,884,000; in 1999, 12, 681,000.3) What happens when you have such dramatic increases in enrollment at the college level? It's a lot like what happens to high schools under the pressure to send more and more students to college: inertia besetting the status quo ensures that this population explosion isn't accompanied by a concomitant increase in resources, support, funding. So the pressure starts to build. Something has to give. The outlet is a great outcry over standards. The high schools are not doing their job, people say; students should be ready for college but too many (of the too many on the doorstep) are not.

What's the evidence for this? As I begin to address this question, I will give you what only seem to be answers, so bear with me. The chief thing people - not least of all politicians and policy-makers - point to is the prevalence of remediation. Among the data we find in The Condition of Education (a publication of the Department of Education) is this: over 60 percent of students attending 2-year colleges and 40 percent of attending 4-year colleges need to take at least one remedial course. ${ }^{4}$ As this same publication indicates, the kind of remediation that correlates most powerfully with college completion is placement in remedial reading: students who place thus have the lowest likelihood of completing a college degree. And the National Assessment of Education Progress (which, since the 1970s, has assessed the reading levels of $4^{\text {th }}, 8^{\text {th }}$, and $11^{\text {th }}$ graders using three designations: basic, proficient, and advanced) reports that only about a third of the nation's 17year-olds read at or above the proficient level, the middle level in its three-tier scale (Campbell et al.). Circumstances like these have so incensed some people (notably politicians) that a major redistribution of remedial education (and the blame for it) has been underway in the last decade. The trends are nutshelled nicely in the introduction to the report "College Remediation: What It Is, What It Costs, What's at Stake" (prepared by Ronald Phipps, Senior Associate of the Institute for Higher Education Policy, and sponsored by the FordFoundation): 
Over the past several years, attempts have been made to limit remedial education in states such as Arkansas, California, Louisiana, Oklahoma, Tennessee, and Virginia. More recently, in states like New York and Massachusetts, efforts are underway to reduce the amount of remedial courses offered in postsecondary education. Legislators in Texas and other states are troubled that tax dollars are being used in colleges to teach high school courses, and some states like Florida have shifted virtually all remediation efforts to the community college level. The legislatures in New Jersey, Montana, Florida, and other states have considered proposals that would force public school systems to pay for any remedial work that one of their graduates must take in college. (1)

For many, at least, the issue seems clear: high schools are not doing their job and must be held accountable. And so the demand for accountability is on. For those in positions to direct policy, it has a clear channel to flow in: Christopher Mazzeo recently noted not only how relatively new the trend in "accountability testing" is but why it is so attractive to politicians, observing that "accountability testing provides politicians with a highly visible symbol of action, while also offering at least some leverage to shape and change what educators do and how the system is run" (390). In a wave of change we can fix primarily in this past decade, though the first such step was taken by Florida in the late seventies, 26 states have made exit exams high school graduation requirements. Leading the pack are the most populous states in the nation: New York, California, Texas. Of the 26, 20 have mandated tests coming into full implementation on or after the year 2000. Moreover, these are the results of state initiatives; in fact, this information comes from the National Governors Association "2001 Graduation Exit Exam Matrix" (published at the start of 2002) - the NGA's means of tracking follow-through on its 1998 Issue Brief "High School Exit Exams: Setting High Expectations."

With the states literally taking the initiative, what can be said for or even to the high schools except "High time! Somebody better put this house in order!"? Well, things are a good deal more complicated than I've just made them seem or most people realize. For instance, I've been talking as if what everyone does is go to elementary school, middle school, secondary school, and then post-secondary school. You're a high school senior graduating, and three months later you're a college freshman. Well, yes, sometimes. But it doesn't always work that way. In particular, it doesn't work that way when we take a closer look at who those students in remedial classes in college are. Nearly half of all freshmen taking remediation are over the age of 22 (Phipps 9). They didn't go straight to college; in fact, that may be part of the 
problem. If high schools lay a foundation for college, it's not a concrete foundation; a few years away from school will tend to dim ideas of just what constitutes a good essay or a quadratic equation. When we realize that most students do go from high school to college and yet nearly half of those who wind up in remediation are exceptions to the rule, high schools begin to look more like the solution than the problem.

Then there's the issue of whether it's entirely fair to expect every student to be college-ready at the end of high school. For one thing, high schools consistently have less time to work with more students: class periods typically run under an hour and have 30 or more students; teachers can have 5-6 such a day. But that isn't the point to stress here. The fact is that high schools don't (and can't) cast college attendance as the inevitable aftermath of high school. That's cast as a choicea desirable one as far as all parties are concerned in most cases, but a choice nonetheless. And it's not the high school's choice. It's the students' choice. You can see where I'm heading here: we're leading horses to water only to find that we can't always make them drink. There's proof of this, and I'm not talking about the dropouts now. High schools, with the help of well-established (typically state-mandated) standards, have identified those courses in their curricula that are college preparatory. That's been done so clearly that you can go in and count them as well as the students taking them. Using that data and thereby determining that "just less than half of our high school graduates didn't take the entire curriculum judged by educators to be a prerequisite for college entry," Hunter R. Boylan, longtime Director of the National Center for Developmental Education, also notes (as we already have) that just less than half of those in remediation have let the space of about half a decade intervene between high school completion and college entry. "Given all this," says Boylan, "it should not be surprising that almost a third of those entering our colleges and universities are underprepared. We should have no reason to expect them to be fully prepared. That does not mean, however, that they have no business being in college" (3).

So what's my point here? I mean, whose fault is it anyway? I hope you agree that's the wrong way of putting the question-the wrong question altogether. The more you look at the data, I would suggest, the more you wonder if all the handwringing and outcry is justified. Lord Macaulay, the great Victorian historian, once noted that the one constant throughout history is that, at any point in time, it has seemed to a great many people that the world is going to hell in a handbasket ${ }^{5}$, and that may be the case here. Remember how the National Association of Educational Progress has determined that only about a third of our $11^{\text {th }}$ graders read at or above the proficient (or mid-range) level? The NAEP has been conducting its reading assess- 
ments for three decades now, and they recently published a full overview. The average score for an $11^{\text {th }}$ grader in 1971 was 285 (out of a possible 500); it was 288 in 1999. In fact, in three decades, it has never gone out of the five-point range between 285 and 290, and most changes over half-decade periods have been such slight inchings up or inchings down (like the drop from the 290 peak of 1988-92 to the present 288), that NAEP has to stress these changes are not statistically significant (Campbell et al.). Now, it may be that not making greater progress is in fact a great failure. To believe that, you would have to have much greater faith in NAEP's assessment methods than I do. I'm inclined to say what Andrea Lunsford and the late Bob Connors said in their famous article on the frequency of errors in college writing: working from a stratified sampling of 20,000 college papers and gauging their findings against studies from the thirties to the present, they found that the frequency of errors remained remarkably constant; taking into account the mania for TV watching, video games, and other things we could most kindly call extratextual literacies, Lunsford and Connors said, "In this case, not losing means we're winning" (406). But let's keep in mind most of all the tabulations that really count, the sort of data I mentioned at the very beginning, data from the National Center for Education Statistics. More people are graduating from high school and going on to college than ever before. And this is a matter of clear statistical significance. The high school dropout rate has gone down $60 \%$ since 1960 . The number of students going on directly from high school to college has gone up $15 \%$ in just the past decade. These are major reasons, if not the only reasons, we have seen nearly a $50 \%$ increase in the number of students pursuing bachelor's degrees in the last three decades.

But the good feeling (or at least the feeling that we are not, in fact, going to hell in a handbasket) reminds us that what may look like evidence that problems are being solved (or at least addressed) is actually the very thing that loomed as a problem at the outset, the very thing that meant more pressure was being put on the high schools - and the colleges - and all this pressure was finding an outlet in demands to determine accountability and raise standards. We haven't solved that problem at all. We've just found that high schools in particular, coping with the stresses of rising expectations to turn out more and more college-ready students, are finding that no good deed goes unpunished. It is precisely because more students are going to college - significantly more - that the high schools are in trouble. And so are the colleges. Resources are finite, but the students just keep coming, and in ever greater numbers. What to do?

The major answer already being visited on us is the major form that educational reform takes today: mandated assessments (mandated in the name of accountability). As a capitalist society, we do defer to 
market-driven solutions whenever possible, and so some outlet is being found in charter schools and voucher systems, but only enough to release a little steam. Ranging from very qualified successes to unqualified, voted-down failures, these outlets are far from the snowballing movement some predicted they would be only a few years ago. We do have a steamrolling or snowballing movement on our hands, and that is the political solution, the matter of mandated standards and assessments. As I noted before, more than half the states either require or plan to require high school exit exams as determinants of graduation from high school. My state, New York, is one that already does. When I talk to people about this growing interest in high school exit exams, they are often aware of how things are locally (though just as often they are not); very few are aware that this is such a powerful trend nationally or what it means. No doubt George Hillocks' magisterial analysis of the trend and its implications in The Testing Trap: How State Writing Assessments Control Learning, published just months ago, will do much to change this. Heretofore, however, a "big picture" view has been offered only rarely, as in last year's article from the Chronicle of Higher Education, which noted, "Nineteen states already require their high-school students to pass a test before graduating, and eight more plan to do so. Every state but Iowa requires their high-school students to undergo some form of statewide assessment." The real kicker, the special spin, is in the title of the article: "Universities Push to Influence State Tests for High-School Students." The article itself actually reveals that universities are in no position to have high schools toe the lineyet. David T. Conley, a University of Oregon professor who is director of the Standards for Success project (a nationwide effort on the part of universities to exert such influence), in fact notes that "universities haven't been at the table in any systematic fashion.[...]We want to try to make sure there is some alignment that exists between what state systems are doing and what universities are doing" (Hebel).

In the meantime, all we can really be sure of is this move to mandated assessments, a move that, more than any other circumstance, gives purpose and point to my title-high schools are indeed becoming crucibles of college prep - and mandated assessments, particularly as exit exams that are also college admissions screening instruments, are the great reason why. What's happening in consequence? To be honest, some pretty dispiriting stuff is happening. Massive summer school programs have been initiated in New York and Chicago. Occasioned by these exit exams - or rather failure to pass them on the part of too many students - they are accompanied by charges that their standards are too low (Hadderman). Alaska, Alabama, Arizona, Maryland, and North Carolina have delayed their statewide tests because of concern for similar consequences (Hebel). Because accountability is a kind of behavior-mod approach to education reform (predicated on rewards 
and punishments), it's no surprise that there have been cheating scandals in a number of states - most recently Indiana, California, and Texas ("More Test Cheating"). Since one thing we have always known is that educational advantages are unequally distributed among the student population - race, ethnicity, gender, and above all socio-economic status have always been powerful predictors of academic success - one important consequence of the mandated exit exams is widespread fear that drop-out and failure rates have increased for poor and minority students in states with mandated tests (Cavanaugh). And even those who hang in there are all the more likely to lag ever further behind their more affluent peers since the tests have, according to George Hillocks, "a powerful effect on increasing the gap by restricting what students are allowed to learn in many poorer districts" (102). These problems have prompted widespread discussion, not least of all by teachers' unions, of a 5th year for high school students, a year to address what the tests say must be addressed (Bradley). Finally, I'm sorry to report that there are no great success stories to counter all this bad news: there is simply no established correlation in improved college attendance/performance. On the contrary, as Orfield and Wald report, "High-stakes tests attached to grade promotion and high school graduation lead to increased dropout rates, particularly for minority students"(39). And there is particular concern about this in the case of LEP (Limited English Proficiency) students (see, for example, Ioannou). Such consequences and fallout have moved one critic of mandated assessments, Peter Sacks, to say that "the nation's elites now perpetuate their class privilege with rules of their own making, [...] rules legitimated and protected by a pseudo-scientific objectivity" (11).

But not all the news is bad, nor all the indicators downturns. If mandated testing is a cloud (a great gray thunderhead, overspreading the land like a gathering storm filmed in time-lapse), it has a silver lining. The fact is that all this testing, as we have just noted, has created problems. They are in fact problems that state mandates have created, and so, as you might imagine, some have state-mandated solutions. Small steps these, they are nevertheless significant ones because the point us to a third solution: not a market solution (charter schools or voucher systems), not even a political solution (mandated testing), and only a top-down solution in terms of where the money is coming from (sometimes but not always). This third solution, neither marketdriven nor politically mandated, is collaboration. Colleges and high schools, the greatest and most essential learning communities we have, are starting to take a learning communities approach to their mutual concerns and problems. The way is often opened or paved with wherewithal supplied by the state, but the state doesn't script this part. The script is for the high schools and the colleges to write, at least up to a point.

Here are some instances where I actually know the players. Cal 
State University had $\$ 9$ million made available to 18 campuses to work with high schools as the new high school exit exam in California rolled out (Crouch and McNenny 57). In the wake of the new New York State Regents exams, CUNY asked for $\$ 10$ million and was given $\$ 7$ million in state funds for its 17 campuses to work with high schools. A FIPSE-funded collaboration between Virginia colleges and high schools called "Aligning Writing Instruction in Secondary and Postsecondary Institutions" proved enough of a success to be extended to a national pilot (Jennings). In each and every case, statewide assessments created a need these ventures are intended to address: the focus was better preparation for college, but the focus of most of the activity and instruction was in the high schools.

Let me tell you a little bit about what's happening in New York, working with that $\$ 7$ million annual investment. What most of that money goes for is personnel: we have adjuncts in the high schools, but we also have high school teachers working as adjuncts - in other words, high school teachers who have become college faculty, if only on a part-time basis. The goals of the most of the instruction are frankly if not exclusively about addressing the tests, but they need not represent some crude teaching to the tests; they can in fact be critical explorations of testing and standards, notably college standards. At present, the instructional program-it's PR-motivated name (really a misnomer) is College Now - is in most of the city's 300 high schools. A small part of this (the part I'm really involved in and really want to talk about) is a professional development program called Looking Both Ways (LBW). It's purpose is to bring together high school and college teachers to talk through issues of language and literacy, sharing concerns as well as assignments, modeling activities as well as talk.

Let me tell you a little bit more about the way LBW works. I should explain that it is by no means the full program of professional development for the larger project of working with the high schools. (A principle of LBW is that we don't do training or basic staff development, that we are interested in working with experienced teachers who are themselves likely to do professional and curricular development.) We invite applications from all the CUNY campuses as well as all the NYC high schools, and, upon reviewing them, create seminars of 15 scattered about the boroughs, with each seminar co-led by both a high school and a college teacher. These seminars meet 5 hours for each of 6 Saturdays spread over an academic term; the leaders themselves spend another month beforehand meeting and planning these seminars together. Each of the leaders gets a course release (or the equivalent); each of the participants gets a $\$ 1000$ stipend or graduate credit (the choice is theirs). That, basically, is where the money goes. But LBW is four years old now, so it also has (and has funded) scholarly research projects, publications, a website, and a conference. 
So what is happening as the result of this small project in a vast system? Well, a number of things, and it's useful to say not just what is happening but why. One of the things about New York's ELA Regents (the English/Language Arts Regents) that almost goes without saying (at least for the sort of people who read this journal) but was also given too little thought (by the people who instituted the requirement to pass the exam with a certain score) was the enormous disadvantage LEP (Limited English Proficiency) students had when confronted with the exam. In New York City, more than a third of the students in the system are not native speakers of English; they were taking a 4-part, 6hour, 2-day exam in reading, writing, and even listening comprehension, and this test was a terror for them. One consequence of the work done by participants in LBW (who have a tendency to appreciate and even relish the complexity of the teaching and learning situations they contemplate) was to help people realize that the solution couldn't be a quick fix. The targeting of LEP students now begins with the $9^{\text {th }}$ gradeand the purpose, quite the opposite of tracking as a separating-off, is to have intensive work with English integrated with work in core subjects like math and science. The discussion of assessments - another place where LBW's resistance to oversimplification is very much at work - has not meant a uniform resistance to mandated assessments. It has, however meant a broadened discussion of the tests and standards, particularly ways of reclaiming some freedom and flexibility in the face of mandated assessments; people have even found how to make working with and toward the tests serve their own pedagogical goals - and they have shared their findings with others. With LBW participants attaining a kind of critical mass in some instructional fields and sites, the project was able to mount a city-wide conference in 2001 ("Braided Lives: Language, Literacy and Urban Classrooms") for sharing concerns, practices, strategies. Held over two days, the conference was keynoted jointly by the Executive Vice Chancellor of CUNY and the Deputy Chancellor of the New York Public School system, each the head administrator for instruction in her respective system. In addition, as I have noted, we've done a book, a series of seminar-specific monographs, writing groups called "scholars programs," and a website.

I don't what to oversell our success, however. On the contrary, I want to lay down some caveats and cautions. First of all, I need to stress again that LBW is a small corner of a much vaster project. (Remember that $\$ 7$ million per annum figure for work with the high schools? LBW does all that it does on about $\$ 200$ thousand a year.) The larger project may well involve people who are not adequately prepared or supported. And I should say immediately that even and especially what constitutes adequate preparation or support is something we have to be cautious about. Motivated by mandated assessments, part of the top-down movement of money and imperatives, the situa- 
tion I'm describing in New York (like the others I've mentioned) is an instance of what we might call forced collaboration - hence my invocation of the crucible and my focus on the high schools. There are some truly tricky steps to take (or avoid) here, particularly for the college partners. The most dangerous is presuming to pull rank and talk down: colleges don't enter partnerships to tell the high schools what to do. (That violates the very idea of partnership.) Another misstep is the white knight syndrome (here we come to the rescue, institutionalized education's form of noblesse oblige). Each of these has its corresponding danger from the high school end: being too deferential to the college representatives; expecting to be rescued.

A true partnership requires equal footing, and that has to start from the ground up, not the top down. The very definition of plans and purposes has to be a shared activity. Partners have to co-construct goals as well as share in the work of carrying them out. And owning those goals equally means being wary of putting the partnership in the service of someone else's agenda (supposing the desired outcomes can be adequately measured by improved test scores, for example, or by some crudely defined sense of quid pro quo).

So what should a true partnership be? (I don't want to spend more time saying what it isn't than saying what it is.) It should be something that makes knowledge-making about effective teaching and learning a shared activity, a visible enterprise. That's rarer than you might suppose. Teaching is a paradoxical endeavor in that it is always a public performance (something done in front of students as well as on their behalf) that is also a closeted activity. Teachers know remarkably little about how other teachers teach; this is true of their own colleagues, still more true of the teachers who taught the students before or will teach them after. As an experience, high school or college is probably considerably less compartmentalized, more of a continuous and coherent affair from the student's point of view than from any teacher's. (That's a frightening thought, especially if you think back to your own experience.) We are cordoned off from each other, separated by institutional and disciplinary and other boundaries that make our worlds remarkably closed off and self-contained. The profoundest experience for most people involved in the LBW project-the one that repeatedly shows up at the top of the evaluative surveys we do of participants - is what we have come to call intervisitations. High school and college teachers partner up: you visit my classroom, witness my teaching, and I return the favor. On a small scale, this represents what we need to be doing on a vast scale: rediscovering each other on both sides of that divide that, in its transversal, gives most students the strongest shock of cultural dislocation anyone is likely to experience in a lifetime. Faced by a compelling need to bridge that divide, we need to collaborate, and we need to find ways that transcend or circumvent 
forced collaboration. The question is how.

In a recent article "Why Learning Communities? Why Now?" K. Patricia Cross, formerly of Berkeley's (and also formerly of Harvard's) School of Education, argues that learning communities are no mere trend; they participate in a revolution both epistemological and practi$\mathrm{cal}$. And both revolutions are reflected in how learning communities help to fulfill the dual mission of most universities as well as most high schools: to train the future workforce and educate a responsible citizenry. Interestingly, she elects to make her most impressive argument on practical grounds. Drawing on The Double Helix of Education and the Economy (1992) - a book arguing that A Nation at Risk, that famous and infamous bombshell of the ' 80 s, misdiagnosed the problem in education-Cross argues,

The problem is not so much the deterioration of the quality of education, the solution to which is to invoke higher standards and stiffer requirements.[...] It is that students at all levels need a different kind of education.[...] The structure of traditional schools met the demands of the old workplace pretty well. In the old economy, the goal was to reduce unit costs through standardization and mass production. That was best accomplished in a system of slow change, low worker discretion, and high supervision... The schools operated with a similar structure - high supervision, high standardization, and interchangeable students. The problem is that standardization and high supervision are failing in both education and industry. This is not an era of slow change and predictable futures in the economy. Industry is beset by intense international competition, the demand for more varied and customized products, and faster product cycles - all accompanied by increasing instability and uncertainty. Such a system requires workers who can operate independently of supervision in a less well-defined environment. (9-10)

Cross points out an interesting semi-paradox: collaboration breeds independence. By working together - by building and participating in a community of practices that builds from the deepest sense of common ground we can discover together - we can learn to how to be much more effective at working independently. If we can do that we are likely to see another key principle emerging: the chief point of collaboration between high schools and colleges is that this knowledge-sharing and community-building models what it produces: a way of building knowledge, pooling information, sharing resources-and in a time when knowledge is unstable (in need of constant re-creation), information rapidly obsolescent, and resources both too scarce and too var- 
ied not to share. True collaboration, based on equal partnerships and mutual respect, produces greater independence and self-realization. And it practices what it preaches: it models the very learning it seeks to cultivate. This agenda, as a call to research and action, is what I'd like to leave you with as I leave the editorship of $J B W$.

\section{Notes}

Author's Note: This piece is based in part on a keynote address I gave at a conference titled "Strategies for Effective Transitions: High Schools and Universities Working Together," University of Houston, April 2001.

\section{National Center for Education Statistics. Digest of Education Statistics,} 2001. Chapter 3: Postsecondary Education. Data Table 184. College enrollment rates of high school completers, by race/ethnicity: 1960 to 2000 . $<$ http://nces.ed.gov/pubs2002/digest2001/tables/dt184.asp>

Given the difficulty of locating the specific data table without a full citation (too unwieldy for intext documentation) or a URL that's unintelligible out of context, I am citing the NCES data via endnotes. Here I'll add that there has been a slight falling off since 1997 in high school graduates going on to college - so that the percentage for 2000 , the last year for which numbers are provided, is only slightly more than $63 \%$. It's unfortunate that, at present, the NCES statistics stop when they do: they document the situation during a boom time of unprecedented low unemployment, when job opportunities even for high school graduates proved extraordinarily high: the time since has seen a sharp turn into sustained recession and high unemployment, and these causes would no doubt send the percentages back up significantly.

\section{National Center for Education Statistics. Digest of Education Statistics,} 2001. Chapter 5: Outcomes of Education. Data Table 382: Median annual income of year-round, full-time workers 25 years old and over, by level of education completed and sex: 1989 to 1999. <http://nces.ed.gov/pubs2002/ digest2001/tables/dt382.asp>

\section{National Center for Education Statistics. Digest of Education Statistics,} 2001. Chapter 3: Postsecondary Education. Data Table 188. Total undergraduate fall enrollment in degree-granting institutions, by attendance status, sex of student, and control of institution: 1969 to 1999. <http:// nces.ed.gov/pubs2002/digest2001/tables/dt188.asp>

\section{National Center for Education Statistics. The Condition of Education.} Student Effort and Educational Progress - Postsecondary Persistence and Progress - Indicator 29: Remediation and Degree Completion. <http:// nces.ed.gov/programs/coe/2001/section3/indicator29.asp > (This site 
collects data from the three annual publications of The Condition of Education: 2000, 2001, 2002.)

5. Actually what Lord (Thomas Babington) Macaulay said was "Those who compare the age in which their lot has fallen with a golden age which exists only in imagination, may talk of degeneracy and decay; but no man who is correctly informed as to the past, will be disposed to take a morose or desponding view of the present" (History of England. Volume 1. Chapter 1).

\section{Works Cited}

Berryman, Sue E., and Thomas R. Bailey. The Double Helix of Education and the Economy. New York: Institute on Education and the Economy (Teachers College, Columbia University), 1992.

Boylan, Hunter R. " Developmental Education: Demographics, Outcomes, and Activities." Journal of Developmental Education 23.2 (1999): 2-10.

Bradley, Ann. "Union Heads Issue Standards Warnings." Education Week 19.2 (July 12, 2000): 1,20-21

Campbell, J.R., C.M. Hombo, and J. Mazzeo. NAEP 1999 Trends in Academic Progress: Three Decades of Student Performance. Washington, DC: NCES, 2000. <http://nces.ed.gov/nationsreportcard/pubs/ main1999/2000469.asp>

Cavanaugh, Sean. "Exit-Exam Trend Prompts Scrutiny of Consequences." Education Week 22.1 (September 4, 2002): 1, 18-19.

College Now. <http://collegenow.cuny.edu/>

Cross, K. Patricia. "Why Learning Communities? Why Now?" About Campus 3.3 (1998): 4-11.

Crouch, Mary Kay, and Gerri McNenny, "Looking Back, Looking Forward: California Grapples with Remediation." JBW19.2 (2000): 4471.

Hadderman, Margaret. "Standards: The Policy Environment." ERIC Digest, Number 138. ERIC Clearinghouse on Educational Management, August 2000. <http://www.ed.gov/databases/ ERIC_Digests/ed444239.html>

Hebel, Sara. "Universities Push to Influence State Tests for High-School Students." Chronicle of Higher Education 9 February 2001: A23.

Hillocks, George Jr. The Testing Trap: How State Writing Assessments Control Learning. New York: Teachers College P, 2002.

Ioannou, Constantine. "Board Stands Up to High-Stakes Testing." Friends in TESOL (Winter 2001-2002). <http://www.tesol.org/ assoc/bd/fit/2001/winter-5.html\#3> 
Jennings, Chris (Project Director). "Aligning Writing Instruction in Secondary and Postsecondary Institutions." FIPSE Grant

P116B980621.<http://www.fipse.aed.org/ grantshow.cfm?grantNumber=P116B980621>

Looking Both Ways. <http://lbw.cuny.edu/home.html>

Looking Both Ways: High School and College Teachers Talk about Literacy and Learning. Ed. George Otte. New York: CUNY Office of Academic Affairs, 1999. <http://lbw.cuny.edu/publications/ book.html>

Lunsford, Andrea, and Robert Connors. "Frequency of Formal Errors in Current College Writing, or Ma and Pa Kettle do Research." College Composition and Communication 39 (1988): 395-409.

Mazzeo, Christopher. "Frameworks of State: Assessment Policy in Historical Perspective." Teachers College Record 103.3 (2001): 367397.

"More Test Cheating." FairTest Examiner (Summer 2002 - Web Exclusive). <http://www.fairtest.org/examarts/Summer\%2002/Cheating.html>

A Nation At Risk: The Imperative for Educational Reform (April 1983). <http://www.ed.gov/pubs/NatAtRisk/>

National Center for Education Statistics. The Condition of Education, 20002002. <http://nces.ed.gov/programs/coe/>

- . Digest of Education Statistics, 2001. <http://nces.ed.gov/pubs2002/ digest2001/>

National Governors Association. 2001 Graduation Exit Exam Matrix $(1 / 8 / 02) .+<$ http://www.nga.org/center/divisions/

1,1188,C_ISSUE_BRIEF^D_3007,00.html>

-. 1998 Issue Brief "High School Exit Exams: Setting High Expectations." <http://www.nga.org/center/divisions/ $1,1188, C$ ISSUE_BRIEF^ ${ }^{\wedge}$ _1478,00.html $>$

Orfield, Gary, and Johanna Wald. "Testing, Testing." The Nation 270.22 (June 5, 2000): 38-40.

Phipps, Ronald. "College Remediation: What It Is, What It Costs, What's at Stake." Institute for Higher Education Policy, 1998. <http:// www.ihep.com/Pubs/PDF/Remediation.pdf>

Sacks, Peter. Standardized Minds: The High Price of America's Testing

Culture and What We Can Do to Change It. Cambridge, MA:

Perseus Books, 2000.

Smoke, Trudy. "What Is the Future of Basic Writing?" JBW20.2 (2001): 88-96. 


\section{News and Announcements}

Call for Papers: JAEPL, Journal of the Assembly for Expanded Perspectives on Learning invites submissions for its ninth annual issue. JAEPL invites theory-grounded papers that discuss pedagogical concerns focusing on exploring the boundaries of teaching and learning beyond traditional disciplines and methodologies. Send by January 31, 2003, four copies of letter quality manuscripts (attach postage for mailing 3 copies to readers) or electronic submission in rich text format (RTF), MLA style, approximately 12-15 pages to: Linda Calendrillo, JAEPL Co-Editor, English Department, Western Kentucky University, Bowling Green, KY 42101 or linda.calendrillo@wku.edu. Send, editorial to Kristie S. Fleckenstein, JAEPL Co-Editor, English Department, Ball State University, Muncie, IN 47306 or kflecken@gw.bus.edu. For more information, visit the website at <http://www.bsu.edu/english/jaepl/ index.htm>.

Call for Participation: The Writing Centers Research Project Survey of Writing Centers. The Writing Centers Research Project (WCRP) at the University of Louisville is updating the benchmark data for its longitudinal student of writing centers. The WCRP requests that all writing center directors visit its web site <http://www.wcrp.louisville.edu $>$ and either complete the survey online or download a printable version to complete by hand. Participants may also request a hard copy of the survey. Questions about the survey or requests for hard copies should be directed to Christopher Ervin (chris.ervin @louisville.edu) or The Writing Centers Research Project, 312 Ekstrom Library, University of Louisville, Louisville, KY 40292.

Call for Proposals: NCTE-LEA Research Series in Literacy and Composition, co-published by he National Council of Teachers of English and Lawrence Erlbaum Associates and co-edited by Andrea A. Lunsford (Stanford University) and Beverly J. Moss (The Ohio State University), aims to publish groundbreaking work on literacy, on composition, and on the intersections between the two. Volumes in this series will be primarily original, authored or co-authored works that are theoretically significant and hold broad relevance to literacy studies, composition, and rhetoric. The series may also include occasional landmark compendiums of research. The scope of the series includes qualitative and quantitative methodologies; a range of perspectives and approaches (e.g., sociocultural, cognitive, feminist, psycholinguistic, pedagogical, critical, historical); and research on diverse populations, contexts (e.g., classrooms, school systems, families, communities), and forms of literacy (e.g., print, electronic, popular media). The intended audience includes scholars, professionals, and 
students in a range of fields in English studies, including literacy education, language arts, composition and rhetoric. For more information about the NCTE-LEA Research Series in Literacy and Composition and guidelines for submitting proposals, contact: Professor Andrea A. Lunsford, Department of English, Stanford University, Stanford, CA 94305-2087 (lunsford@stanford.edu) or Professor Beverly J. Moss, Department of English, The Ohio State University, Columbus, OH 432101370 (moss.1@osu.edu).

Training Announcement: The 2003 Kellogg Institute for the Training and Certification of Developmental Educators will be held June 28 - July 25 at Appalachian State University in Boone, NC. The Kellogg Institute will train faculty counselors, and administrators from developmental and learning assistance programs in the most current techniques for promoting learning improvement. The Institute program consists of a summer session followed by a fall term practicum project on the home campus of each participant. The 2003 summer program will focus on assessment and placement of developmental students; use of learning styles and their implications for instruction; the process of designing and implementing developmental evaluation activities; developmental instruction techniques; classroom assessment; research in developmental education; and leadership and academic support services for developmental students. Applications and additional information about the Institute may be obtained by contacting Sandy Drewes, Director of the Kellogg Institute, or Maggie Mock, Administrative Assistant, National Center of Developmental Education, ASU Box 32098, Appalachian State University, Boone, NC 28608-2098; (828) 262-3057; <http://www.ncde.appstate.edu>. 


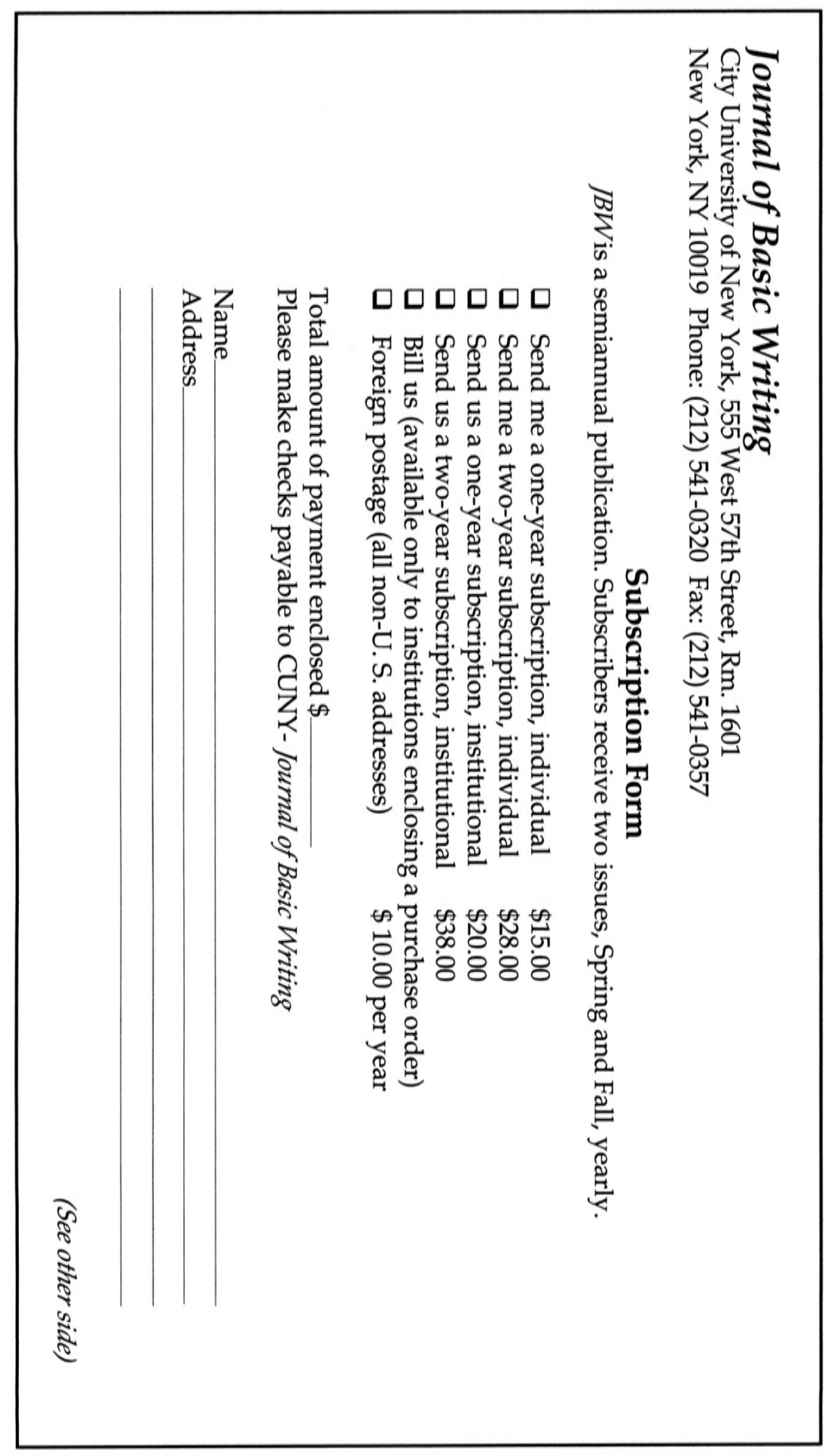




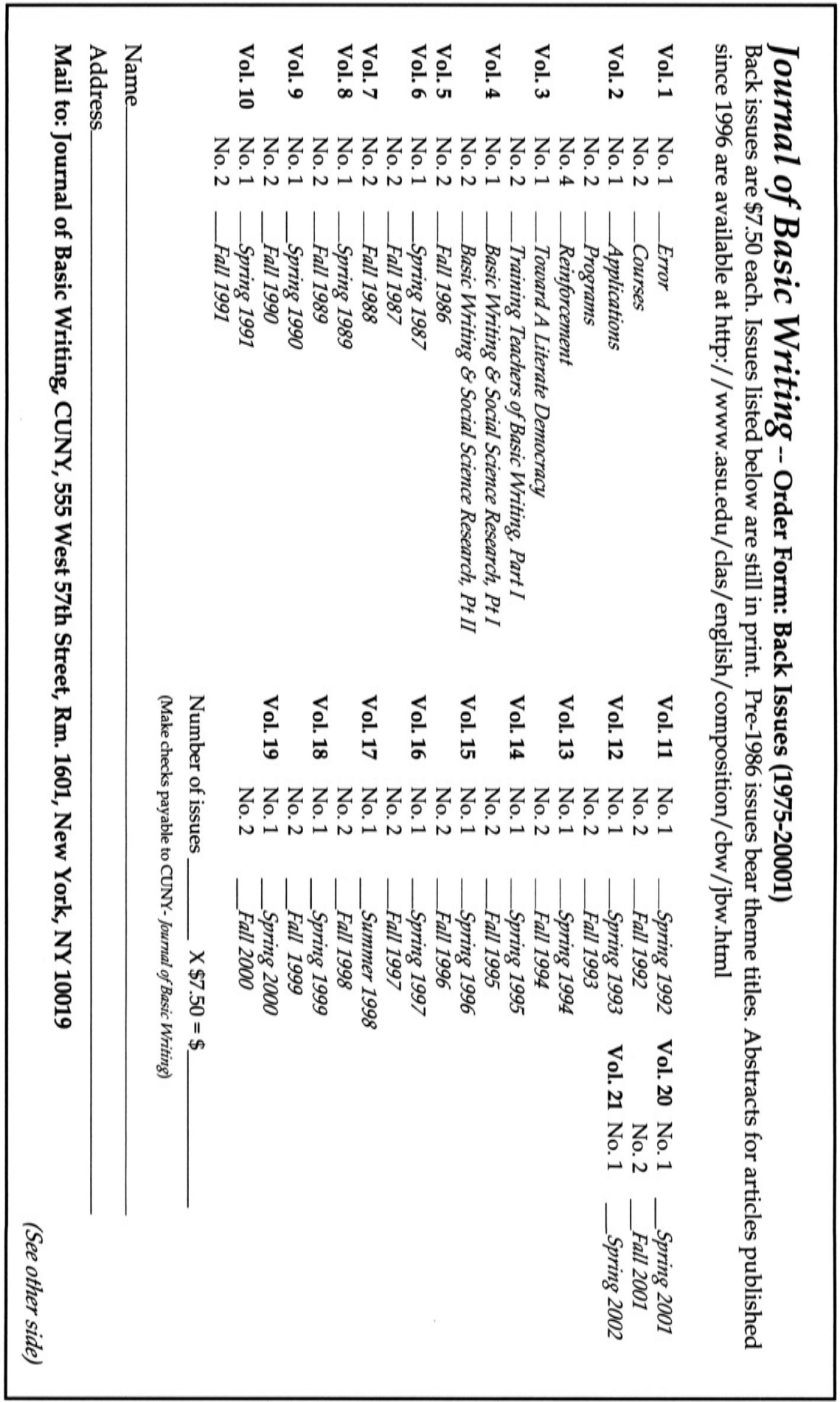





